\title{
ANALOG-HYBRID DYNAMIC SIMULATION OF THE FFTF REACTOR AND HEAT TRANSPORT SYSTEM
}

\author{
C. D. FLOWERS \\ AND
}

L. H. GERHARDSTEIN

\section{APRIL 1968}

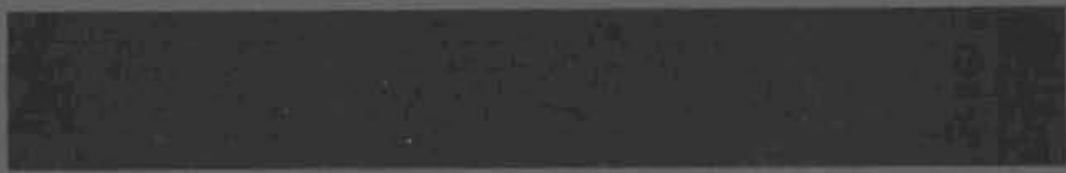

\section{AEC RESEARCH \& DEVELOPMENT REPORT}

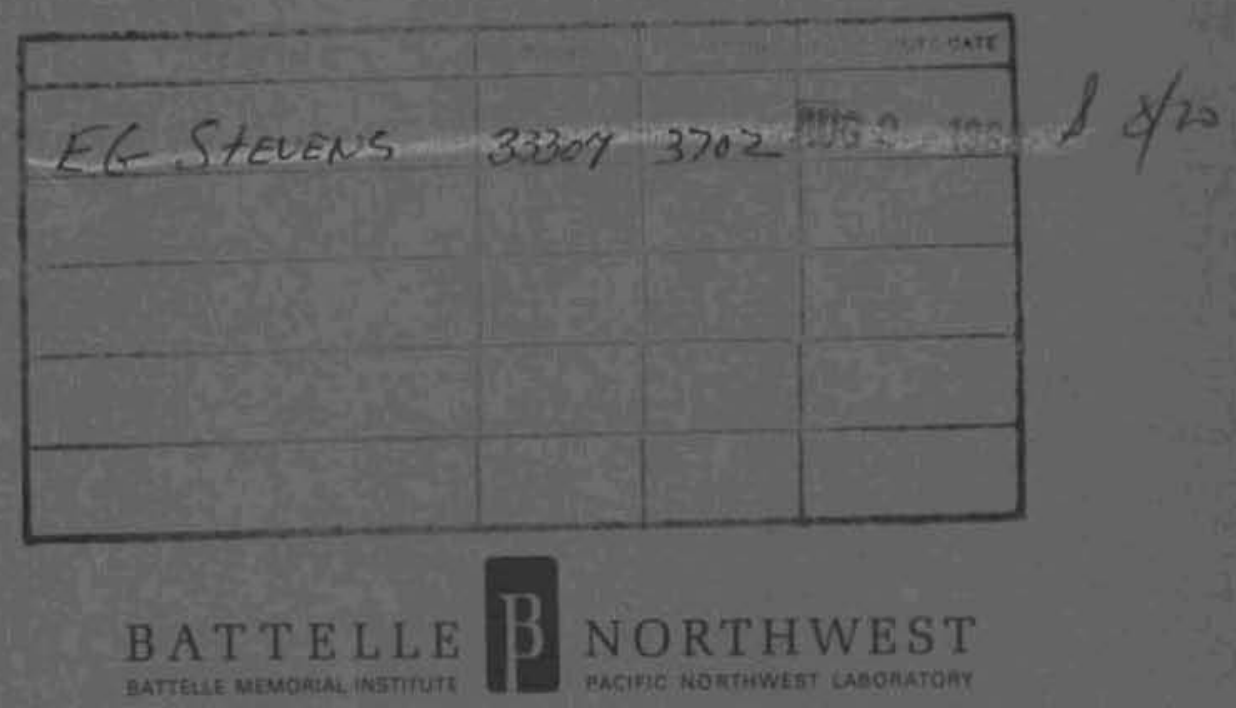




\section{LEGAL NOTICE}

This report was prepared os an account of Government sponsored work. Neither the United States, nor the Commission, nor any person acting an behalf of the Commissian:

A. Makes any worranty or representation, expressed or implied, with respect to the occuracy, com. pleteness, or usefulness of the information contained in this report, of that the use of any information, apparatus, method, or process dlsclosed in this report may not infringe privately owned rightsi or

B. Assumes any liabilities with respect to the use of, or for damages resulting from the use of any information, opporatus, method, or process disclosed in this report.

As used in the above, "person acting on behalf of the Commission" includes any employee or contractor of the Commission, or employes of such contractor, to the extent that such employee or con. tractor of the Commission, or employee af such contractor prepares, disseminates, or provides access to, any information pursuant to his employment or cantract with the Commission, or his employment with such contractor.

\section{PACIFIC NORTHWEST LABORATORY}

RACHIAND, WASHINGTON

operated by

BATTELLE MEMORIAL INSTITUTE

for the

UNITED STATES ATOMIC ENERGY COMMISSION UNDER CONTRACT AT(45-1)-1830 


\author{
BNWL - 707 \\ $\mathrm{UC}-80$, \\ Reactor Technology \\ ANALOG-HYBRID DYNAMIC SIMULATION \\ OF THE FFTF REACTOR \\ AND HEAT TRANSPORT SYSTEM \\ By \\ C. D. Flowers \\ Reactor and Systems Analysis Section \\ FFTF Project Department \\ And \\ L. H. Gerhardstein \\ Computer and Control Section \\ Applied Physics and Electronics Department
}

April 1968

Finst vinestiono

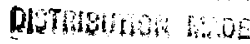

19: 99

PACIFIC NORTHWEST LABORATORY

RICHLAND, WASHINGTON 


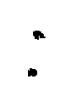

.

$-1$

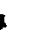

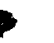

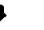

.

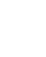

t

. 


\author{
ANALOG-HYBRID DYNAMIC SIMULATION \\ OF THE FFTF REACTOR \\ AND HEAT TRANSPORT SYSTEM \\ C. D. Flowers and L. H. Gerhardstein
}

\title{
$\underline{\text { ABSTRACT }}$
}

A mathematical model has been developed for investigating the dynamic response and control characteristics of the Fast Flux Test Facility (FFTF) Reactor and heat removal systems. The model was developed for solution on the analog-hybrid computer facility at Pacific Northwest Laboratory (PNL). The mathematical modeling techniques used to simulate each system component are discussed in detail, and sample transient results are presented. Prospective uses of the simulation are also discussed.

One complete heat removal circuit (out of four) is simulated, and the total heat is accounted for by a multiplying factor. The reactor simulation includes point kinetics with temperature feedbacks, single-node representation of fuel, coolant, leakage, and reflector regions, and inlet and outlet mixing plenums. Multinode heat exchanger models are employed to represent the intermediate and air-dump heat exchangers. The system model also includes simulation of coolant transport time lags, sodium pumps, motors, electromagnetic clutches, air fans, and sodium and air hydraulics. 


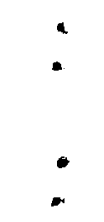

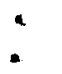

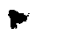

•



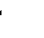




\section{TABLE OF CONTENTS}

ABSTRACT

LIST OF FIGURES.

0. INTRODUCTION

1. SUMMARY . .

2. PLANT DESCRIPTION

2.1 Reactor Description . . . . . . . . 3

2.2 Heat Removal Circuit Description . . . . 6

3. MATHEMATICAL MODELS OF THE FFTF SUBSYSTEMS . . 8

3.1 Reactor Model . . . . . . . . . . 8

3.1.1 Heat Generation . . . . . . . 8

3.1 .2 Reactor Kinetics - Neutron Power . . 9

3.1.3 Reactivity Feedbacks . . . . . . 11

3.1.4 Fission Product Power . . . . . 13

3.1.5 Reactor Thermal Model Description . 15

3.1.6 Reactor Thermal Model Equations . . 16

3.2 Intermediate Heat Exchanger Model . . . . 20

3.3 Transport Delay Mode1 . . . . . . . . 24

3.4 Hydraulics Models for Primary and Secondary Loops . . . . . . . . . . 25

3.5 Sodium Pump Mode 1 . . . . . . . . . 27

3.6 Pump Drive Assemb1y Model . . . . . 32

3.7 Dump Heat Exchanger Mode1 . . . . . 37

3.8 Tertiary Coolant Hydraulics Mode1. . . . 41

4. SAMPLE TRANSIENT RESUltS . . . . . . . . 51

NOMENCLATURE . . . . . . . . . . . . . 61

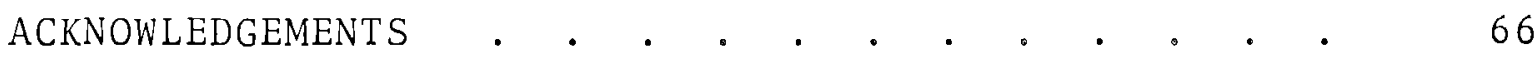

APPENDIX A . . . . . . . . . . . . . A A-1

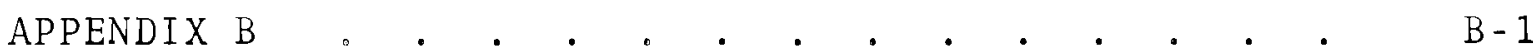

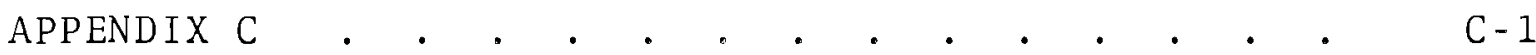



REFERENCES • . . . . . . . . . . . . . $\operatorname{Ref-1}$

DISTRIBUTION $. \quad . \quad . \quad . \quad . \quad . \quad . \quad . \quad . \quad . \quad$. Distr-1 


\section{LIST OF FIGURES}

2.1.1 FFTF Heat Removal System Arrangement - One 4 Circuit, Typical of Four

2.1.2 Reactor Vessel Internals

2.1.3 Reactor Core Cross Section (Conceptual Design) 5

3.1 .1 Nodalized Reactor Model 14

3.1.2 Fission Product Decay Heat Generation Following Reactor Scram

3.2.1 Basic Configuration and Coordinate System for the IHX Model

3.4.1 Primary/Secondary Coolant Loop Hydraulics Model Functional Diagram

3.5.1 Head Curve for Primary Centrifugal Pump Simulation

3.5.2 Typical Pump Efficiency Curves

3.6.1 Motor Torque Curve with a Typical Load Torque

3.6.2 Typical Electromagnetic Clutch Torque Curve

3.6 .3 Clutch Torque Functions 36

3.7.1 DHX Module Arrangement (Four Modules Per DHX) 37

3.7.2 DHX Model Node Arrangement 39

3.8.1 Schematic of the Tertiary Coolant Hydraulic System for One DHX Module

3.8.2 Normalized Fan Characteristics (Typical) 44

3.8.3 Butterfly Valve Coefficients (Typical) 46

3.8.4 DHX Air Flow Per Module Versus Valve Angle of Opening for Fan at Full Design Speed

3.8.5 DHX Air Flow Per Module Versus Valve Angle of Opening for Fan off

4.1 Hybrid Simulation Model Results for Manual Scram with Full Primary, Secondary, and Tertiary Flows (Results from Output Channels 1-8)

4.2 Hybrid Simulation Model Results for Manual Scram with Full Primary, Secondary, and Tertiary Flows (Results from Output Channels 9-16)

4.3 Hybrid Simulation Model Results for Manual Scram with Immediate Primary, Secondary, and Tertiary Flow Decays (Results from Output Channels 1-8) 
4.4 Hybrid Simulation Model Results for Manual Scram with Immediate Primary, Secondary, and Tertiary Flow Decays (Results from Output Channels 9-16)

A-1 Fue1 Pin Cross-Section

A-2 Clad Heat Flow Resistance as a Function of Coolant Temperature

A-3 Fuel Heat Flow Resistance as a Function of Average Fuel Temperature

A-4 Coolant Film Heat Flow Resistance as a Function of Tube Flow Rate and Coolant Temperature

A-5 Overa11 Fue1-Coolant Heat Transfer Conductance as a Function of Average Fuel Temperature A-5

B-1 IHX Tube Geometry B-1

B-2 Heat Transfer Coefficient Through IHX Tube Wa11 B-3

B-3 Value of ( $\mathrm{EM} / v$ ) max for Fully Established Turbulent Flow of Liquid Metals Through Circular Tubes, and Rod Bundles with Equilateral Spacing

B-4 She11 Side IHX Inverse Film Coefficient B-7

B-5 Tube Side IHX Inverse Film Coefficient B-7

D-1 DHX Tube and Fin Geometry D-1

D-2 Transverse-Fin Heat Transfer and Pressure Drop D-4

D-3 Efficiency of Annular Fins of Constant Thickness D-6 


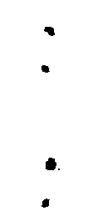

. 


\section{INTRODUCTION}

The Fast Flux Test Facility will be the main facility for testing fuels and structural materials in the USAEC's Liquid Metal Fast Breeder Reactor (LMFBR) Program. The dynamic behavior of the reactor and its associated heat removal systems is critical in the total design of the plant. The system must be controllable and it must be designed to survive the expected system transients. To analyze the system dynamic characteristics, a dynamic simulation model of the plant has been developed for solution on the analoghybrid computer at Pacific Northwest Laboratory. (1) This report provides a detailed description of the mathematical models used to simulate each system component. The model is basically an expansion of the simplified model described in Reference 2 and accounts for:

- Reactor Kinetics and Feedbacks

- Heat Transfer

- Sodium and Air Hydraulics

- Coolant Transport Time Lags

- Rotating Equipment.

Typical transient results from the simulation are also given. Actual design data are not included in the report since: 1) the design is only conceptual at this time, and 2) the purpose of the report is to describe the mathematical modeling methods.

The model will be used to provide transient information in the following areas:

- Component Design

- Safety System Design

- Process Control and Data Handling Design

- Operator Training. 
Temperature and flow transient information will be provided for the design of system components. Such information is required, for example, in heat exchanger and reactor vessel procurement specifications. Safety studies will include evaluation of system response to the credible range of disturbances, and determination of instrument trip limits needed to limit system component transients. Process control studies will aid in demonstrating and choosing the best control scheme for the system. The model may also be utilized to analyze and demonstrate data handling systems prior to installation in the facility. Finally, the simulation will be used for a comprehensive operator training program.

\section{SUMMARY}

A mathematical model of the FFTF Reactor and heat removal system has been developed to study the plant dynamic characteristics. The model is programmed on the analog-hybrid facility at PNL. The purpose of this report is to provide a detailed description of the mathematical modeling techniques used to simulate each system component. Sample transient results are also included.

Due to the limitation of computing equipment, only one complete heat removal circuit (out of four) has been simulated. The total heat is accounted for by applying the appropriate multiplying factor. One heat removal circuit consists of a primary sodium loop, a secondary sodium loop, and a tertiary air heat dump system. The total simulation includes models of: 1) reactor, 2) multinode intermediate heat exchanger (IHX), 3) multinode dump heat exchanger (DHX), 4) primary, secondary and tertiary coolant hydraulics, 5) coolant transport time lags, 6) sodium pumps, motors and clutches, and 7) air blowers. The complete system model has been programmed 
and debugged, and is available for transient studies. The addition of a second heat removal circuit to the simulation is planned for investigating multiloop interaction and control.

\section{PLANT DESCRIPTION}

The FFTF heat removal system consists of four independent, parallel cooling circuits that have a common flow path through the reactor vessel. Each circuit consists of three major systems as shown in Figure 2.1.1.

- A radioactive primary sodium system.

- A secondary sodium system.

- A tertiary air-cooled heat dump system.

The plant is designed to allow full-load reactor operation using any three of the four cooling circuits.

\subsection{Reactor Description}

Figure 2.1.2 shows the internals of the FFTF split core arrangement. Figure 2.1.3 shows a cross-sectional view of the core. The primary sodium coolant enters the inlet nozzles and flows through downcomers to a high-pressure inlet plenum. There is a three-way flow split from the inlet plenum:

- Main sodium flow through the reactor tubes (containing fuel subassemblies, open loops, and control elements) to remove heat generated by the fuel, axial reflectors, and control elements

- Leakage flow around the outside of the subassemblies (including the flow up through center of core around the closed 10ops)

- Radial reflector coolant flow that removes heat generated in the radial reflector regions.

The three flows dump into a common mixing plenum at the subassembly outlet. From the outlet mixing plenum, the sodium flows to the four parallel heat removal circuits. 


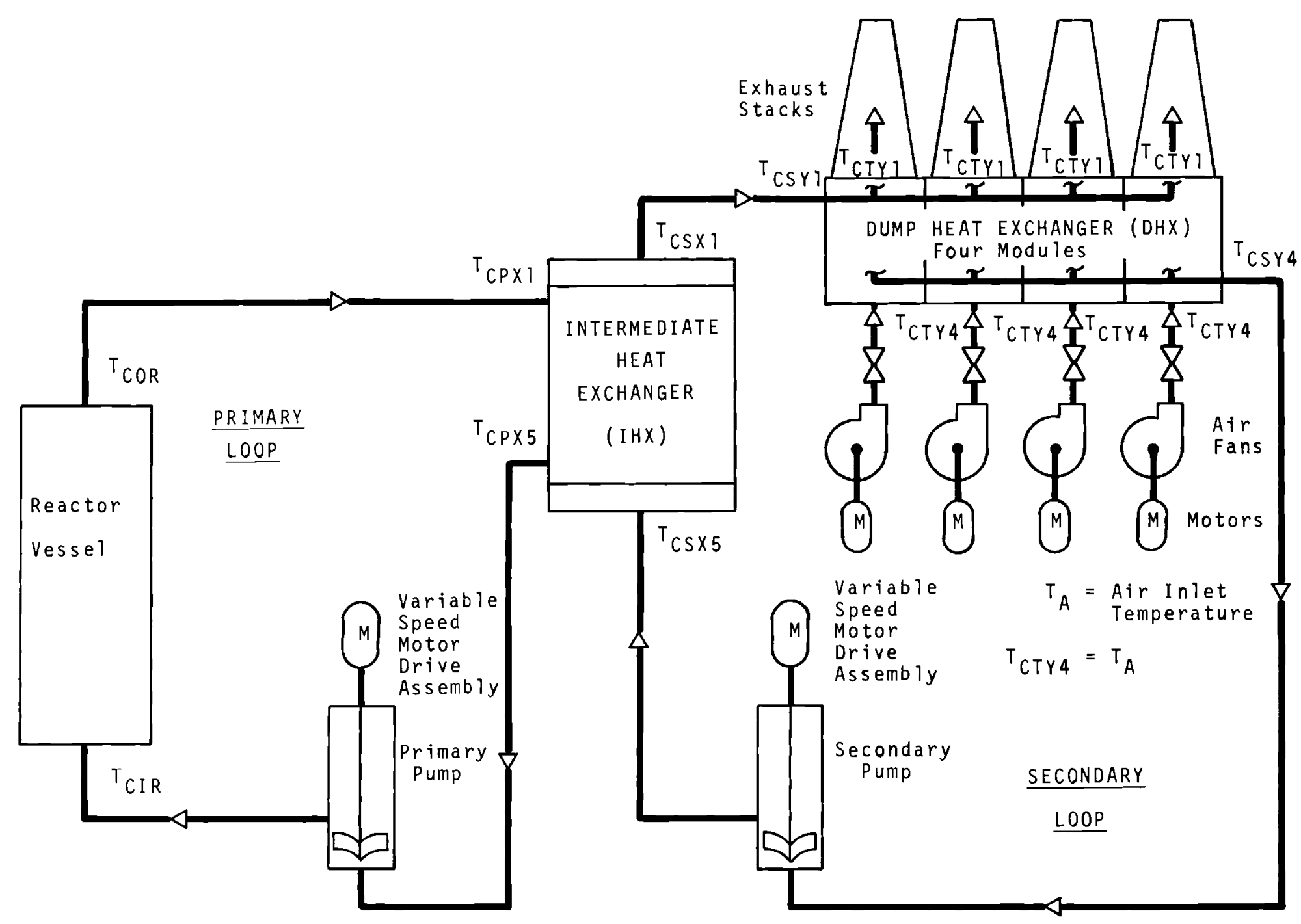

FIGURE 2.1.1. FFTF Heat Removal System Arrangement--one Circuit, Typical of Four (Inlet and outzet coolant temperatures are labeled for the major components) 


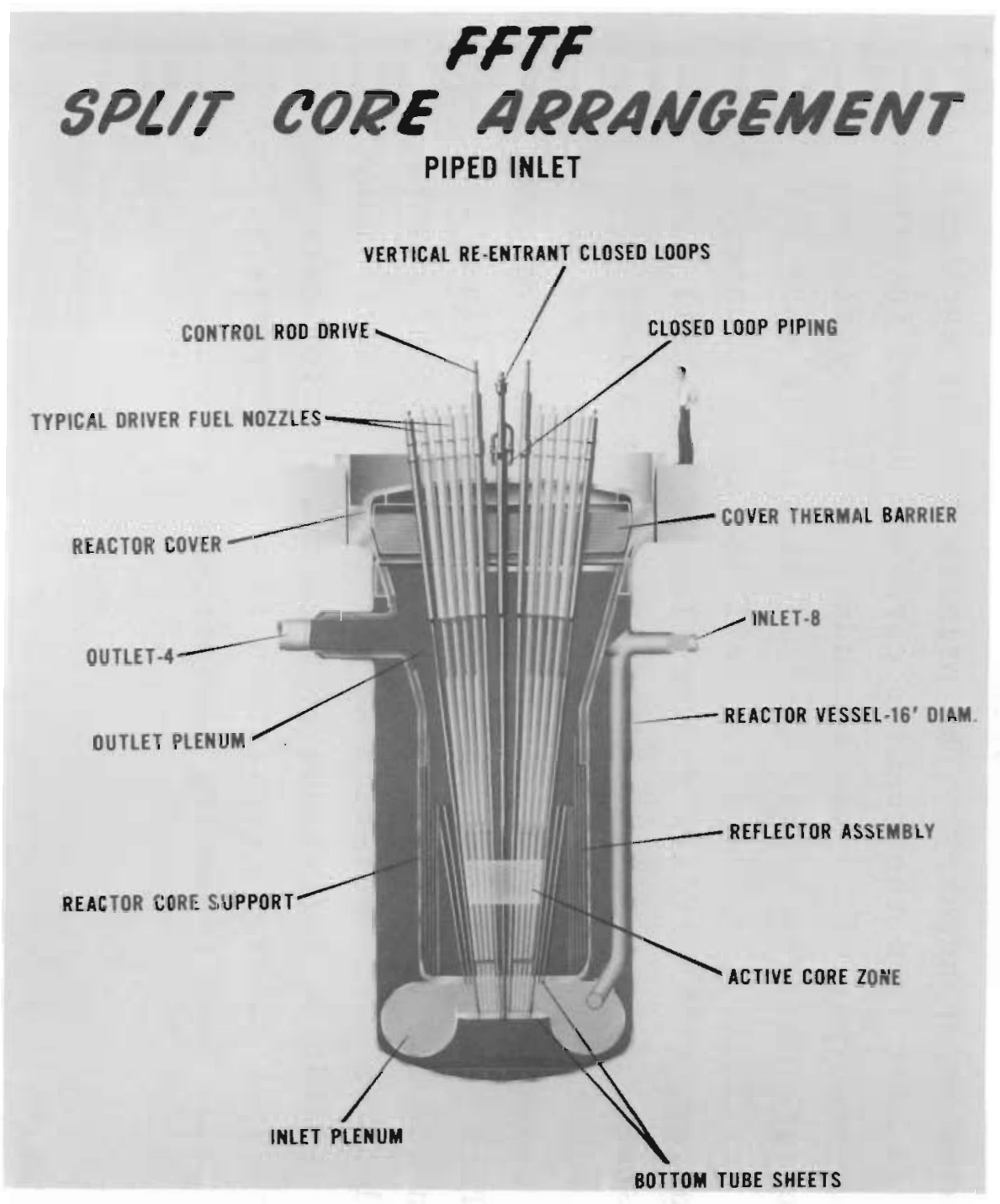

Neg $0674071-1$

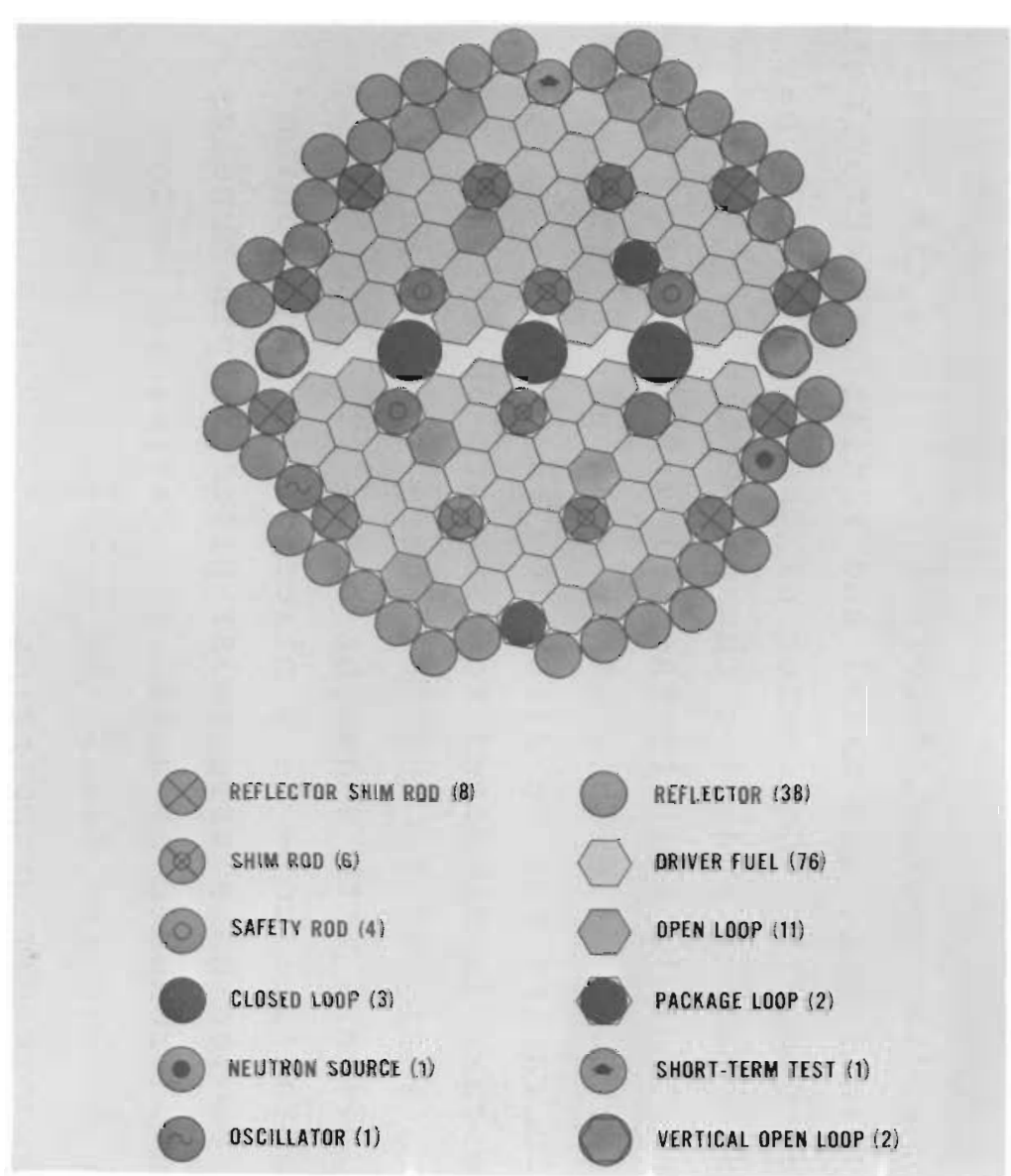

Neg $0673276-2$

Simulation only accounts for driver fuel, open loops, closed Loops, and reflectors.)

FIGURE 2.1.3. Reactor Core Cross Section (Conceptual Design) er 
The primary sodium coolant receives heat from the driver fuel elements, open loops, and axial and radial reflector material. The closed loops in the center of the core have separate heat removal systems and, for the present design, are assumed to add negligible heat to the primary coolant. The core design is extremely flexible at this stage of conceptual design, thus only ranges can be given for the various core parameters. The core is expected to generate 300 to $400 \mathrm{MW}$ with a core delta-T of 300 to $400^{\circ} \mathrm{F}$. Core volume can range from 800 to 1100 liters with a height of $\sim 3 \mathrm{ft}$. The fuel material for the initial core is a mixed plutonium-uranium oxide and is assembled on a triangular pitch in pin bundles. The core zone is surrounded by axial and radial reflector regions as shown in Figures 2.1.2 and 2.1.3.

\subsection{HEAT REMOVAL CIRCUIT DESCRIPTION}

Each of the four heat removal circuits is identical and each operates independently. The primary loop of each circuit removes heat from the reactor core and vessel internals. The heat is transported to the secondary sodium system via an intermediate heat exchanger (IHX). The IHX in each circuit is a vertical, single-pass, shell and tube, counterflow heat exchanger, with primary sodium flow on the shell side. A single stage, free surface, centrifugal pump drives the primary coolant. Variable pump speed is provided and is presently assumed to be included by eddy current drive couplings. This method of pump speed control is not final in the design and is subject to change. Auxiliary pony motors are provided for pump operation at $\sim 10$ to $15 \%$ of rated pump speed. An elevation difference between the reactor core and the IHX provides natural circulation flow in the primary loop to remove decay heat following an emergency shutdown. 
The secondary sodium loop receives heat from the tube side of the IHX. This heat is removed by the air heat dump system (DHX) in each circuit. The secondary sodium pumps are similar to the primary pumps, and are located in the cold leg of each circuit. Variable pump speed control on the secondary pumps is also provided by eddy current clutch couplings. Sodium expansion tanks are included in the secondary cold legs of each circuit to allow for sodium thermal expansion and to provide the required pump suction head. A natural circulation head is also provided in the secondary loops by a height difference between the IHX and DHX.

Forced draft air heat dumps remove heat from the secondary sodium loops. The heat dumps for each of the four heat removal circuits are divided into four modules, each with its own heat exchanger coil and blower. The heat exchanger sections consist of multipass finned tubes, containing secondary sodium, that are cooled by cross-flowing air. The DHX is designed so that each module can be operated independently of the other parallel modules. Air flow is provided by electric motor driven blowers of either axial flow or centrifugal type. The blowers are equipped with variable-position inlet vanes for flow control. Blower discharge dampers are provided to allow manual control during low load conditions. Heated air is exhausted from the DHX modules through insulated stacks that are equipped with low-leakage dampers for blockage of air flow. Each of the four heat removal circuits is designed so that three circuits will handle the entire maximum heat load. 


\section{MATHEMATICAL MODELS OF THE FFTF SUBSYSTEMS}

The mathematical bases for the models used in the FFTF dynamics simulation are presented in this section. Where detailed analysis is necessary, refer to the appendices. The general assumptions made in developing the models are presented in each subsection discussion.

3.1 REACTOR MODEL

The reactor model simulates the heat generated and transmitted within the reactor vessel. The model is nodalized to simulate the regions where heat is stored or generated and where primary sodium coolant flows. Figure 3.1.1, p. 14, represents the nodalized reactor model.

\subsubsection{Heat Generation}

The total power $\left(\mathrm{PL}_{\mathrm{T}}\right)$ within the reactor vessel originates in the core zone and consists of neutron (both prompt and delayed) power $\left(\mathrm{PL}_{N}\right)$ and fission product decay power $\left(\mathrm{PL}_{F}\right)$ :

$$
P L_{T}=P L_{N}+P L_{F}
$$

The total reactor power results from heat generation in the following regions within the reactor vessel:

- Driver Fuel and Open Loops

- Closed Loops

- Radial Reflectors

- Axial Reflectors.

The driver fuel elements and the open loops are combined into an equivalent number of average driver fuel elements $\left(N_{E R}\right)$. Each open loop is assumed to produce a given fraction of the heat generated in an average driver fuel element (e.g., 12 open loops are assumed to be equivalent to six driver elements in the present simulation). 
The closed loops are in the core zone and their total heat generation consists of neutron and fission products. The closed loops, however, have their own heat removal systems and are assumed to be thermally insulated from the primary sodium coolant. Therefore, the closed-loop heat generation is subtracted from the total heat generation $\left(\mathrm{PL}_{\mathrm{T}}\right)$ when determining driver fuel heat generation. The closedloop power $\left(\mathrm{PL}_{\mathrm{CR}}\right)$ is unknown at this time and is assumed to be a fraction $\left(\gamma_{C R}\right)$ of the total power:

$$
\mathrm{PL}_{\mathrm{CR}}=\gamma_{\mathrm{CR}} \mathrm{PL}_{\mathrm{T}}
$$

The fission product heat is confined within the active core zone. Therefore, the reflector regions are heated only by the bombardment of neutrons that escape from the active core zone. The radial reflector heat generation $\left(\mathrm{PL}_{\mathrm{RR}}\right)$ is assumed to be a fraction $\left(\gamma_{R R}\right)$ of the neutron power level:

$$
P L_{R R}=\gamma_{R R} P L_{N}
$$

The axial reflector heat is included with the driver fuel heat generation since the axial reflectors are not modeled as separate nodes.

The heat generated in the equivalent driver fuel elements (open loops plus drivers) and axial reflectors is the remainder of the total heat. Heat generated in the driver fuel and open loops $\left(\mathrm{PL}_{\mathrm{FR}}\right)$ is the total power minus the closed-loop power and the radial reflector power:

$$
\begin{aligned}
\mathrm{PL}_{\mathrm{FR}} & =P L_{\mathrm{T}}-P L_{C R}-P L_{R R} \\
& =\left(1-\gamma_{\mathrm{CR}}\right) P L_{F}+\left(1-\gamma_{\mathrm{CR}}-\gamma_{\mathrm{RR}}\right) \mathrm{PL}_{\mathrm{N}} \cdot(3.1-3)
\end{aligned}
$$

\subsubsection{Reactor Kinetics - Neutron Power}

The neutron power is calculated from the standard space independent reactor kinetics equations ${ }^{(3)}$ with the assumption that 


$$
\delta k=\frac{k_{\text {eff }}-1}{k_{\text {eff }}} \simeq k_{\text {eff }}-1
$$

Therefore,

$$
\frac{d\left(P L_{N}\right)}{d t}=\frac{\delta k-\beta}{\ell^{*}}\left(P L_{N}\right)+\sum_{i=1}^{3} \lambda_{i} C_{i}
$$

where

$$
\frac{\mathrm{dC}}{\mathrm{dt}}=\frac{\beta_{i}}{\ell^{*}}\left(P L_{N}\right)-\lambda_{i} \mathrm{C}_{i}
$$

Algebraic manipulation of these equations yields an alternate form that is better suited for analog simulation of reactors with small neutron lifetimes, ( $\ell^{*}=3.5 \times 10^{-7}$ sec for the FTR). The alternate equations that have been simulated are

$$
\begin{aligned}
\mathrm{PL}_{N}+\frac{\ell^{*}}{\beta} \frac{\mathrm{d}\left(\mathrm{PL}_{\mathrm{N}}\right)}{\mathrm{dt}} & =\frac{\delta \mathrm{k}}{\beta}\left(\mathrm{PL}_{\mathrm{N}}\right)+\sum_{i=1}^{3} \frac{\ell^{*} \lambda_{i} \mathrm{C}_{i}}{\beta}, \\
\frac{\mathrm{d}\left(\frac{l^{*} \lambda_{i} C_{i}}{\beta_{i}}\right)}{\mathrm{dt}} & =\lambda_{i}\left(\mathrm{PL}_{N}\right)-\lambda_{i}\left(\frac{l * \lambda_{i} C_{i}}{\beta_{i}}\right), \\
\frac{\ell^{*} \lambda_{i} C_{i}}{\beta} & =\frac{\beta}{\beta}\left(\frac{l^{*} \lambda_{i} C_{i}}{\beta_{i}}\right)
\end{aligned}
$$

Three reduced delayed neutron groups are used. The delayed group constants are calculated with the computer code prepared by Albrecht. (4) The code uses six equivalent groups with either the first or sixth group isolated and the remaining five groups reduced to two groups. For short-time response 
to fast transients, the short-lifetime group is isolated as one of the three groups, and for long-time, slow transients, the long-lifetime group is isolated.

3.1.3. Reactivity Feedbacks

The following terms are included in the reactivity feedback model for the reactor:

1. Sodium temperature feedback, $\delta \mathrm{k}_{\mathrm{C}}$

2. Fue1 Doppler feedback, $\delta k_{D}$

3. Structural feedbacks,

a. Tube deflection due to radial core expansion, $\delta k_{E}$

b. Tube deflection due to fuel shroud tube bowing, $\delta \mathrm{k}_{B}$

4. Miscellaneous control inputs

a. Scram reactivity, $\delta \mathrm{k}_{\mathrm{s}}$

b. Control reactivity, $\delta k_{C R}$, for power level control

c. Reactor state reactivity-for steady-state $\delta k$

balance, $\delta \mathrm{k}_{z}$.

The sodium temperature feedback coefficient is small and negative for the FTR core, and the reactivity feedback is a function of the average shroud tube coolant temperature in the core zone:

$$
\delta k_{C}=\alpha_{C} T_{\text {ACTR }} .
$$

The Doppler feedback coefficient is also negative and is a function of the average fuel temperature. The Doppler feedback coefficient is expressed as follows:

$$
\alpha_{D}=\mathrm{T} \frac{\mathrm{d} k}{\mathrm{dT}}
$$

Integrating this expression between a reference fuel temperature $\left(T_{A F R Z}\right)$, in degrees Farenheit, and the average calculated fuel temperature $\left(\mathrm{T}_{\mathrm{AFR}}\right)$, in degrees Farenheit, we obtain the Doppler reactivity feedback term

$$
\delta \mathrm{k}_{\mathrm{D}}=\alpha_{\mathrm{D}}\left\{\ln \left[\left(\mathrm{T}_{\mathrm{AFR}}+460\right) /\left(\mathrm{T}_{\mathrm{AFRZ}}+460\right)\right]\right\} \cdot(3.1-11)
$$


Any reference fuel temperature $\left(\mathrm{T}_{\mathrm{AFRZ}}\right)$ can be used in this term as long as the reactivity balance at steady-state power yields a zero total $\delta \mathrm{k}$. The value for TAFRz normally used is the steady-state initial condition value of average fuel temperature, $\mathrm{T}_{\mathrm{AFR}}$.

The structural feedback due to radial core expansion provides a negative feedback from the temperature of the shroud tubes and spacers. The feedback is assumed to be a function of the average shroud coolant temperature. This appears to be a reasonable assumption since the shroud tube material temperature will follow the tube coolant temperature quite closely. The equation for radial core expansion feedback is

$$
\delta \mathrm{k}_{\mathrm{E}}=\alpha_{\mathrm{E}}\left(\mathrm{T}_{\mathrm{ACTR}}-\mathrm{T}_{\mathrm{ACTRZ}}\right) \text {. }
$$

As with the Doppler feedback equation, any reference average coolant temperature $\left(\mathrm{T}_{\mathrm{ACTRZ}}\right)$ can be used as long as the total reactivity balance is correct.

The shroud tube bowing is assumed to contribute a positive reactivity feedback with increasing core delta-T. This feedback is caused by the inward (towards core centerline) bowing of the shroud tubes caused by a transverse temperature gradient across the tube diameter. This temperature gradient is proportional to the core radial flux profile and can be approximated mathematically as a function of the axial core coolant delta-T $\left(\mathrm{T}_{\mathrm{CTR}}-\mathrm{T}_{\mathrm{CIP}}\right)$. The reactivity feedback due to bowing is

$$
\delta k_{B}=\alpha_{B}\left(T_{C T R}-T_{C I P}\right)
$$

The miscellaneous control reactivities are either forced onto the system by controllers or by the systems engineer to study a transient or to achieve a steady-state reactivity balance. These terms, therefore, have no fixed mathematical representation at this time. 
The total reactivity ( $\delta \mathrm{k})$ utilized in Equation (3.1-4) is the sum of the individual reactivity feedbacks:

$$
\delta \mathrm{k}=\delta \mathrm{k}_{\mathrm{C}}+\delta \mathrm{k}_{\mathrm{D}}+\delta \mathrm{k}_{\mathrm{E}}+\delta \mathrm{k}_{\mathrm{B}}+\delta \mathrm{k}_{\mathrm{CR}}+\delta \mathrm{k}_{\mathrm{S}}+\delta \mathrm{k}_{\mathrm{Z}} .
$$

\subsubsection{Fission Product Power}

A portion of the total heat generated in the core zone is due to decay of fission products. At full power steady-state operating conditions the fission products contribute only about $5 \%$ of the total core power. However, in less than 1 min after a reactor scram, the fission product decay heat becomes the major portion of the total heat generated. Decay heat generation curves (5) have been used to obtain a model representing the fission product decay heat (following shutdown) as a fraction of full power, steady-state neutron power level.

This relationship is shown in Figure 3.1 .2 and applies to a plutonium fueled fast reactor (100 day exposure) and includes the power generation due to beta and gamma decay of all fission product isotopes. The data used to obtain this curve are preliminary and are subject to future revision.

To simulate the fission product decay, three groups are assumed to approximate the decay curve, represented by the assymptotes shown in Figure 3.1.2. The equations for the three fission product decay groups are

$$
\begin{aligned}
& \frac{d\left(P L_{F 1}\right)}{d t}=\lambda_{F 1}\left(\beta_{F 1} P L_{N}-P L_{F 1}\right), \\
& \frac{d\left(P L_{F 2}\right)}{d t}=\lambda_{F 2}\left(\beta_{F 2} P L_{N}-P L_{F 2}\right), \\
& \frac{d\left(P L_{F 3}\right)}{d t}=\lambda_{F 3}\left(\beta_{F 3} P L_{N}-P L_{F 3}\right),
\end{aligned}
$$




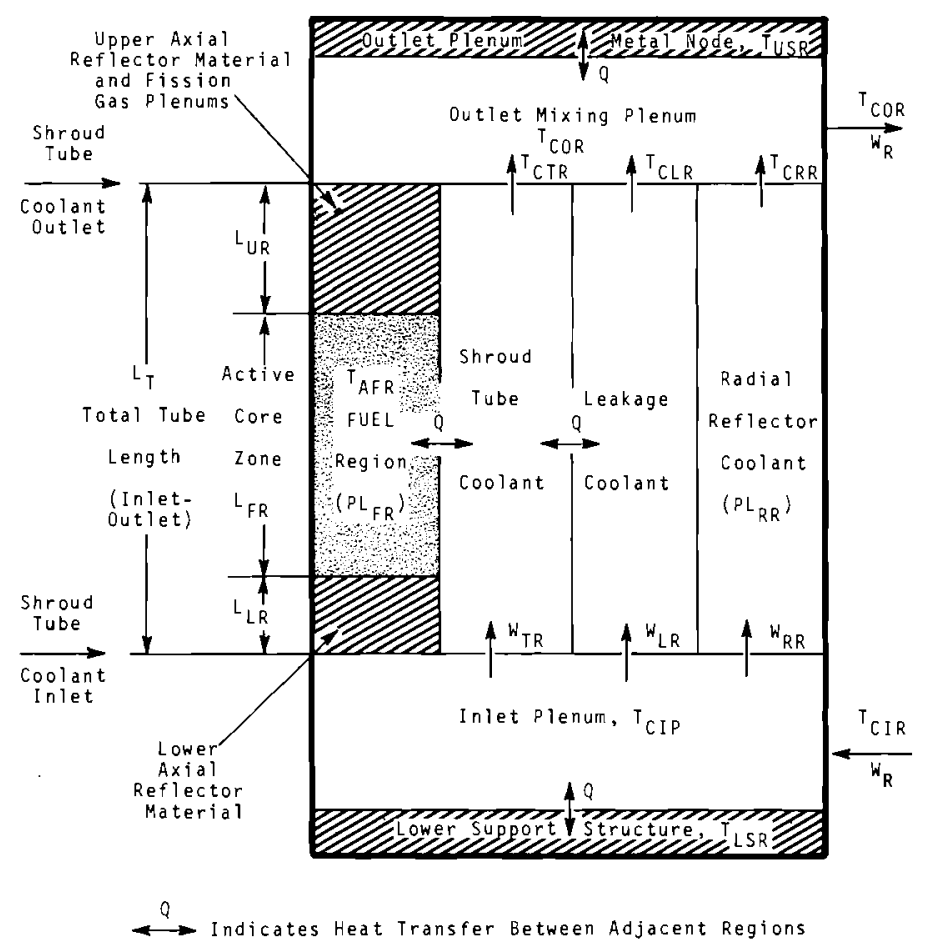

\section{FIGURE 3.1.1. Nodalized Reactor Model}

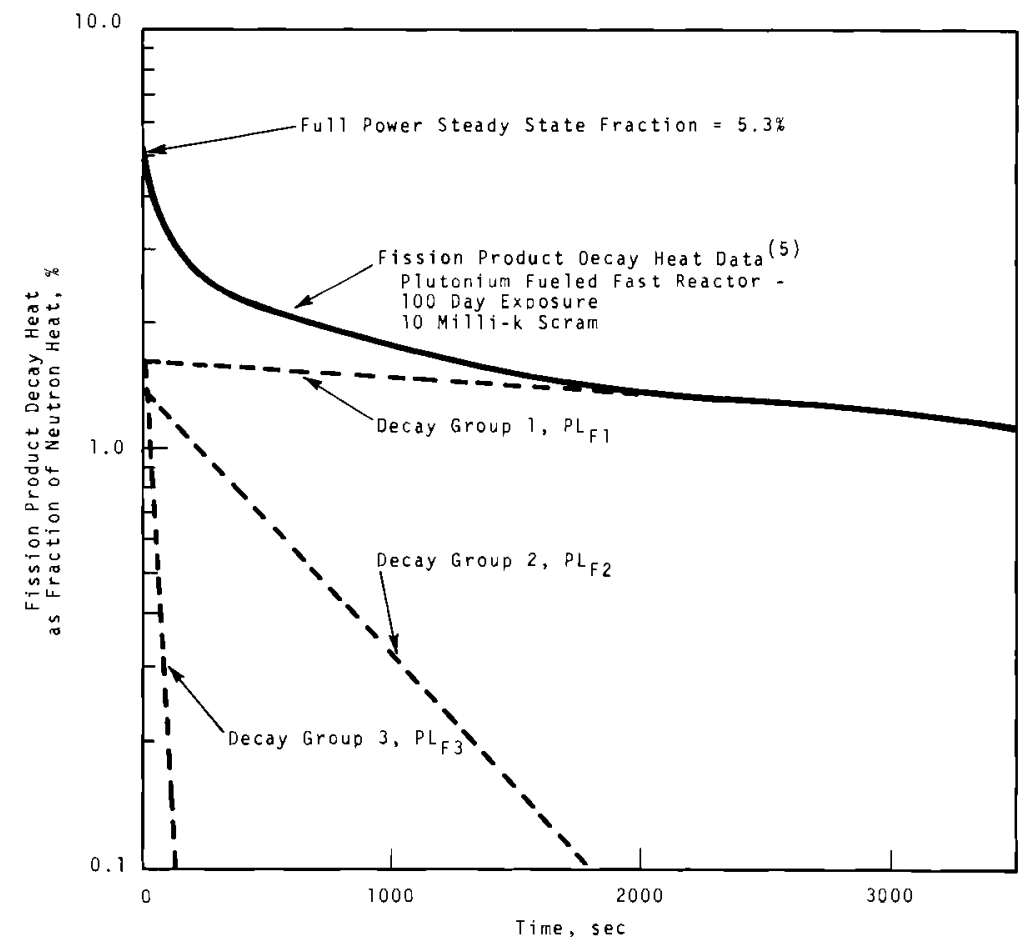

FIGURE 3.1.2. Fission Product Decay Heat Generation Folzowing Reactor Scram 
The total fission product heat is then the sum of three groups:

$$
\mathrm{PL}_{\mathrm{F}}=\mathrm{PL}_{\mathrm{F} 1}+\mathrm{PL}_{\mathrm{F} 2}+\mathrm{PL}_{\mathrm{F} 3} \text {. }
$$

3.1.5. Reactor Thermal Model Description

The block diagram for the reactor thermal model is shown in Figure 3.1.1. Primary coolant enters the inlet plenum from the reactor inlet nozzle and is distributed to the subassembly shroud tubes, leakage region, and radial reflectors. A node for the stainless steel lower support structure is included adjacent to the inlet plenum to account for heat transfer between the inlet plenum, where perfect mixing is assumed, and the lower support structure. Gamma heating in the lower support structure is assumed to be negligible. The liquid sodium coolant entering the tubes flows upward through the core region, removes heat from the fuel and axial reflectors, and exits into the outlet plenum. Liquid sodium flowing in the radial reflectors removes the heat generated in the radial reflector material and exits into the outlet plenum. Heat transfer is included between the adjacent regions in the reactor model (small arrows in Figure 3.1.1).

The radial reflector material heat capacity is accounted for by converting the reflector material volume to an equivalent sodium volume and lumping it with the radial reflector coolant. The radial reflector heat generation is included in the radial reflector coolant equation. The lower axial reflector material volume and the sodium volume in the shroud tubes up to the bottom of the core zone are lumped with the inlet plenum volume; likewise, the upper axial reflector material, fuel fission gas plenum volume, and sodium volume (inside of shroud tube) from the core zone outlet to the shroud tube outlet are lumped with the outlet plenum volume. Perfect mixing is assumed in the outlet plenum and heat 
transfer to a metal node is included. The metal node includes the volume of the tubes that extend up through the outlet plenum and the volume of all other steel in the outlet plenum region.

\subsubsection{Reactor Thermal Mode1 Equations}

Linear coolant temperature distributions are assumed through each of the three parallel flow paths, and the rate of change of the nodal outlet temperature is assumed to be equal to the rate of change of the average nodal temperature. The flow rates in the tubes, leakage, and reflector are assumed to split from the total flow in the inlet plenum as a constant percentage of total reactor flow $\left(W_{R}\right)$.

$$
\begin{aligned}
& \text { Tube Flow: } \quad W_{\mathrm{TR}}=\mathrm{a}_{\mathrm{TR}} \mathrm{W}_{\mathrm{R}} \text {, } \\
& \text { Leakage Flow: } \quad W_{L R}=a_{L R} W_{R} \text {, } \\
& \text { Radial Reflector Flow: } W_{R R}=a_{R R} W_{R} \text {; } \\
& a_{T R}+a_{L R}+a_{R R}=1 \text {. }
\end{aligned}
$$

Thermal properties (density and specific heat) are assumed to be constant, and axial heat conduction in the coolant is neglected.

The mixing equation for the reactor inlet plenum temperature $\left(\mathrm{T}_{\mathrm{CIP}}\right)$ is (perfect mixing assumed):

$$
\frac{{ }^{d T_{C I P}}}{d t}=\frac{W_{R} C_{C I P}}{(\rho V \bar{C})_{I P}}\left(T_{C I R}-T_{C I P}\right) \frac{(U A)_{L S R}}{(\rho V C)_{I P}}\left(T_{C I P}-T_{L S R}\right)
$$

where $\mathrm{T}_{\mathrm{CIR}}=$ reactor inlet temperature, ${ }^{\circ} \mathrm{F}$

$(\rho V C)_{I P}=$ density $x$ volume $x$ specific heat-(inlet plenum sodium-assumed constant)

$(U A)_{L S R}=$ overall heat transfer conductance, metal-sodium. 
The equation for the lower support structure temperature $\left(\mathrm{T}_{\mathrm{LSR}}\right)$ is :

$$
\frac{\mathrm{dT}_{\text {LSR }}}{\mathrm{dt}}=\frac{(\mathrm{UA})_{\text {LSR }}}{(\rho \mathrm{VC})_{\text {LSR }}}\left(\mathrm{T}_{\mathrm{CIP}}-\mathrm{T}_{\text {LSR }}\right)
$$

where $(\rho V C)_{L S R}=$ density $x$ volume $x$ specific heat-(lower support metal-assumed constant).

The heat transfer conductance between the metal and sodium, (UA) LSR, is assumed to be constant with temperature and includes the metal thermal conductivity and surface area. The heat transfer resistance of the sodium film at the metal surface is neglected. This is a reasonable assumption since liquid sodium has excellent heat transfer properties.

The equations for the average fuel temperature and the subassembly shroud tube coolant temperature are written for an average equivalent driver fuel subassembly. Therefore, the following volumes and areas are per equivalent driver element, per unit length: $V^{\prime}{ }_{F R}, A^{\prime}{ }_{R}, V^{\prime}{ }_{C T R}$, and $A^{\prime}{ }_{T R}$. The leakage coolant temperature and radial reflector coolant temperature equations are written for the total leakage and reflector volumes. Therefore, $V_{C L R}, A_{R R}$, and $V_{R R}$ are total volumes and areas. The average equivalent driver fuel temperature $\left(\mathrm{T}_{\mathrm{AFR}}\right)$ is obtained from:

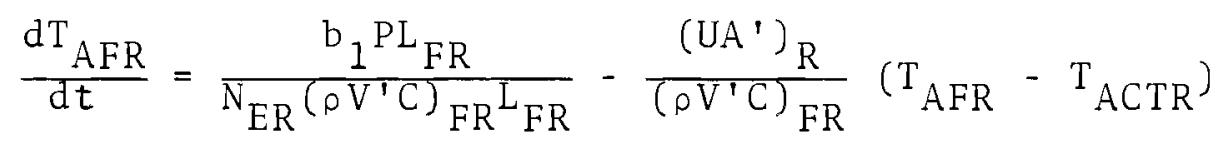

where $\left(\mathrm{UA}^{\prime}\right)_{\mathrm{R}}=$ overall heat transfer conductance/unit length(fuel to coolant), discussed below

$$
\begin{aligned}
\mathrm{N}_{\mathrm{ER}}= & \text { number of equivalent driver fuel elements } \\
\mathrm{T}_{\mathrm{ACTR}}+\mathrm{T}_{\mathrm{CIP}} & \frac{\mathrm{C}_{\mathrm{C}}}{2}=\text { average coolant temperature } \\
\mathrm{L}_{\mathrm{FR}}= & \text { fuel length, ft } \\
\left(\mathrm{\rho V} \mathrm{V}^{\prime}\right)_{\mathrm{FR}}= & \text { density } \mathrm{x} \text { (fuel volume/unit length) } \mathrm{x} \text { specific } \\
& \text { heat-(fuel region-assumed constant) } \\
\mathrm{b}_{1}= & \text { conversion constant, Btu/sec-MW. }
\end{aligned}
$$


The heat transfer conductance (per unit length) between the fuel and the shroud tube coolant, (UA') ${ }_{R}$, includes a fuel resistance, a clad resistance and a clad surface resistance. The fuel to coolant heat transfer coefficient is simulated as a function of fuel temperature as explained in Appendix A.

The shroud tube coolant outlet temperature equation includes heat removed by the coolant, heat transfer from the fuel, and heat transfer to the leakage. The clad, fuel pin spacers, and subassembly shroud tube wall are all lumped with the tube coolant. This is accomplished by calculating equivalent density and specific heat terms on a volume weighted basis as follows:

$(\rho C)^{*}$ equivalent $=(\rho C)_{\text {coolant }}(V F)_{\text {coolant }}+(\rho C)_{\text {metal }}(V F)_{\text {metal }}$ where $(V F)_{\text {coolant }}=$ coolant volume fraction

$$
\begin{aligned}
(V F)_{\text {metal }}= & \text { metal volume fraction (includes clad, } \\
& \text { spacers, and tube wall). }
\end{aligned}
$$

Note: $(\rho C)^{*}$ denotes lumped coolant and metal properties. The tube coolant outlet temperature $\left(\mathrm{T}_{\mathrm{CTR}}\right)$ is calculated by the following equation

$$
\begin{aligned}
& \frac{\mathrm{dT}_{\mathrm{CTR}}}{d t}=-\frac{\mathrm{w}_{\mathrm{TR}} \mathrm{C}_{\mathrm{CTR}}}{\mathrm{N}_{E R} \mathrm{~L}_{F R}\left(\rho V^{\prime} \mathrm{C}\right){ }_{\mathrm{CTR}}^{*}}\left(\mathrm{~T}_{\mathrm{CTR}}-\mathrm{T}_{\mathrm{CIP}}\right) \\
& +\frac{\left(U A^{\prime}\right)_{R}}{\left(\rho V^{\prime} C\right)_{C T R}^{*}}\left(T_{A F R}-T_{A C T R}\right) \\
& -a_{T L R} \frac{\left(U^{\prime}\right)_{T R}}{\left(\rho V^{\prime} C\right)_{C T R}^{*}}\left(\frac{T_{C T R}-T_{C L R}}{2}\right)
\end{aligned}
$$

where $\left(U A^{\prime}\right)_{T R}=$ overall heat transfer conductance/unit length(tube coolant to leakage coolant), discussed below $\mathrm{T}_{\mathrm{CLR}}=$ leakage region coolant outlet temperature. 
The last term accounts for heat transferred from the shroud tube coolant, through the tube wall, to the leakage coolant. The temperature difference for heat transfer results from taking the difference between the average tube and leakage coolant temperatures. Since the adjacent coolant regions have the same inlet temperature, the driving force between the tube coolant and leakage coolant becomes one-half the difference between the node outlet temperatures. A length ratio $\left(a_{T L R}\right)$ accounts for the portion of the tube (bottom of core to tube outlet) where heat transfer from the shroud tube coolant to the leakage coolant actually occurs:

$a_{T L R}=\frac{\text { active heat transfer length }}{\text { active core length }}=\frac{\mathrm{L}_{F R}+\mathrm{L}_{U R}}{\mathrm{~L}_{\mathrm{FR}}}$.

The shroud tube coolant to leakage coolant heat transfer conductance, $\left(\mathrm{UA}^{\prime}\right)_{\mathrm{TR}}$, is assumed to be a constant with temperature. The term consists of inside and outside film coefficients, and the tube wall thermal conductivity.

The bypass leakage outlet coolant temperature ( $\mathrm{T}_{\mathrm{CLR}}$ ) equation includes heat removed by the leakage coolant and heat transfer from the shroud tube coolant. Heat transfer between leakage coolant and radial reflector coolant was found to be negligible and, therefore, has not been included.

$$
\begin{aligned}
& \frac{d T_{C L R}}{d t}=-\frac{W_{L R} C_{C L R}}{(\rho V C)_{C L R}}\left(T_{C L R}-T_{C I P}\right) \\
& +a_{T L R} \frac{N_{E R} L_{F R}\left(U^{\prime}\right)_{T R}}{(\rho V C)}\left(\frac{T_{C L R}-T_{C L R}}{2}\right) .
\end{aligned}
$$

The heat transfer conductance between the tube coolant and leakage coolant is multiplied by the number of equivalent driver elements and the core length since the total leakage volume $\left(V_{C L R}\right)$ is used in this region. 
The radial reflector coolant outlet temperature equation includes heat removal by the coolant, and heat generation in the reflector material. The reflector material is lumped with the coolant by calculating equivalent $(\rho C)^{*}$ terms as before. $\frac{\mathrm{dT}_{\mathrm{CRR}}}{\mathrm{dt}}=-\frac{\mathrm{W}_{\mathrm{RR}} \mathrm{C}_{\mathrm{CRR}}}{(\rho \mathrm{VC})_{\mathrm{RR}}^{*}}\left(\mathrm{~T}_{\mathrm{CIP}}-\mathrm{T}_{\mathrm{CRR}}\right)+\frac{\mathrm{b}_{1}{ }^{\mathrm{PL}} \mathrm{R}_{\mathrm{RR}}}{(\rho \mathrm{VC})_{\mathrm{R} R}^{*}}$.

The three flows (tube, leakage, and reflector) are combined in the outlet mixing plenum. Constant and equivalent specific heats are assumed for each flow and also for the mixed flow. This is reasonable since the outlet temperatures from each region will not be greatly different. The outlet plenum temperature equation is

$\frac{\mathrm{dT}_{C O R}}{\mathrm{dt}}=\frac{\mathrm{w}_{\mathrm{R}}}{(\rho \mathrm{V})_{\mathrm{OR}}}\left(\mathrm{a}_{\mathrm{TR}} \mathrm{T}_{\mathrm{CTR}}+\mathrm{a}_{\mathrm{LR}} \mathrm{T}_{\mathrm{CLR}}+\mathrm{a}_{\mathrm{RR}} \mathrm{T}_{\mathrm{CRR}}-\mathrm{T}_{\mathrm{COR}}\right)$

$$
-\frac{(\mathrm{UA}) \mathrm{USR}}{(\mathrm{\rho VC}) \mathrm{OR}}\left(\mathrm{T}_{\mathrm{COR}}-\mathrm{T}_{\mathrm{USR}}\right) \text {. }
$$

The equation for the outlet plenum metal is

$\frac{\mathrm{dT}_{\mathrm{USR}}}{\mathrm{dt}}=\frac{(\mathrm{UA})_{\mathrm{USR}}}{(\rho \mathrm{VC})_{\mathrm{USR}}}\left(\mathrm{T}_{\mathrm{COR}}-\mathrm{T}_{\mathrm{USR}}\right)$.

The outlet plenum coolant to metal heat transfer conductance, (UA) USR, is assumed constant and includes a metal thermal conductivity resistance similar to the lower support plate heat transfer coefficient. Resistance due to the surface film conductance is neglected in the heat transfer conductance.

3.2 INTERMEDIATE HEAT EXCHANGER MODEL

The intermediate heat exchanger (IHX) to be used in each FFTF coolant loop will be of the tube-in-shell, counter flow type. A multinode model is used to describe heat transfer from primary to secondary as shown in Figure 3.2.1. After 


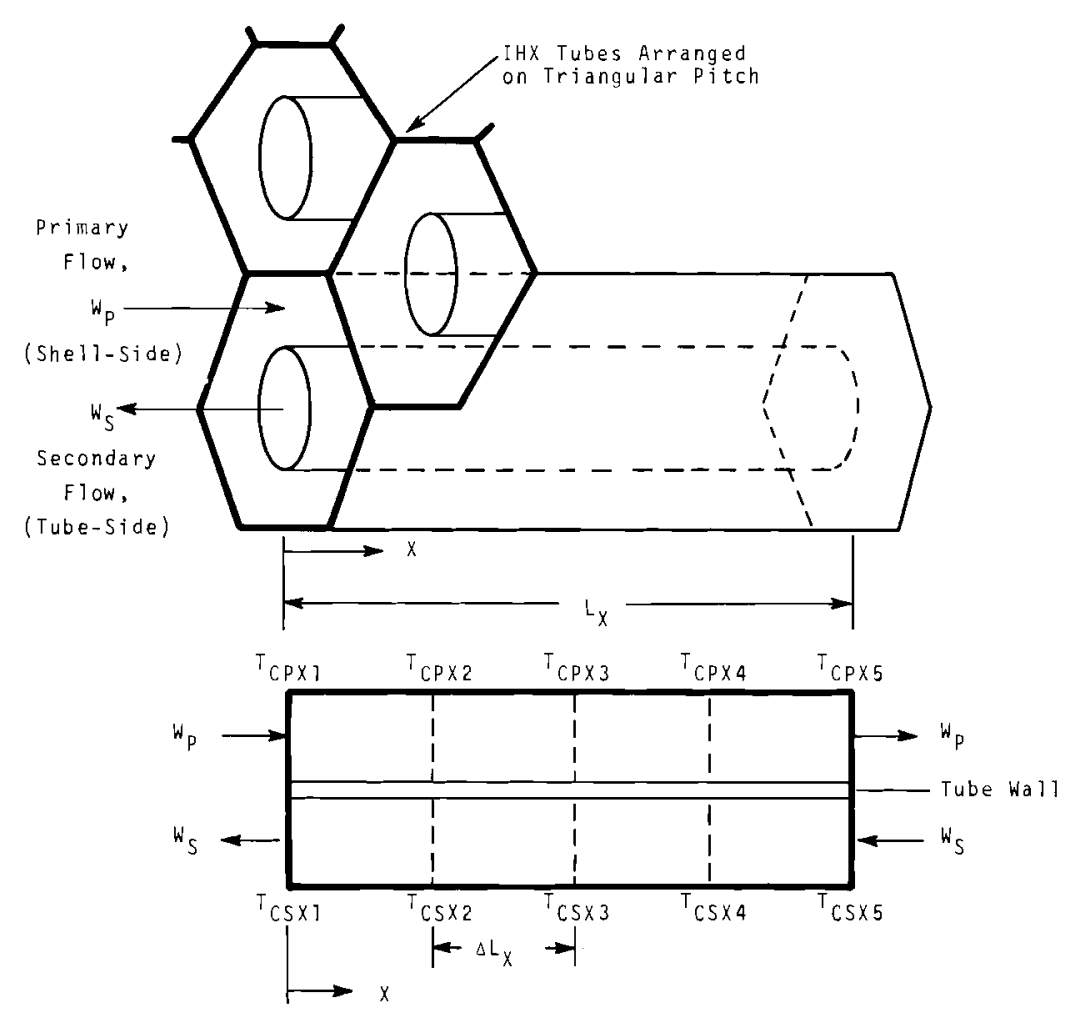

\section{FIGURE 3.2.1. Basic Configuration and Coordinate} System for the IHX Model

studying the transient response of several number of nodes, a four-node approach was selected as a reasonable compromise between accuracy and available analog computing equipment.

Heat transfer is described by the usual partial differential equations, in which temperature is a function of both time and axial position. Axial heat conduction is neglected in both tube wall and coolant, and heat storage in the tube metal is divided equally between the stored heat in primary and secondary sodium. Density and specific heat are assumed constant with temperature over the range of interest in each particular problem. The basic equations for the coolant temperature at each node(i) then appear as follows: 
BNWL - 707

$\underline{\text { Primary Side }}$

$\left(\rho V^{\prime} C\right)_{P i}^{*} \frac{\partial T_{C P i}}{\partial t}=-W_{P} C_{C P i} \frac{T_{C P i}}{\partial x}-\left(U A^{\prime}\right)\left(T_{C P i}-T_{C S i}\right)$,

Secondary Side

$\left(\rho V^{\prime} C\right)_{S i}^{*} \frac{\partial T_{C S i}}{\partial t}=W_{S} C_{C S i} \frac{\partial T_{C S i}}{\partial x}+\left(U A^{\prime}\right)\left(T_{C P i}-T_{C S i}\right)$,

where the $\left(\rho V^{\prime} C\right)^{*}$ coefficients include tube metal heat storage. The terms $V^{\prime}$ and $A^{\prime}$ represent volume and area per unit length.

A finite difference approximation is used to represent the axial temperature gradient $(\partial \mathrm{T} / \partial \mathrm{x})$ for each node. Several such approximations were studied by comparing temperature transients for realistic response of the coolant outlet temperatures. The best approximation of the axial temperature distribution was found to be a combination of a "central difference" approximation at each inlet node and "three-point backward" differences at the remaining three nodes. The term "backward" is used in this context to indicate a direction opposite to that of coolant flow. Note that five temperatures are used to describe the heat transfer of four nodes (Figure 3.2.1). The finite difference approximations are as follows:

Central Difference

$$
\frac{\partial T_{i}}{\partial x}=\frac{T_{i+1}-T_{i-1}}{2 \Delta L_{X}}
$$

Three-Point Backward

$$
\begin{aligned}
\frac{\partial T_{i}}{\partial x} & =\frac{3 T_{i}-4 T_{i-1}+T_{i-2}}{2 \Delta L_{X}} \ldots \text { primary } \\
& =\frac{-3 T_{i}+4 T_{i+1}-T_{i+2}}{2 \Delta L_{X}} \ldots \text { secondary }
\end{aligned}
$$

where $\Delta \mathrm{L}_{\mathrm{X}}=\mathrm{L}_{\mathrm{X}} / 4$ is the length between node points. 
The above equations are combined to give the following complete set of expressions for IHX heat transfer. Subscripts are included for clarity:

$\mathrm{C}=$ coolant, $\mathrm{P}=$ primary, $\mathrm{S}=$ secondary, and $\mathrm{X}=\mathrm{IHX}$.

$\left(\rho V^{\prime} C\right)_{P X}^{*} \frac{{ }^{d T}{ }_{C P X}}{d t}=\frac{2 W_{P} C_{C P X}}{L_{X}}(\Delta T)_{C P X i}-\left(U^{\prime}\right)_{X}\left(T_{C P X i}-T_{C S X i}\right)$

for $i=2,3,4,5$, and

$\left(\rho V^{\prime} C\right)_{S X}^{*} \frac{d_{C X X i}}{d t}=-\frac{2 W_{S} C_{C S X}}{L_{X}}(\Delta T)_{C S X i}+\left(U A^{\prime}\right)_{X}\left(T_{C P X i}-T_{C S X i}\right)$

for $i=1,2,3,4$, where

$$
\begin{aligned}
& \left(\Delta \mathrm{T}_{\mathrm{CPX} 2}=-\mathrm{T}_{\mathrm{CPX} 1}+\mathrm{T}_{\mathrm{CPX} 3}\right. \\
& (\Delta \mathrm{T})_{\mathrm{CPX} 3}=3 \mathrm{~T}_{\mathrm{CPX} 3}-4 \mathrm{~T}_{\mathrm{CPX} 2}+\mathrm{T}_{\mathrm{CPX1}} \\
& (\Delta \mathrm{T})_{\mathrm{CPX} 4}=3 \mathrm{~T}_{\mathrm{CPX} 4}-4 \mathrm{~T}_{\mathrm{CPX} 3}+\mathrm{T}_{\mathrm{CPX} 2} \\
& (\Delta \mathrm{T})_{\text {CPX } 5}=3 \mathrm{~T}_{\text {CPX } 5}-4 \mathrm{~T}_{\text {CPX4 }}+\mathrm{T}_{\text {CPX3 }} \\
& (\Delta)_{\operatorname{CSX} 1}=-3 \mathrm{~T}_{\operatorname{CSX} 1}+4 \mathrm{~T}_{\operatorname{CSX} 2}-\mathrm{T}_{\operatorname{CSX} 3} \\
& \left(\Delta \mathrm{T}_{\operatorname{CsX} 2}=-3 \mathrm{~T}_{\operatorname{CsX} 2}+4 \mathrm{~T}_{\operatorname{CsX} 3}-\mathrm{T}_{\operatorname{CsX} 4}\right. \\
& (\Delta)_{\operatorname{CsX} 3}=-3 T_{\operatorname{CSX} 3}+4 T_{\operatorname{CSX} 4}-\mathrm{T}_{\operatorname{CSX} 5} \\
& \left(\Delta \mathrm{T}_{\operatorname{CSX} 4}=-\mathrm{T}_{\operatorname{CSX} 3}+\mathrm{T}_{\operatorname{CSX} 5} .\right.
\end{aligned}
$$

Areas and volumes are easily computed from design data as shown in Appendix B. The heat transfer coefficient is a function of coolant flows and average temperatures, and is computed using the methods of Dwyer (6) for fluid flow within and around tube bundles. A complete description of the computation of (UA') $X$ and its simulation is found in Appendix $B$. 


\subsection{TRANSPORT DELAY MODEL}

Liquid sodium coolant is transported by the primary and secondary coolant loop piping. The time delay in the temperature leaving a section of piping with respect to the inlet temperature is simulated by a variable flow, no-mixing time delay program on the digital portion of the hybrid computer. (7) The theory is similar to that of the digital transport delays developed by Walker. (8)

Time delays are calculated between the reactor and IHX in the primary loop, and between the IHX and DHX in the secondary 10op. The cold leg time delays include the pipe sections on both the upstream and downstream sides of the pumps in primary and secondary loops. The following assumptions were made in simulating the piping time delays.

1. No mixing occurs within the pipe section.

2. There is no axial heat conduction.

3. There are no heat gains or losses to the piping.

4. Coolant density within a piping leg is assumed constant. With these assumptions, the pipe section outlet temperatures at time $(t)$ are defined as:

Primary Loop

$\operatorname{IHX}$ Inlet Temperature $=\mathrm{T}_{\mathrm{CPX} I}(t)=\mathrm{T}_{\mathrm{COR}}\left(t-{ }{ }_{\mathrm{CPH}}\right)(3.3-1)$

Reactor Vessel Inlet

Temperature

$$
=T_{C I R}(t)=T_{C P X 5}\left(t-\tau_{C P C}\right)
$$

Secondary Loop

DHX Inlet Temperature $=\mathrm{T}_{\mathrm{CSY} 1}(t)=\mathrm{T}_{\mathrm{CSX} 1}\left(t-\mathrm{T}_{\mathrm{CSH}}\right)$

IHX Inlet Temperature $=\mathrm{T}_{\mathrm{CSX} 5}(t)=\mathrm{T}_{\mathrm{CSY} 4}\left(t-{ }^{\tau}{ }_{\mathrm{CSC}}\right)$

where $\mathrm{T}_{\mathrm{COR}}=$ reactor vessel outlet temperature

$\mathrm{T}_{\mathrm{CPX} 5}=\mathrm{IHX}$ primary outlet temperature 


$$
\begin{aligned}
\mathrm{T}_{\text {CSX1 }} & =\text { IHX secondary outlet temperature } \\
\mathrm{T}_{\text {CSY4 }} & =\text { DHX secondary outlet temperature } \\
\tau & =\text { time delay for piping section of concern. }
\end{aligned}
$$

For a constant flow rate, the transport delay time $(\tau)$ is

$$
\tau=\frac{\rho V}{\bar{W}}
$$

where $\rho=$ coolant density

$\mathrm{V}=$ pipe section volume

$W=$ mass flow rate.

If the flow rate is varying, the delay time is obtained from the solution of the integral equation

$$
\int_{t-\tau}^{t} W(t) d t=\rho V \text {. }
$$

The digital time delay program in Reference 7 solves Equation (3.3-6) for each of the four transport delays in the simulation.

\subsection{HYDRAULICS MODELS FOR PRIMARY AND SECONDARY LOOPS}

The primary and secondary coolant loops consist of stainless steel piping, fittings, and sodium pumps. The hydraulics model for the primary and secondary loops was derived from Newton's second law of motion applied to a viscous fluid and nonsteady flow (see Appendix C). The basic energy equation for the hydraulics is

$$
\ell \frac{d W}{d t}=\rho H_{p}-\int \rho d z-\Delta P_{f}
$$

where $\ell \frac{d W}{d t}=$ inertance pressure drop

$$
W=\text { loop flow rate }
$$

$$
\begin{aligned}
\rho \mathrm{H}_{\mathrm{p}} & =\text { pump pressure } \\
\int \rho \mathrm{dZ} & =\text { natural circulation head } \\
\Delta \mathrm{P}_{\mathrm{f}} & =\text { frictional pressure loss. }
\end{aligned}
$$


The model development is based on the following assumptions:

1. The fluid viscous properties are governed by a smooth pipe relationship.

2. Coolant density and viscosity are assumed to be constant in all sections of the loop being considered. (The maximum error in this assumption for the entire temperature range of interest is $\sim 3 \%$.)

A functional diagram of the hydraulics model is shown in Figure 3.4.1.

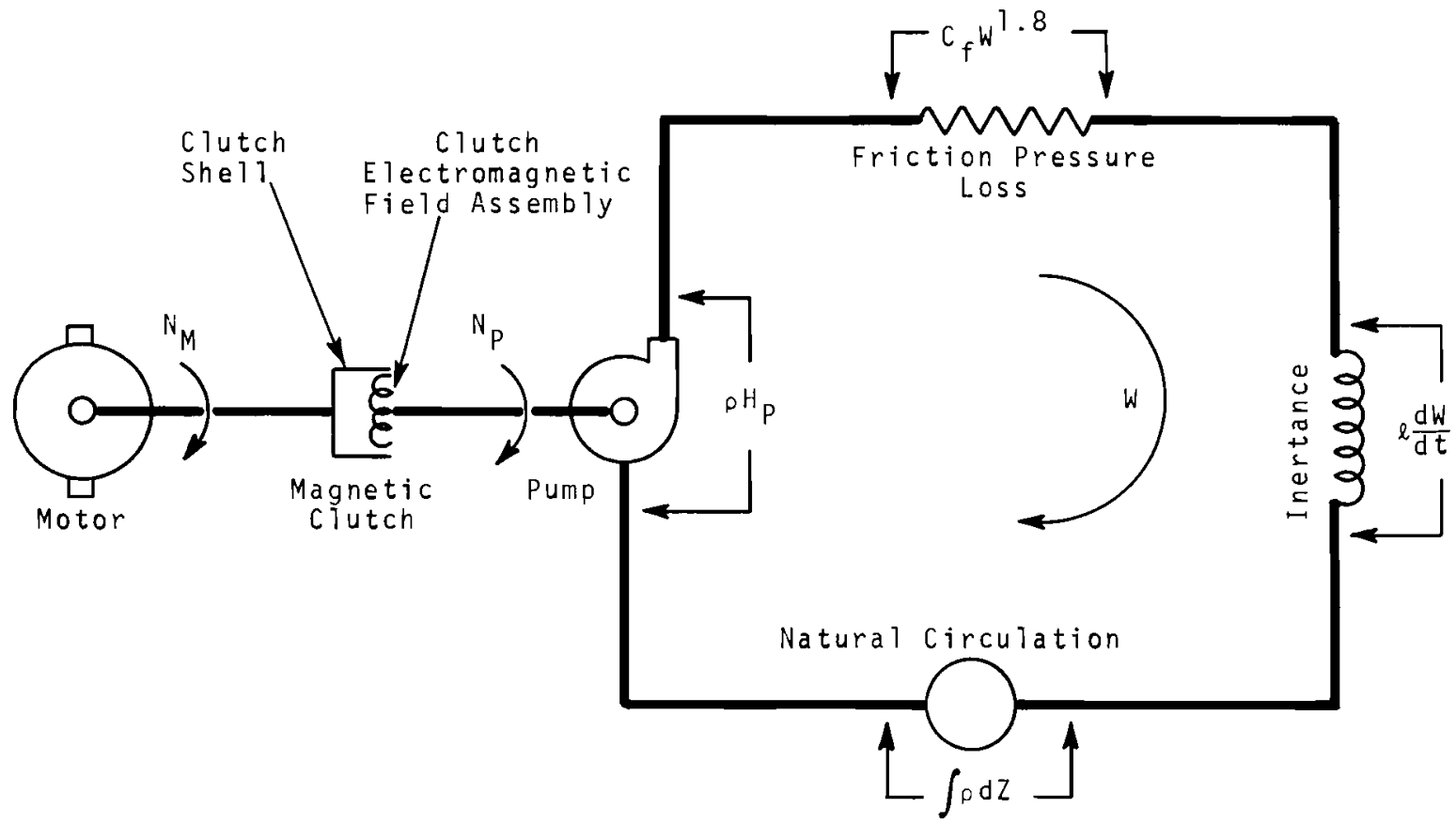

FIGURE 3.4.1. Primary/Secondary Coozant Loop Hydrauzics Model Functional Diagram 
The inertance coefficient, $\ell\left(\sec ^{2} / f t^{2}\right)$, is given by the following summation over the loop:

$$
\ell=\frac{1}{g_{c}} \sum \frac{(\Delta L)}{A_{i}}
$$

where $g_{C}$ is the gravitational acceleration constant, $(\Delta L)_{i}$, is the length of section $i$, and $A_{i}$ is the section area. Calculation of $\ell$ is explained in Appendix $C$.

The natural circulation head is approximated by

$$
\int \rho d Z=(\Delta Z)\left(\frac{\partial \rho}{\partial T}\right)\left(T_{A H}-T_{A C}\right)
$$

where $\mathrm{T}_{\mathrm{AH}}=$ average hot-leg temperature of loop (linear average)

$\mathrm{T}_{\mathrm{AC}}=\begin{aligned} & \text { average cold-leg temperature of loop (1inear } \\ & \text { average) }\end{aligned}$

$\Delta Z=$ elevation difference of active elements

$\frac{\partial p}{\partial T}=$ coolant density temperature coefficient (this term is negative - see Appendix C).

The friction pressure loss term of Equation (3.4-1) is given by

$$
\Delta \mathrm{P}_{\mathrm{f}}=\mathrm{C}_{\mathrm{f}} \mathrm{W}^{1.8}
$$

(The pressure loss coefficient $C_{f}$ includes all pressure losses in a loop and is explained in Appendix C.) The driving force for the primary and secondary hydraulics is the head developed by the sodium coolant pumps $\left(\mathrm{H}_{\mathrm{p}}\right)$ which is obtained from the pump simulation.

\subsection{SODIUM PUMP MODEL}

The primary and secondary coolant is transported by head produced in the centrifugal coolant pumps. The driving power for each pump is developed in a squirrel cage induction motor and is transmitted to the pump by an electromagnetic 
(eddy-current) clutch assembly. The pump speed and coolant flow rate are controlled by varying the clutch excitation current.

Pump performance curves are required to simulate the primary and secondary pumps. Since the design is not fixed, actual pump performance curves are not available. Therefore, typical centrifugal pump performance curves have been assumed for the present simulation. The performance curves assumed for the primary pumps are shown in Figures 3.5.1 and 3.5.2. Similar curves have been assumed for the secondary pumps. The curves presently being used will be replaced by the actual pump performance curves when they become available.

Figure 3.5.1 gives the primary pump head as a function of flow and speed and Figure 3.5 .2 gives the pump efficiency as a function of normalized flow and speed. The efficiency curve applies to both primary and secondary pumps.

The following empirical equation was found to adequately represent the pump head curves:

$$
H_{p}=H_{D C P}\left(\frac{N_{p}}{N_{D P}}\right)^{2}+a_{1} w^{1.8}
$$

where $H_{p}=$ pump head

$\mathrm{H}_{\mathrm{DP}}^{\mathrm{p}}=$ pump design head

$\mathrm{H}_{\mathrm{DCP}}=$ pump design shutoff head (at zeroflow, full speed)

$\mathrm{N}_{\mathrm{p}}=$ pump speed

$N_{D P}=$ pump design speed

$W=100 p$ flow rate

$W_{D}=10 o p$ design flow rate

$a_{1}=$ curve fit constant.

The curve fit constant $\left(a_{1}\right)$ is calculated from the shutoff head and the pump design conditions as follows:

at the design operating point, $\mathrm{N}_{\mathrm{p}}=\mathrm{N}_{\mathrm{DP}}, \mathrm{H}_{\mathrm{p}}=\mathrm{H}_{\mathrm{DP}}$, and $\mathrm{W}=\mathrm{W}_{\mathrm{D}}$. 


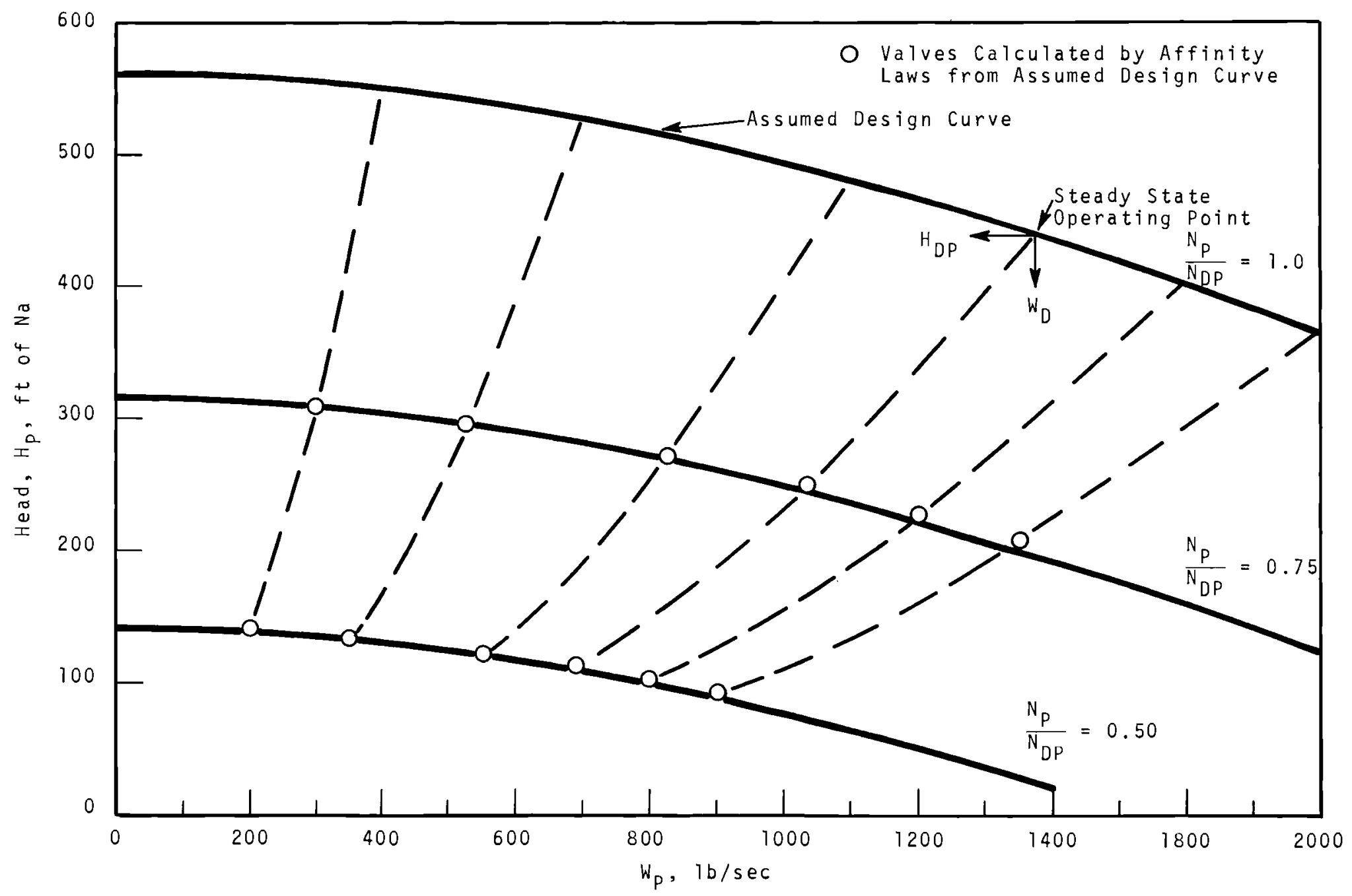

FIGURE 3.5.1. Head Curve for Primary Centrifugal Pump Simulation 


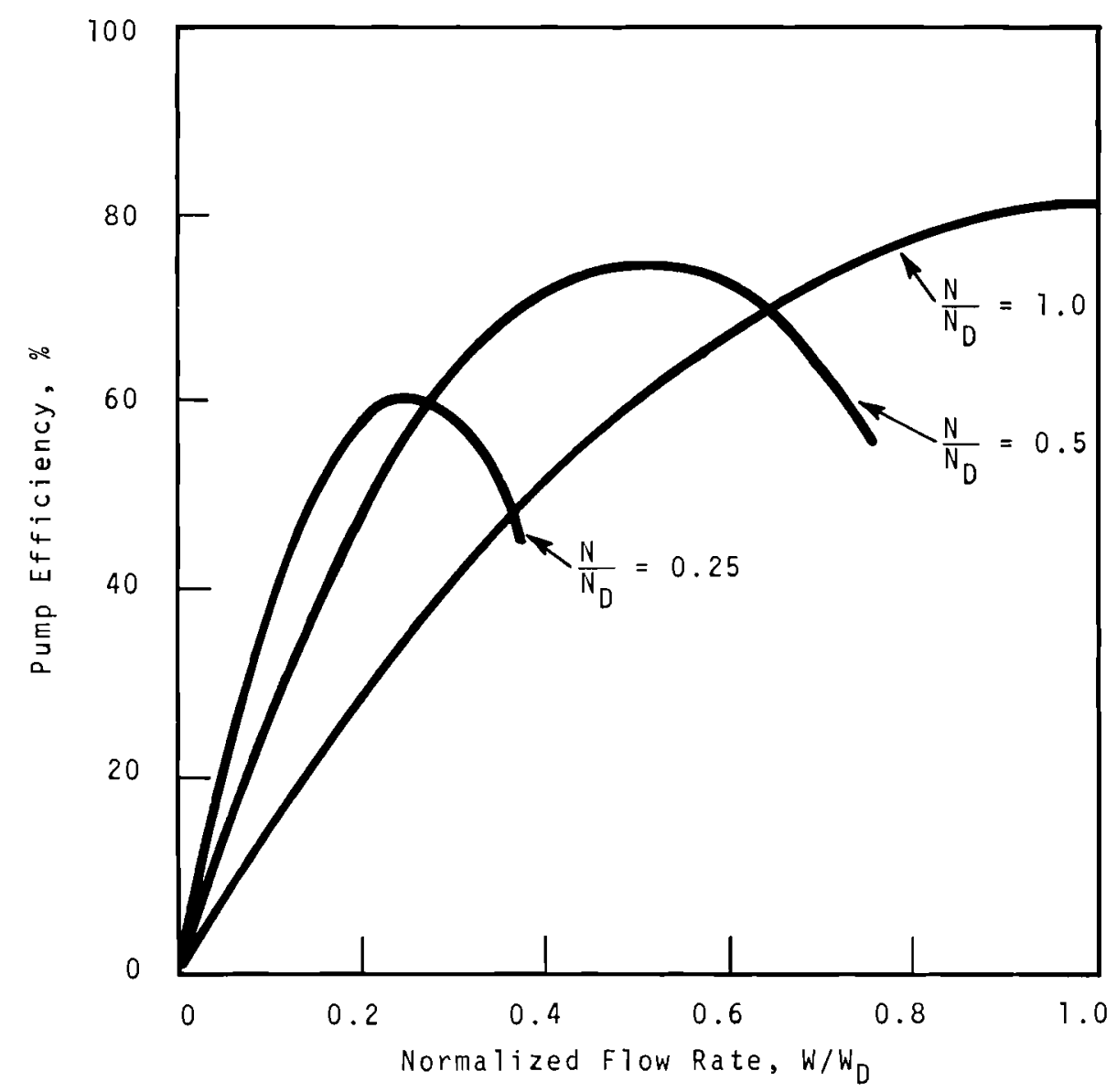

FIGURE 3.5.2. Typical Pump Efficiency Curves

Therefore,

$$
a_{1}=\frac{H_{D P}-H_{D C P}}{\left(W_{D}\right)^{1.8}} \text {. }
$$

The reduced-speed head curves calculated by Equation (3.5-1) obey the affinity laws quite well as shown by the circled data points in Figure 3.5.1. These points were calculated from the assumed full speed design curve using the affinity laws. 
A more complex relation is necessary to simulate the pump efficiency curves shown in Figure 3.5.2. The following empirical form was found adequate to represent these curves:

$E_{p}=\left[a_{2}\left(\frac{W}{W_{D}}\right)\left(\frac{N_{D P}}{N_{p}}\right)-a_{3}\left(\frac{W}{W_{D}}\right)^{2}\left(\frac{N_{D P}}{N_{p}}\right)^{2}\right]\left(1-e^{-a_{4}{ }^{N}{ }_{p} / N_{D P}}\right)$

where $E_{p}=$ pump efficiency.

Other terms are previously defined.

The pump torque is calculated from the head, efficiency, speed and flow as

$$
\mathrm{T}_{\mathrm{p}}=\frac{\mathrm{H}_{\mathrm{p}} \mathrm{W}}{\mathrm{b}_{2} \mathrm{~N}_{\mathrm{p}} \mathrm{E}_{\mathrm{p}}}
$$

where $b_{2}=(2 \pi) \frac{\text { radians }}{\text { revolution }} \cdot \frac{1 \mathrm{~min}}{60 \mathrm{sec}}=\frac{\pi}{30}$.

The flow (W) is calculated in the hydraulics simulation (Section 3.4).

The pump shaft speed is obtained from the dynamic relationship for rotating bodies defined by Newton's first law. This can be expressed as a torque balance on the pump as follows :

$$
\sum \mathrm{T}=\frac{{ }_{\mathrm{p}} \mathrm{b}_{2}}{\mathrm{~g}_{\mathrm{c}}} \frac{\mathrm{d} \mathrm{N}_{\mathrm{p}}}{\mathrm{dt}}
$$

where $g_{C}=$ gravity constant

$I_{p}=$ moment of inertia of the pump shaft, pump impeller and clutch electromagnet assembly.

The summation of torques is equal to the torque provided by the clutch $\left(\mathrm{T}_{c}\right)$ minus the pump load torque $\left(\mathrm{T}_{\mathrm{p}}\right)$. Therefore, the equation becomes

$$
\frac{d N_{p}}{d t}=\frac{g_{c}}{I_{p} b_{2}}\left(T_{c}-T_{p}\right) \text {. }
$$

The clutch torque is calculated in the next section. 


\subsection{PUMP DRIVE ASSEMBLY MODEL}

The pump drive assembly consists of the induction motors and the eddy-current clutch coupling. Figure 3.4 .1 shows the motor, clutch and pump arrangement for the primary and secondary loops.

The dynamics of the induction motor can be described by Newton's first law of motion as applied to rotating bodies which will reduce to the following torque balance:

$$
\frac{\mathrm{dN}_{M}}{\mathrm{dt}}=\frac{\mathrm{g}_{\mathrm{C}}}{\mathrm{I}_{\mathrm{M}} \mathrm{b}_{2}}\left(\mathrm{~T}_{\mathrm{M}}-\mathrm{T}_{\mathrm{ML}}\right)
$$

where $N_{M}=$ motor speed in $\mathrm{rpm}$

$$
\begin{aligned}
I_{M} & =\text { motor moment of inertia } \\
T_{M} & =\text { motor torque (provided by electrical input) } \\
T_{M L} & =\text { motor load torque. }
\end{aligned}
$$

The motor torque is obtained from a typical motor torque curve as shown in Figure 3.6.1. Similar curves have been assumed for primary and secondary pump motors. These curves will be replaced by the actual motor torque curves when they are available. A typical load torque curve for one steadystate operating motor speed is also shown in Figure 3.6.1. The torque difference between the two curves for a given speed is the acceleration torque which is described by Equation $(3.6-1)$.

The motor torque curve in Figure 3.6.1 can be expressed as a function of the maximum torque, motor slip, and slip at maximum torque by the following equation:

$$
\mathrm{T}_{M}=\frac{2 \mathrm{~T}_{M}^{*}}{\frac{\mathrm{S}_{M}}{\mathrm{~S}_{M}^{*}}+\frac{S_{M}^{*}}{S_{M}}}
$$




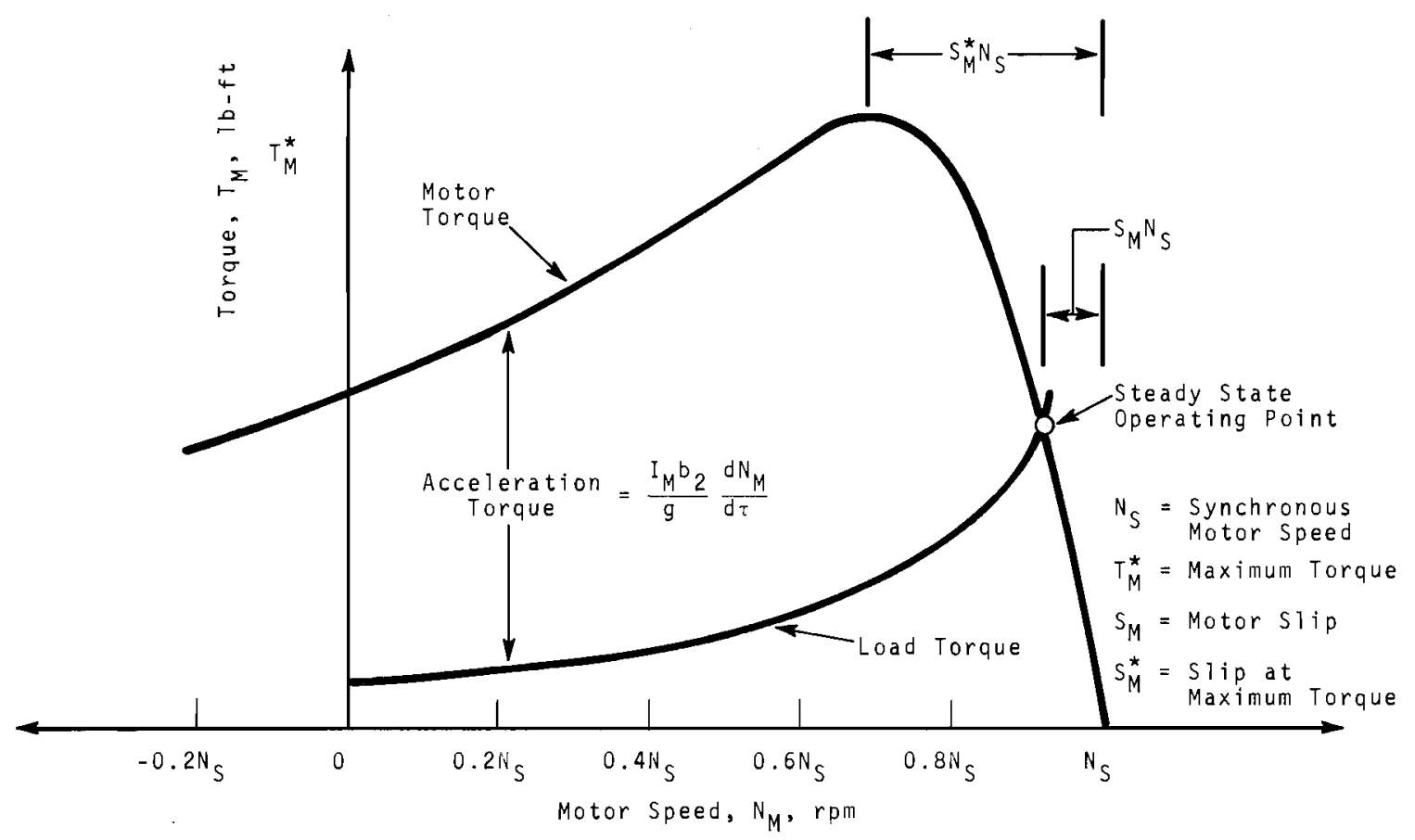

FIGURE 3.6.1. Motor Torque Curve with a Typical Load Torque

where $S_{M}=$ motor slip, rpm

$S_{M}^{*}=$ motor slip at maximum torque

$\mathrm{T}_{\mathrm{M}}^{*}=\operatorname{maximum}$ torque.

The motor slip is calculated as

$$
S_{M}=\frac{N_{S}-N_{M}}{N_{S}}
$$

where $\mathrm{N}_{\mathrm{S}}$ is the synchronous speed of the motor.

The motor load torque $\left(\mathrm{T}_{\mathrm{ML}}\right)$ is the only remaining undefined term in Equation (3.6-1). By performing a free-body torque balance on the motor, clutch, and pump impeller, we find that the clutch output torque is equal to the motor load torque:

$$
{ }^{T}{ }_{C}=T_{M L} \quad \text {. }
$$


The clutch torque $\left(\mathrm{T}_{\mathrm{C}}\right)$ is determined by the difference in motor shaft speed and pump shaft speed, and by the amount of electromagnetic coupling between the two shafts. The shaft speed difference is called the clutch slip speed $\left(\mathrm{N}_{S C}\right)$ and is represented as

$$
\mathrm{N}_{\mathrm{SC}}=\mathrm{N}_{\mathrm{M}}-\mathrm{N}_{\mathrm{P}} \text {. }
$$

The degree of coupling in the clutch is determined by the amount of excitation current that is supplied to the electromagnetic windings. By varying this current, the pump speed becomes a controllable value.

As with the motor and pump, typical electromagnetic clutch torque curves have been assumed until actual data is available. The curves, shown in Figure 3.6.2, provide clutch torque as a function of slip speed and percent excitation current. The breakpoint slip $\left(N_{S C}^{*}\right)$ is defined as the slip speed above which the clutch torque is constant for a constant excitation current.

For simulation, the clutch torque curves in Figure 3.6 .2 have been broken down into two curves (functions) such that

$$
\mathrm{T}_{\mathrm{C}}=\mathrm{T}_{\mathrm{C}}^{*} \cdot \mathrm{F}_{1 \mathrm{C}} \cdot \mathrm{F}_{2 \mathrm{C}}
$$

where $\mathrm{T}_{\mathrm{C}}^{*}=\operatorname{maximum}$ clutch torque

$$
\begin{aligned}
& \mathrm{F}_{1 \mathrm{C}}=\text { percent excitation function } \\
& \mathrm{F}_{2 \mathrm{C}}=\text { percent breakpoint slip function. }
\end{aligned}
$$

The curves that apply to Equation (3.6-6) are shown in Figure 3.6.3. The curves shown in Figures 3.6.2 and 3.6.3 apply to the primary loop clutches. Similar curves with a different maximum clutch torque have been assumed for the secondary clutches. 


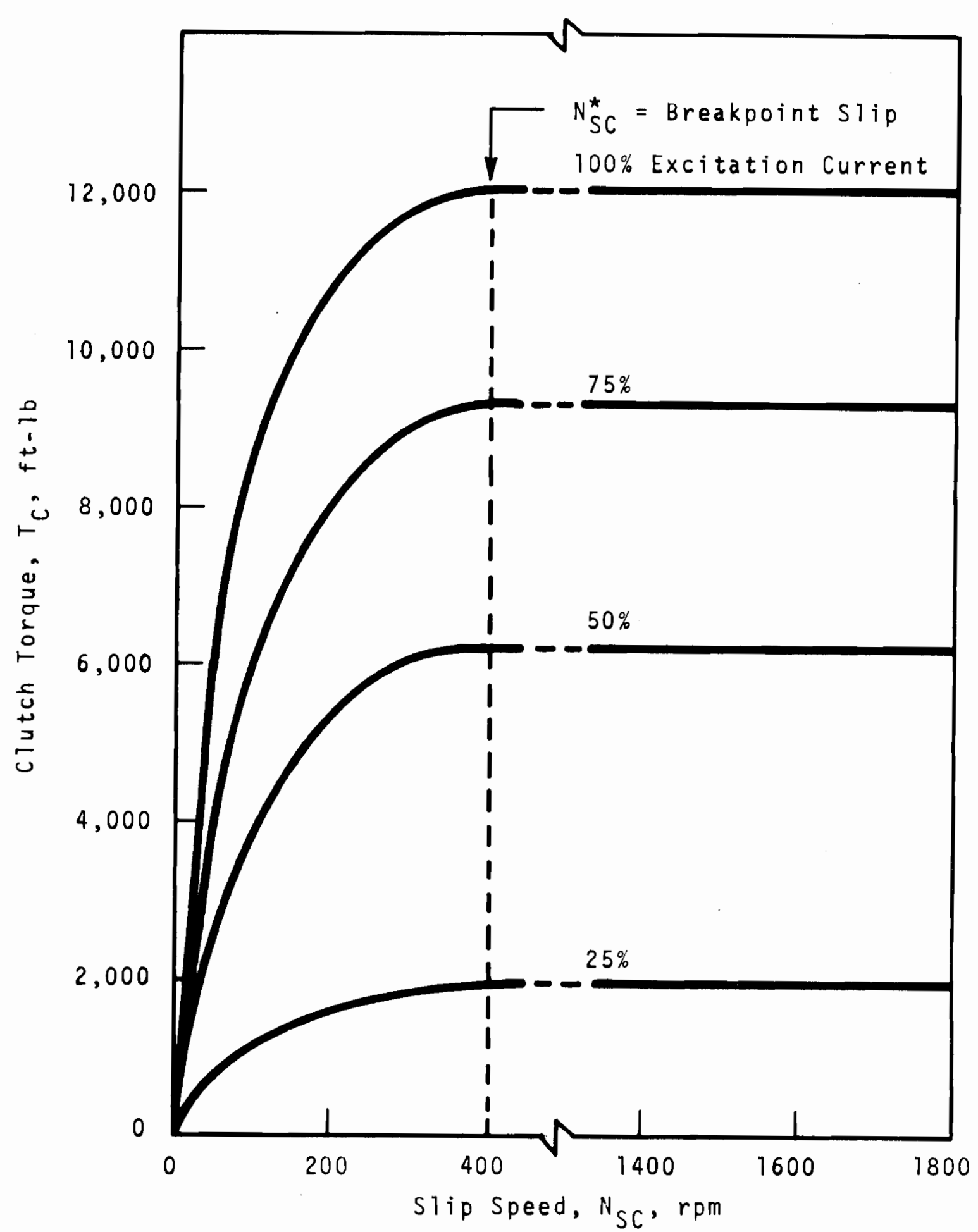

FIGURE 3.6.2. Typical Electromagnetic Clutch Torque Curve 


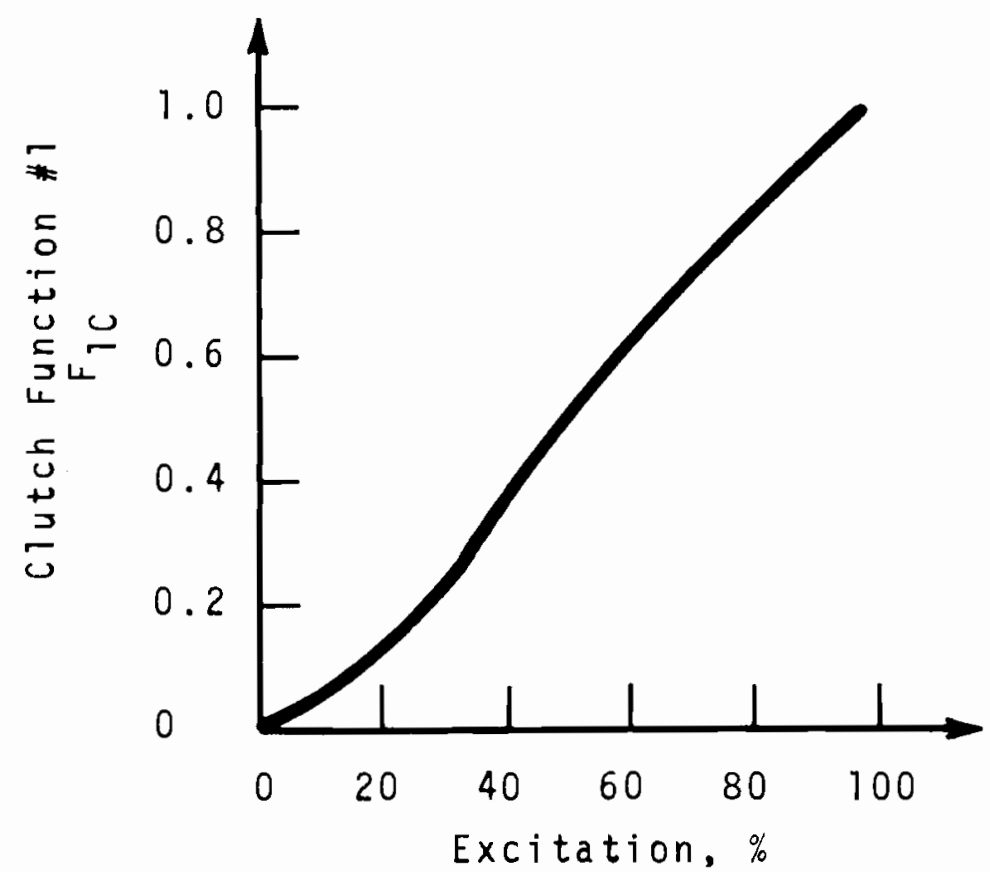

(a) Excitation Current Dependency

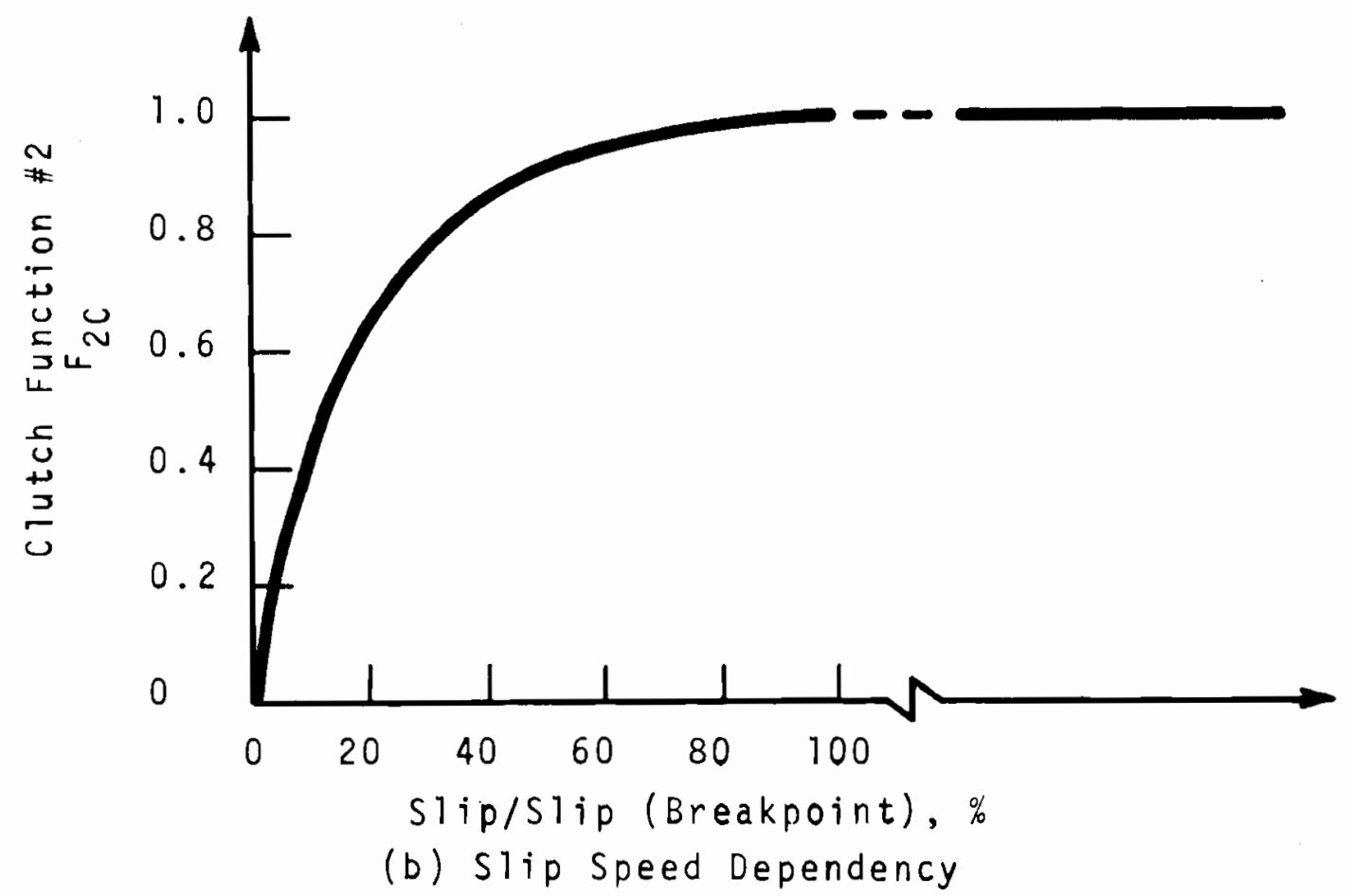

FIGURE 3.6.3. Clutch Torque Functions; ${ }^{T}{ }_{C}=T_{M A X}{ }^{F_{1 C}}{ }_{2 C}{ }_{2}$ Slip $=N_{M}-N_{P}$, slip (Breakpoint) as in Figure $3.6 .2=400 \mathrm{rpm}=N_{S C}^{*}$ 


\subsection{DUMP HEAT EXCHANGER MODEL}

Heat is removed from the secondary sodium loops by aircooled dump heat exchangers (DHX). Each DHX unit (one per loop) is divided into four separate modules as explained in Section 2.2. All modules are assumed to operate identically, therefore, only one module is simulated. The total heat is accounted for by applying the appropriate multiplying factor. Each DHX module contains multipass finned tubes arranged on a triangular pitch as shown in Figure 3.7.1.

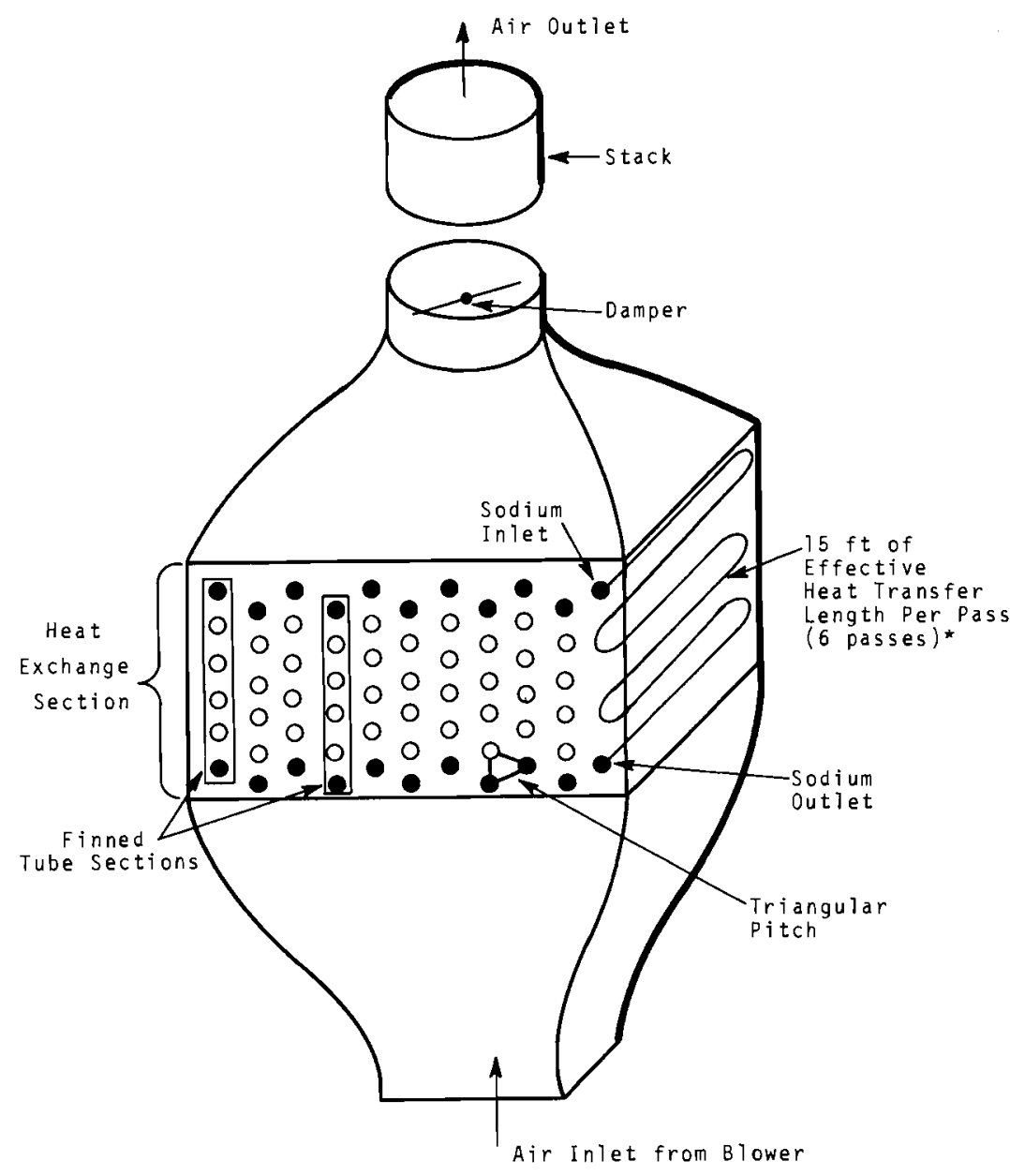

* Reference Concept 
Air enters at the bottom, flows across the tubes and exits through stacks at the top. The sodium enters the tube sections at the top on the air outlet end and exits at the bottom.

Cross-flow heat exchangers are difficult to simulate due to their unsymmetrical and multidimensional temperature distributions. Preliminary simulation studies were made of several cross-flow models and a simple counter-current model (with and without log-mean temperature difference, LMTD, correctors for cross flow). These studies indicated that a counter-current representation (without LMTD correctors) provides adequate overall agreement with more complex crossflow models. Therefore, due to the limit on available computing equipment, a three-node counter-current model was chosen for the DHX simulation. To obtain a counter-current model from the crossflow arrangement shown in Figure 3.7 .1 , the tube sections are assumed to be straightened to their total length (90 ft for reference concept - six $15 \mathrm{ft}$ passes per tube section). The straightened tubes are then assumed to be arranged on a triangular pitch so that the air volume per foot of tube is the same as in the actual crossflow arrangement. Finally, the air is assumed to flow parallel to the tubes in a counter-flow manner. The total effective heat transfer area is unchanged (corners connecting the tube passes are neglected in determining the effective heat transfer area). The counter-current node arrangement is shown in Figure 3.7.2.

With the counter-current assumption, the DHX modeling technique is nearly identical to that used for the intermediate heat exchanger, except there are three axial nodes instead of four. Fluid temperature and velocity profiles are assumed to be uniform over any cross-section normal to the direction of flow and axial heat conduction is neglected. Since the metal temperature approaches the sodium temperature, the metal heat storage is included with the sodium. Air is assumed an 


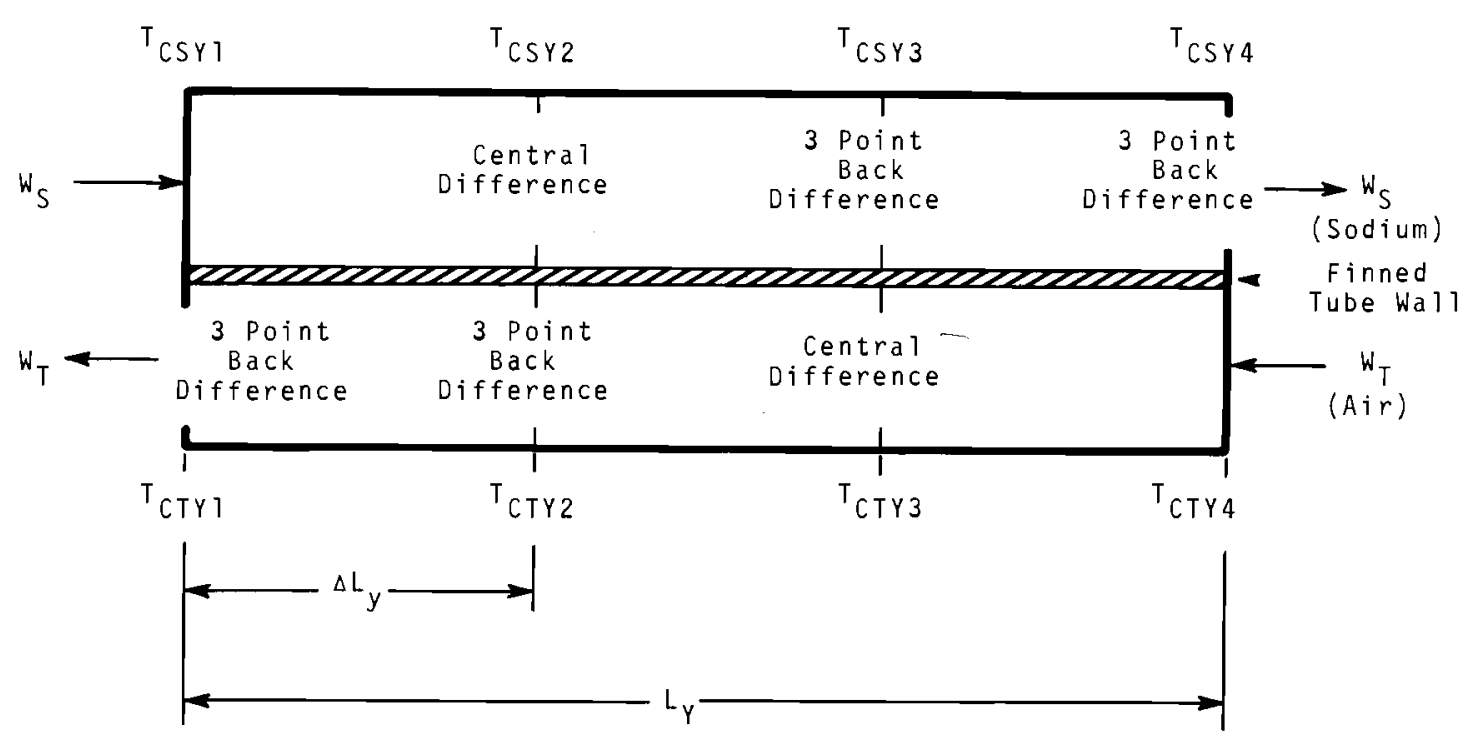

\section{FIGURE 3.7.2. DHX Model Node Arrangement}

ideal gas and the effective air temperature for heat transfer is the average of the inlet and outlet temperatures at any cross-section. Heat losses from the air duct are also neglected. Density and specific heat for both air and sodium are assumed constant with temperature for any given problem. Although air density varies with temperature, the air heat storage term $\left(\rho V^{\prime} C\right)_{\mathrm{Ti}}$ is small and the air temperature transient response is not affected appreciably.

The basic partial differential equations for the coolant temperatures at each nodal point (i) are as follows:

Secondary Side

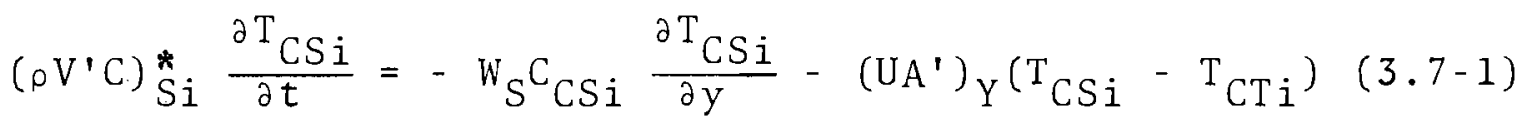


Tertiary Side

$\left(\rho V^{\prime} C\right)_{T i} \frac{\partial{ }^{T} \mathrm{CTi}}{\partial t}=W_{T} C_{C T i} \frac{\partial T_{C T i}}{\partial y}+\left(\mathrm{UA}^{\prime}\right)_{Y}\left(T_{C S i}-T_{C T i}\right) \quad(3.7-2)$

where the $\left(\rho V^{\prime} C\right){ }_{S i}^{*}$ coefficients for the secondary sodium side include the tube metal heat storage. As before, the $\mathrm{V}^{\prime}$ and $\mathrm{A}^{\prime}$ terms represent volumes and areas per unit length. The DHX finite difference scheme for approximating the $\partial \mathrm{T} / \partial \mathrm{y}$ terms is similar to the scheme used for the IHX simulation except there are only three axial nodes. The nodal arrangement and finite difference approximations scheme are shown in Figure 3.7.2. The notations for "central" and "three-point backward" differences are the same as those given in Equation (3.2-3), (3.2-4), and (3.2-5) for the IHX model. However, the length between nodal points is expressed as $\Delta \mathrm{L}_{Y}=\mathrm{L}_{Y} / 3$ since there are only three DHX nodes. Substituting the difference approximations into the general equations, we obtain the following complete set of expressions for one DHX module. Subscripts are included for clarity:

$\mathrm{C}=$ coolant, $\mathrm{S}=$ secondary, $\mathrm{T}=$ tertiary, and $\mathrm{Y}=\mathrm{DHX}$. Secondary Side:

$\left(\rho V^{\prime} C\right)_{S Y}^{*} \frac{d T_{C S Y i}}{d t}=\frac{3 W_{S} C_{C S Y}}{{ }^{2}{ }_{M Y} L_{Y}}(\Delta T)_{C S Y i}-\left(U^{\prime}\right)_{Y}\left(T_{C S Y i}-T_{C T Y i}\right)$

for $i=2,3,4$;

Tertiary Side:

$\left(\rho V^{\prime} \mathrm{C}\right)_{T Y} \frac{\mathrm{dT}_{\mathrm{CTY}}}{d t}=\frac{3 \mathrm{~W}_{\mathrm{FT}} \mathrm{C}_{\mathrm{CTY}}}{2 \mathrm{~L}_{Y}}(\Delta \mathrm{T})_{\mathrm{CTY}}+\left(\mathrm{UA}^{\prime}\right)_{Y}\left(\mathrm{~T}_{\mathrm{CSY}}-\mathrm{T}_{\mathrm{CTY}}\right)$

for $i=1,2,3$, where $N_{M Y}$ is the number of modules per DHX, $W_{S}$ is the secondary flow per loop, and $W_{F T}$ is the air flow per module. 
The temperature differences for node (i) are:

$$
\begin{aligned}
& (\Delta \mathrm{T})_{\text {CSY2 }}=-\mathrm{T}_{\text {CSY1 }}+\mathrm{T}_{\mathrm{CSY} 3} \\
& (\Delta \mathrm{T})_{\mathrm{CSY} 3}=3 \mathrm{~T}_{\mathrm{CSY} 3}-4 \mathrm{~T}_{\mathrm{CSY} 2}+\mathrm{T}_{\mathrm{CSY} 1} \\
& (\Delta \mathrm{T})_{\mathrm{CSY} 4}=3 \mathrm{~T}_{\mathrm{CSY} 4}-4 \mathrm{~T}_{\mathrm{CSY} 3}+\mathrm{T}_{\mathrm{CSY} 2} \\
& (\Delta \mathrm{T})_{\mathrm{CTY} 1}=-3 \mathrm{~T}_{\mathrm{CTY} 1}+4 \mathrm{~T}_{\mathrm{CTY} 2}-\mathrm{T}_{\mathrm{CTY} 3} \\
& (\Delta \mathrm{T})_{\mathrm{CTY} 2}=-3 \mathrm{~T}_{\mathrm{CTY} 2}+4 \mathrm{~T}_{\mathrm{CTY} 3}-\mathrm{T}_{\mathrm{CTY} 4} \\
& (\Delta \mathrm{T})_{\mathrm{CTY} 3}=-\mathrm{T}_{\mathrm{CTY} 2}+\mathrm{T}_{\mathrm{CTY} 4}
\end{aligned}
$$

The equations are written for one module of the total DHX unit. Therefore, the areas and volumes correspond to one module and are calculated from the design data as explained in Appendix D. The overall heat transfer conductance (UA') $Y$ is based on the tube inside surface area, and includes an inside film coefficient, a tube wall resistance and an outside film coefficient. The outside air film coefficient is calculated for air flowing across finned tube banks. The description of the overall heat transfer conductance $\left(U A^{\prime}\right)_{Y}$ can also be found in Appendix D.

\subsection{TERTIARY COOLANT HYDRAULICS MODEL}

The tertiary coolant system provides atmospheric air to the shell side of the DHX to remove heat from the secondary sodium. Each DHX module has its own tertiary coolant system that consists of a heat exchanger section, an inlet filter, a fan, a modulating damper or valve, and a stack exit. A schematic of the assumed arrangement is shown in Figure 3.8.1. The reference concept employs variable inlet vanes on the fan for capacity control. However, due to the lack of data for fans with this type of flow control, we have temporarily assumed damper control by a butterfly valve located downstream 


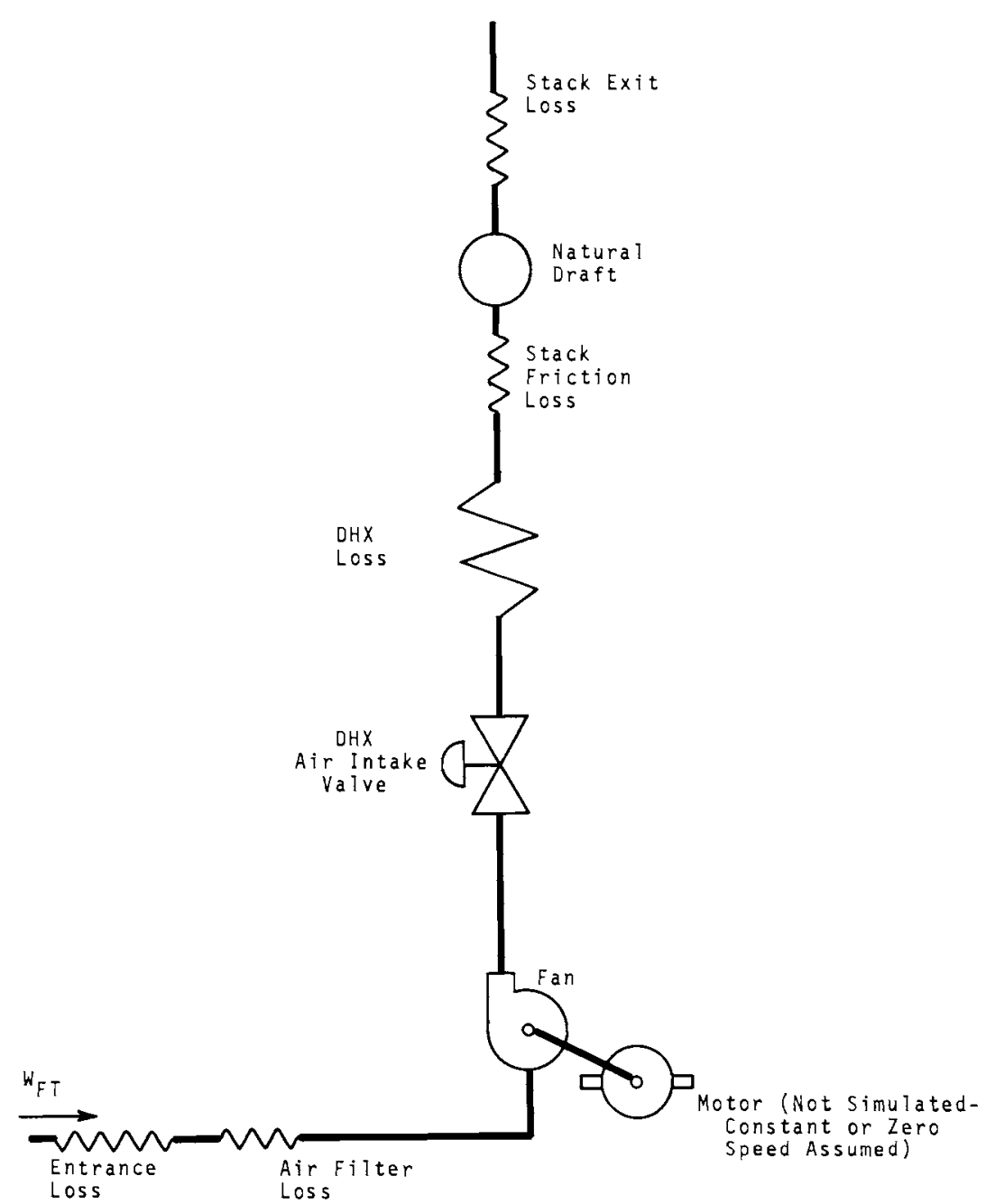

FIGURE 3.8.1. Sehematic of the Tertiary Coolant Hydraulic system for one DHX Module

of the fan. This makes air flow a function of the valve angle of opening for a given fan speed. The fan speed is assumed to be a constant in the present model, and a motor is not simulated. Only full speed and zero speed are presently considered. The fan, however, is simulated so that a motor can be easily added at a later time. More accurate fan data will be incorporated in the model when it is available. 
Newton's second law of motion, applied to a compressible fluid, is used to simulate the tertiary hydraulics. Air is assumed to behave as an ideal gas. Also, energy due to coolant inertia is assumed to be negligible. This is a reasonable assumption since the coolant mass for air is small. The energy balance for the open system therefore reduces to the following pressure balance:

$$
\mathrm{H}_{\mathrm{FT}}=\Delta \mathrm{P}_{\mathrm{IT}}+\Delta \mathrm{P}_{\mathrm{FFT}}+\Delta \mathrm{P}_{\mathrm{VT}}+\Delta \mathrm{P}_{\mathrm{YT}}+\Delta \mathrm{P}_{\mathrm{ST}}-\Delta \mathrm{P}_{\mathrm{DT}}+\Delta \mathrm{P}_{\mathrm{EST}}(3.8-1)
$$

where $\mathrm{H}_{\mathrm{FT}}=$ fan head, in. of water

$\Delta \mathrm{P}_{\mathrm{IT}}=$ inlet loss, in. of water

$\triangle P_{F F T}=$ inlet filter loss, in. of water

$\Delta \mathrm{P}_{\mathrm{VT}}=$ butterfly valve loss, in. of water

$\Delta \mathrm{P}_{Y T}=$ DHX shell side loss, in. of water

$\Delta \mathrm{P}_{S T}=$ stack friction loss, in. of water

$\Delta \mathrm{P}_{\mathrm{DT}}=$ natural draft, in. of water

$\Delta \mathrm{P}_{\mathrm{EST}}=$ stack exit loss, in. of water.

Fan performance curves are required to simulate the fan and thus obtain the fan head $\left(\mathrm{H}_{\mathrm{FT}}\right)$. As stated earlier, actual fan curves are presently not available for fans with variable inlet vane control. Therefore, typical curves for fans without this feature are being used in the fan simulation. These curves are shown in Figure 3.8.2. The curves are normalized to the system design conditions. Curves for lower speeds are obtained from the full-speed design curve by applying the fan laws. Manufacturer's curves are used that provide data only down to $0.8 \mathrm{~W}_{\mathrm{FT}} / \mathrm{W}_{\mathrm{DFT}}$. For $\mathrm{W}_{\mathrm{FT}} / \mathrm{W}_{\mathrm{DFT}}<0.8$ the curves are assumed to take the shape of typical fan performance curves and are shown by dashed lines in Figure 3.8.2.

Since a variable-speed motor may be simulated in the future, the fan head is simulated as a function of both flow and speed. The following empirical equation was found to adequately represent the fan head curves in Figure 3.8.2. 


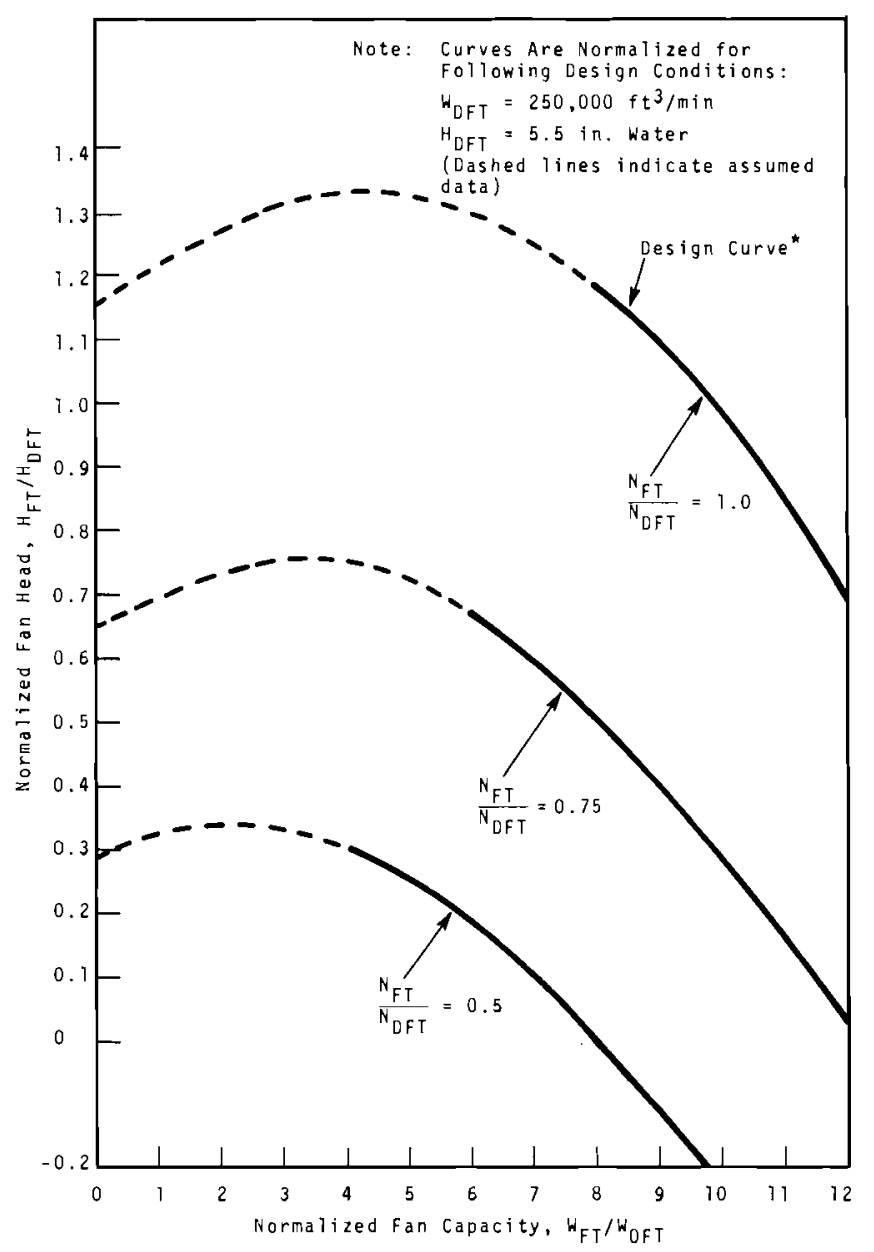

FIGURE 3.8.2. Normalized Fan Characteristics (Typical)

$$
\frac{\mathrm{H}_{\mathrm{FT}}}{\mathrm{H}_{\mathrm{DFT}}}=\mathrm{a}_{1}\left(\frac{\mathrm{N}_{\mathrm{FT}}}{\mathrm{N}_{\mathrm{DFT}}}\right)^{2}-\mathrm{a}_{2}\left(\frac{\mathrm{W}_{\mathrm{FT}}}{\mathrm{W}_{\mathrm{DFT}}}-\mathrm{a}_{3} \frac{\mathrm{N}_{\mathrm{FT}}}{\mathrm{N}_{\mathrm{DFT}}}-\mathrm{a}_{4}\right)^{2}(3.8-2)
$$

where $\mathrm{N}_{\mathrm{FT}} / \mathrm{N}_{\mathrm{DFT}}=$ normalized fan speed (constant input in present analog model)

$$
\begin{aligned}
\mathrm{W}_{\mathrm{FT}} / \mathrm{W}_{\mathrm{DFT}} & =\text { normalized air flow } / \mathrm{DHX} \text { module } \\
\mathrm{H}_{\mathrm{FT}} / \mathrm{H}_{\mathrm{DFT}} & =\text { normalized fan head } \\
\mathrm{a}_{1}, \mathrm{a}_{2}, \mathrm{a}_{3}, \mathrm{a}_{4} & =\text { curve fit constants. }
\end{aligned}
$$


Equation (3.8-2) provides an adequate representation for all cases except the following. With the fan off and with zero flow (valve closed), Equation (3.8-2) will still yield a fan head. This is not possible if an airtight system is assumed. To solve this dilemna, we let the constant $a_{4}=0$ when $\mathrm{N}_{\mathrm{FT}} / \mathrm{N}_{\mathrm{DFT}}=0$. With this condition included, Equation (3.8-2) provides an adequate representation of the assumed fan performance curves.

Since the coolant inertia terms are neglected in the energy balance Equation (3.8-1), we no longer have a differential equation for calculating the tertiary flow $\left(W_{F T}\right)$ as we do in calculating the primary and secondary sodium flows (Appendix C). Therefore, the air flow is calculated from the expression that describes the butterfly valve characteristic. Input to this expression is the valve pressure drop $\left(\Delta \mathrm{P}_{\mathrm{VT}}\right)$ which is calculated by rearranging Equation (3.8-1) as follows: $\Delta \mathrm{P}_{\mathrm{VT}}=\mathrm{H}_{\mathrm{FT}}+\Delta \mathrm{P}_{\mathrm{DT}}-\Delta \mathrm{P}_{\mathrm{IT}}-\Delta \mathrm{P}_{\mathrm{FFT}}-\Delta \mathrm{P}_{\mathrm{YT}}-\Delta \mathrm{P}_{\mathrm{ST}}-\Delta \mathrm{P}_{\mathrm{EST}} \cdot(3.8-3)$

The tertiary flow per module $\left(W_{F T}\right)$ is then calculated by the following equation. (10)

$$
\mathrm{W}_{\mathrm{FT}}=124 \mathrm{C}_{\mathrm{V}} \mathrm{D}^{2} \sqrt{\frac{\mathrm{P}_{\mathrm{YT}} \Delta \mathrm{P}_{\mathrm{VT}}}{\left(\mathrm{T}_{\mathrm{A}}+460\right)}}
$$

where $C_{v}=$ flow coefficient (function of valve angle of opening)

$\mathrm{D}=$ valve diameter, $\mathrm{ft}$

$\mathrm{P}_{\mathrm{YT}}=$ line pressure $=$ atmospheric, psi

$\mathrm{T}_{\mathrm{A}}=$ air inlet temperature, ${ }^{\circ} \mathrm{F}$.

The flow coefficient, $C_{v}$, is obtained from Figure 3.8.3, which provides the flow coefficient as a function of the valve angle of opening, $\theta$. The assumption that $\mathrm{P}_{Y \mathrm{~T}}=$ atmospheric is reasonable since the fans operate at very low head (less than 10 in. water). 


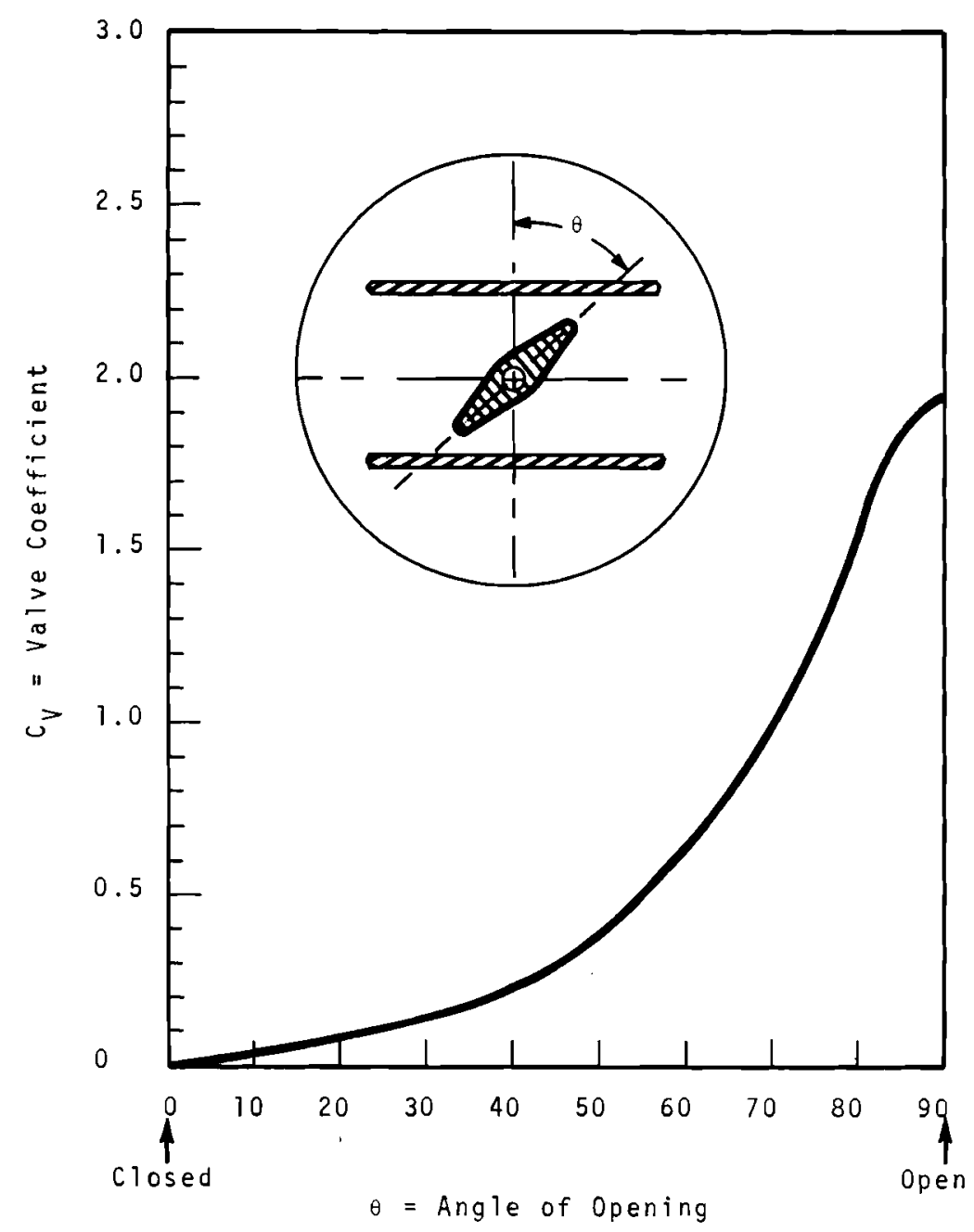

\section{FIGURE 3.8.3. Butterfly Valve Coefficients (Typical)}

The only terms left to define are the pressure losses through the system. Duct losses are neglected. Inlet and Exit Losses, $\Delta \mathrm{P}_{\text {IT }}, \Delta \mathrm{P}_{\text {EST }}$ :

Starting with Bernoulli's equation and assuming constant density, we obtain the following expression for pressure loss.

$$
\frac{\mathrm{P}_{1}-\mathrm{P}_{2}}{\rho}=\frac{\Delta \mathrm{P}}{\rho}=\frac{\mathrm{V}_{2}^{2}-\mathrm{V}_{1}^{2}}{2 \mathrm{~g}_{\mathrm{c}}}+\mathrm{F}
$$


where $F=$ friction pressure loss between points 1 and 2

(point 2 is downstream of point 1)

(potential energy is zero for inlet and exit).

At the duct inlet, $V_{1}=0$ (relative to $V_{2}$ ) and the inlet friction loss is known to be (11)

$$
\mathrm{F}_{\mathrm{IT}}=0.5 \frac{\mathrm{V}_{2}^{2}}{2 \mathrm{~g}_{\mathrm{c}}} .
$$

Substituting in Equation (3.8-5), the inlet pressure loss is

$$
\Delta \mathrm{P}_{\mathrm{IT}}=\frac{\rho \mathrm{V}_{2}^{2}}{2 \mathrm{~g}_{\mathrm{c}}}+\frac{0.5 \rho \mathrm{V}_{2}^{2}}{2 \mathrm{~g}_{\mathrm{C}}}=\frac{1.5 \rho \mathrm{V}_{2}^{2}}{2 \mathrm{~g}_{\mathrm{c}}} \text {. }
$$

Substituting

$$
V_{2}=\frac{W_{F T}}{\rho A_{I T}}
$$

into Equation (3.8-7), we get the inlet pressure loss, in inches of water:

$$
\Delta \mathrm{P}_{\mathrm{IT}}=\frac{1.5 \mathrm{~b}_{3} \mathrm{~W}_{\mathrm{FT}}^{2}}{2 \mathrm{~g}_{\mathrm{C}} \rho \mathrm{A}_{\mathrm{IT}}^{2}}
$$

where $A_{I T}=$ inlet area

$\mathrm{b}_{3}=$ conversion constant, in. water $/ 1 \mathrm{~b}-\mathrm{ft} \mathrm{t}^{2}$.

By the ideal gas 1 aw, density is expressed as

$$
\rho=\frac{\mathrm{P}_{\mathrm{A}}}{\mathrm{R}\left(\mathrm{T}_{\mathrm{A}}+460\right) \mathrm{b}_{4}}
$$

where $\mathrm{P}_{\mathrm{A}}=$ inlet atmospheric pressure, psi

$\mathrm{T}_{\mathrm{A}}=$ air inlet temperature, ${ }^{\circ} \mathrm{F}$

$R=$ ideal gas constant for air, $f t-1 b_{f} / 1 b_{m}{ }^{\circ} R$

$\mathrm{b}_{4}=$ conversion constant, $\mathrm{ft}^{2} / \mathrm{in} .^{2}$. 
Substituting Equation (3.8-10) in (3.8-9), we get

$$
\Delta \mathrm{P}_{\mathrm{IT}}=\frac{1.5\left(\mathrm{~b}_{5}\right)\left(\mathrm{b}_{3}\right) \mathrm{R}\left(\mathrm{T}_{\mathrm{A}}+460\right)}{2 \mathrm{~g}_{\mathrm{C}} \mathrm{P}_{\mathrm{A}} \mathrm{A}_{\mathrm{IT}}^{2}} \mathrm{~W}_{\mathrm{FT}}^{2}
$$

or

$$
\Delta \mathrm{P}_{\mathrm{IT}}=\frac{\mathrm{C}_{\mathrm{GT}}\left(\mathrm{T}_{\mathrm{A}}+460\right)}{\mathrm{A}_{\mathrm{IT}}^{2}} \mathrm{~W}_{\mathrm{FT}}^{2}
$$

where

$$
\mathrm{C}_{\mathrm{GT}}=\frac{1.5 \mathrm{R} \mathrm{b}_{5} \mathrm{~b}_{3}}{2 \mathrm{~g}_{\mathrm{C}} \mathrm{P}_{\mathrm{A}}} \text {. }
$$

Equation (3.8-11) is used to represent the inlet pressure 1oss. To obtain the exit loss at the top of the stack, we let $V_{2}=0$ (relative to $V_{1}$ ) in Equation $(3.8-5)$. This yields

$$
\Delta \mathrm{P}_{E S T}=-\frac{\mathrm{V}_{1}^{2}}{2 \mathrm{~g}_{\mathrm{C}}}+\rho \mathrm{F}_{\mathrm{EST}} \text {. }
$$

The exit friction loss is known to be equal to one velocity head. (11) Therefore, substituting into Equation $(3.8-14)$, we get

$$
\Delta \mathrm{P}_{\mathrm{EST}}=-\frac{\rho \mathrm{V}_{1}^{2}}{2 \mathrm{~g}_{\mathrm{C}}}+\frac{\rho \mathrm{V}_{1}^{2}}{2 \mathrm{~g}_{\mathrm{C}}}=0 .
$$

Equation (3.8-15) states that the change in kinetic energy at the exit is equal to the exit friction loss and the net pressure change is zero.

Inlet Filter Loss, $\triangle \mathrm{P}_{\mathrm{FFT}}$ :

The pressure loss through the inlet filter is assumed to be a function of the filter design loss at rated capacity and the flow squared as follows: 


$$
\Delta \mathrm{P}_{\mathrm{FFT}}=\Delta \mathrm{P}_{\mathrm{DFT}}\left(\frac{\mathrm{W}_{\mathrm{FT}}}{\mathrm{W}_{\mathrm{DFT}}}\right)^{2}
$$

where $\Delta \mathrm{P}_{\mathrm{DFT}}=$ filter loss at design flow, inches of water (assumed to be a constant)

$$
\mathrm{W}_{\text {DFT }}=\operatorname{design} \text { flow. }
$$

Valve Loss, $\Delta \mathrm{P}_{\mathrm{YT}}$ :

The valve pressure drop is described by Equation (3.8-4). DHX Shell Side Loss, $\Delta \mathrm{P}_{\mathrm{YT}}$ :

The DHX shell side pressure loss, $\Delta \mathrm{P}_{Y T}$, is calculated using the Gunter and Shaw (12) correlation for pressure drop in cross-flow through finned tube bundles.

The following expression applies:

$$
\Delta P_{Y T}=\frac{f_{Y T} H_{Y T}\left(D^{\prime}{ }_{e v} / P\right)^{0.4}}{2 g_{C} \bar{\rho}_{Y T} D^{\prime}{ }_{e v} \phi}\left(\frac{W_{Y T}}{A_{C T}}\right)^{2}
$$

where $f_{Y T}=$ friction factor (explained below)

$$
\begin{aligned}
& \mathrm{H}_{Y \mathrm{~T}}=\text { length of the flow path through the tube } \\
& \text { array, } f t \\
& D^{\prime}{ }_{\text {ev }}=\text { equivalent diameter (explained below) } \\
& P=\text { tube pitch, ft (see DHX section) } \\
& A_{C T}=\text { free-flow area for a single bank of tubes } \\
& \text { located at right angles to the air flow } \\
& \text { (i.e., crossflow arrangement), ft } \\
& \phi=\left(\mu_{B} / \mu_{\text {wall }}\right)^{0.14}=\text { air viscosity correction } \\
& \text { factor ( } \phi=1.0 \text { is assumed) } \\
& \mu_{B}=\text { air viscosity at bulk average air temperature } \\
& \mu_{\text {wall }}=\text { air viscosity at wall temperature } \\
& \bar{\rho}_{Y T}=\text { average air density based on average DHX air } \\
& \text { temperature, } 1 \mathrm{~b} / \mathrm{ft} \mathrm{t}^{3} \text {. }
\end{aligned}
$$


The friction factor $\left(f_{Y T}\right)$ is assumed to be a constant in the simulation and is obtained from Curve b in Figure D-2, Appendix D. The equivalent diameter ( ${ }^{\prime}{ }^{\prime}$ ev $)$ is calculated as follows:

$D_{\text {ev }}^{\prime}=\frac{4 x \text { net free volume }}{\text { frictional surface }}$

$D^{\prime}{ }_{\mathrm{ev}}=\frac{4\left[0.867 \mathrm{P}^{2}-\left(\pi \mathrm{D}_{0}^{2} / 4\right)-\pi\left(\mathrm{D}_{\mathrm{Fins}}^{2}-\mathrm{D}_{\mathrm{O}}^{2}\right) \mathrm{y}_{\mathrm{b}} \mathrm{N}_{\mathrm{Fins}} / 4\right]}{\mathrm{A}_{1}^{\prime}+\mathrm{A}^{1} 2}(3.8-18)$

where $A^{\prime}{ }_{1}$ is fin surface area per unit length, $A^{\prime} 2$ is the bare tube surface per unit length, $D_{0}$ is the tube outside diameter, $D_{F i n s}$ is fin diameter, $y_{b}$ is fin thickness, and $N_{F i n s}$ is the number of fins per unit length. The Reynolds number used to obtain $f_{Y T}$ in Figure D-2 (Appendix D) is also based on this same equivalent diameter ( $D^{\prime}$ ev $)$.

Stack Friction Loss, $\triangle \mathrm{P}_{\mathrm{ST}}$ :

The stack friction loss in inches of water is calculated by the following expression: (13)

$\Delta \mathrm{P}_{\mathrm{ST}}=\mathrm{C}_{\mathrm{ST}} \mathrm{W}_{\mathrm{FT}}^{2}$

where $\quad C_{S T}=\frac{f_{S T} H_{S T}}{2 g_{C}(5.19) D_{S T}^{\rho}{ }_{S T}\left(\pi D_{S T}^{2} / 4\right)^{2}}$

$f_{S T}=$ Darcy friction coefficient for steel stack (from Moody diagram with $\varepsilon=0.00015$ for steel stackassumed constant in simulation)

$\mathrm{H}_{\mathrm{ST}}=$ stack height, $\mathrm{ft}$

$D_{S T}=$ stack diameter, $f t$

${ }_{\rho_{\mathrm{ST}}}=$ air density at DHX air outlet temperature, $1 \mathrm{~b} / \mathrm{ft}^{3}$. 
Natural Draft, $\Delta \mathrm{P}_{\mathrm{DT}}$ :

Natural draft occurs in the stack because of a difference in gas density at the stack inlet and outlet. This draft (in inches of water) is calculated as a function of the DHX outlet temperature $\left(\mathrm{T}_{\mathrm{CTY}}\right)$ and the atmospheric air temperature as follows: $(14)$

$$
\Delta P_{D T}=C_{D T}\left(\frac{1}{T_{A}+460}-\frac{1}{T_{C T Y 1}+460}\right)
$$

where $\mathrm{C}_{\mathrm{DT}}=0.52 \mathrm{P}_{\mathrm{A}} \mathrm{H}_{\mathrm{ST}}$

$\mathrm{P}_{\mathrm{A}}=$ atmospheric pressure, psi

$\mathrm{H}_{\mathrm{ST}}=$ stack height, $\mathrm{ft}$

$\mathrm{T}_{\mathrm{A}}=$ atmospheric air temperature, ${ }^{\circ} \mathrm{F}$

$\mathrm{T}_{\text {CTY } 1}=$ DHX air outlet (stack inlet) temperature, ${ }^{\circ} \mathrm{F}$.

This completes the definition of the terms. For simulation purposes, all of the equations have been combined to calculate the tertiary air flow $\left(W_{F T}\right)$ as a function of valve angle of opening and DHX air outlet temperature. Curves for two cases (fan on and fan off) have been calculated by hybrid function generators and are shown in Figures 3.8 .4 and 3.8.5. With the fan on, the flow curves are essentially the same for al1 DHX air outlet temperatures. This is because the natural draft is a small percent of the total flow when the fan is on. With the fan off, however, the air outlet temperature greatly affects the air flow, since the natural draft is the main driving force.

\section{SAMPLE TRANSIENT RESULTS}

Simulation results for the following two typical transients are presented here to demonstrate the system model performance: 1) manual reactor scram with full primary and secondary flows, and air fan off with valve open; 2) manual reactor scram with simultaneous primary, secondary, and 


$$
D E
$$


tertiary flow decays. The system variables of interest for the first transient are presented in Figures 4.1 and 4.2 , while the results of the second transient are given in Figures 4.3 and 4.4. The initial steady-state conditions, given below, were identical for both transients.

\section{Steady State Conditions:}

Total Reactor Power

Reactor Vessel Inlet Temperature,

Reactor Vessel Outlet Temperature, Primary Loop Flow Rate

$$
\text { (four loops), }
$$

IHX Secondary Inlet Temperature, IHX Secondary Outlet Temperature, Secondary Loop Flow Rate

$$
\text { (four loops), }
$$

DHX Air Inlet Temperature, DHX Air Outlet Temperature, Tertiary Air Flow Per Module

$$
\begin{aligned}
\mathrm{PL}_{\mathrm{T}} & =400 \mathrm{MW} \\
\mathrm{T}_{\mathrm{CIR}} & =622^{\circ} \mathrm{F} \\
\mathrm{T}_{\mathrm{COR}} & =907^{\circ} \mathrm{F}
\end{aligned}
$$

$$
\mathrm{W}_{\mathrm{P}}=1102 \mathrm{lb} / \mathrm{sec}-10 \mathrm{op}
$$$$
\mathrm{T}_{\text {CSX } 5}=526^{\circ} \mathrm{F}
$$$$
\mathrm{T}_{\mathrm{CSX} 1}=804^{\circ} \mathrm{F}
$$

$$
\begin{aligned}
\mathrm{W}_{\mathrm{S}} & =1126 \mathrm{lb} / \mathrm{sec}-100 \mathrm{p} \\
\mathrm{T}_{\mathrm{A}} & =50{ }^{\circ} \mathrm{F} \\
\mathrm{T}_{\text {CTY1 }} & =410^{\circ} \mathrm{F}
\end{aligned}
$$

$\mathrm{W}_{\mathrm{FT}}=252 \mathrm{lb} / \mathrm{sec}-\mathrm{module}$.

The reactivity insertion graph appears in all figures for each transient to establish a common time zero, when the transient begins. The reactor scram is simulated by a negative $15 \$$ reactivity step for both sample transients.

The sample results indicate that the complete model performs in a reasonable manner. The model steady-state values provide a heat balance that is accurate to $\sim 1 \%$. Time delays function properly and all loop feedbacks and interactions react as expected. Flow decays and reactor responses are also reasonable. Additional transient studies indicate that all portions of the simulation respond in a reasonable manner, and that the model is ready for application. 

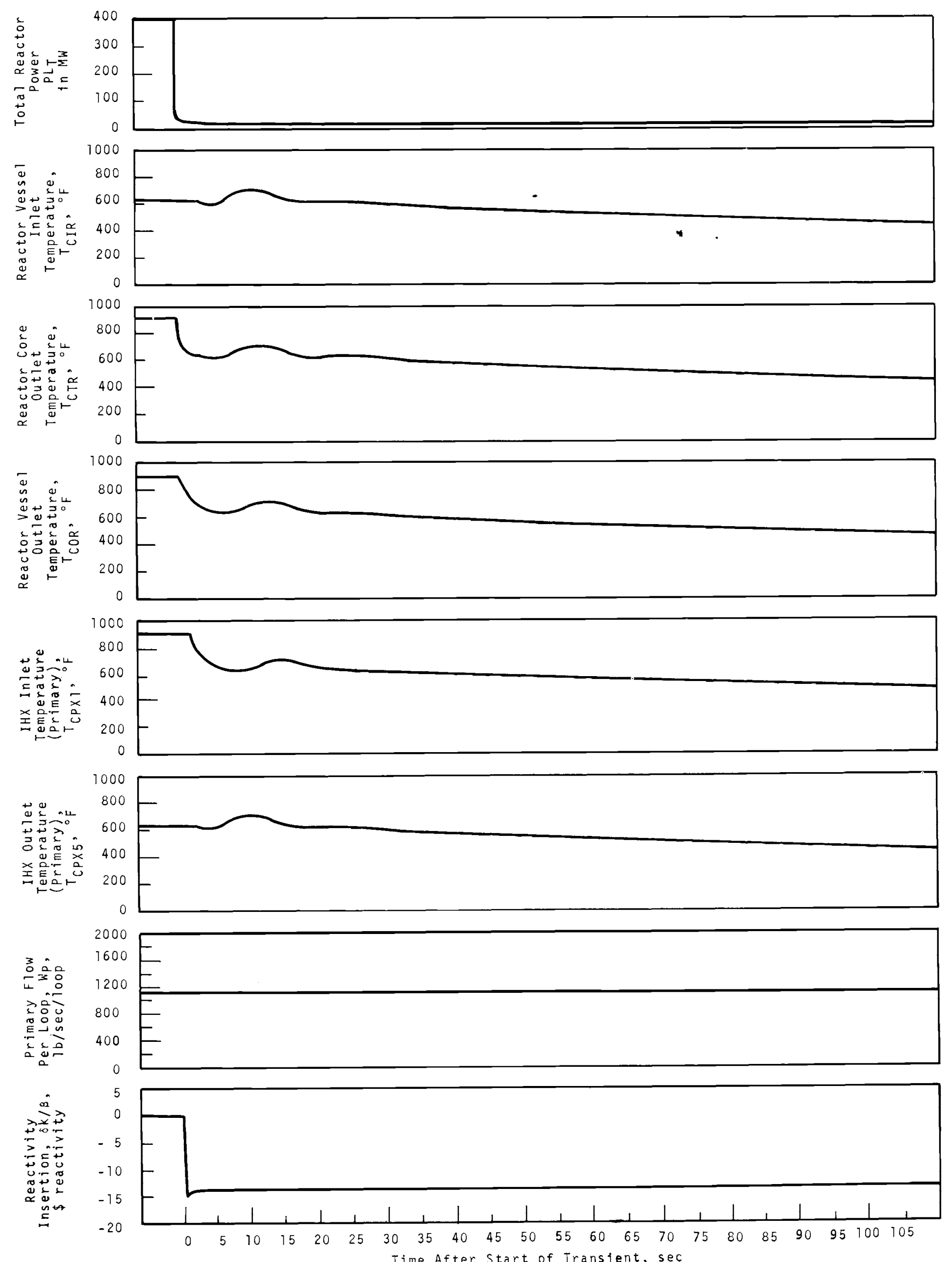

FIGURE 4.1. Hybrid Simulation Model Results for Manual Scram with Full Primary, Secondary, and Tertiary Flows (Results from output Channels 1-8). (Remaining results for this transient are in Figure 4.2.)

FIGURE 4.1. Hybrid Simulation Model Results for Manual Scram with Fulz Primary, Secondary, and Tertiary Flows (Results from output Channels 1-8). (Remaining results for this transient are in Figure 4.2.) 

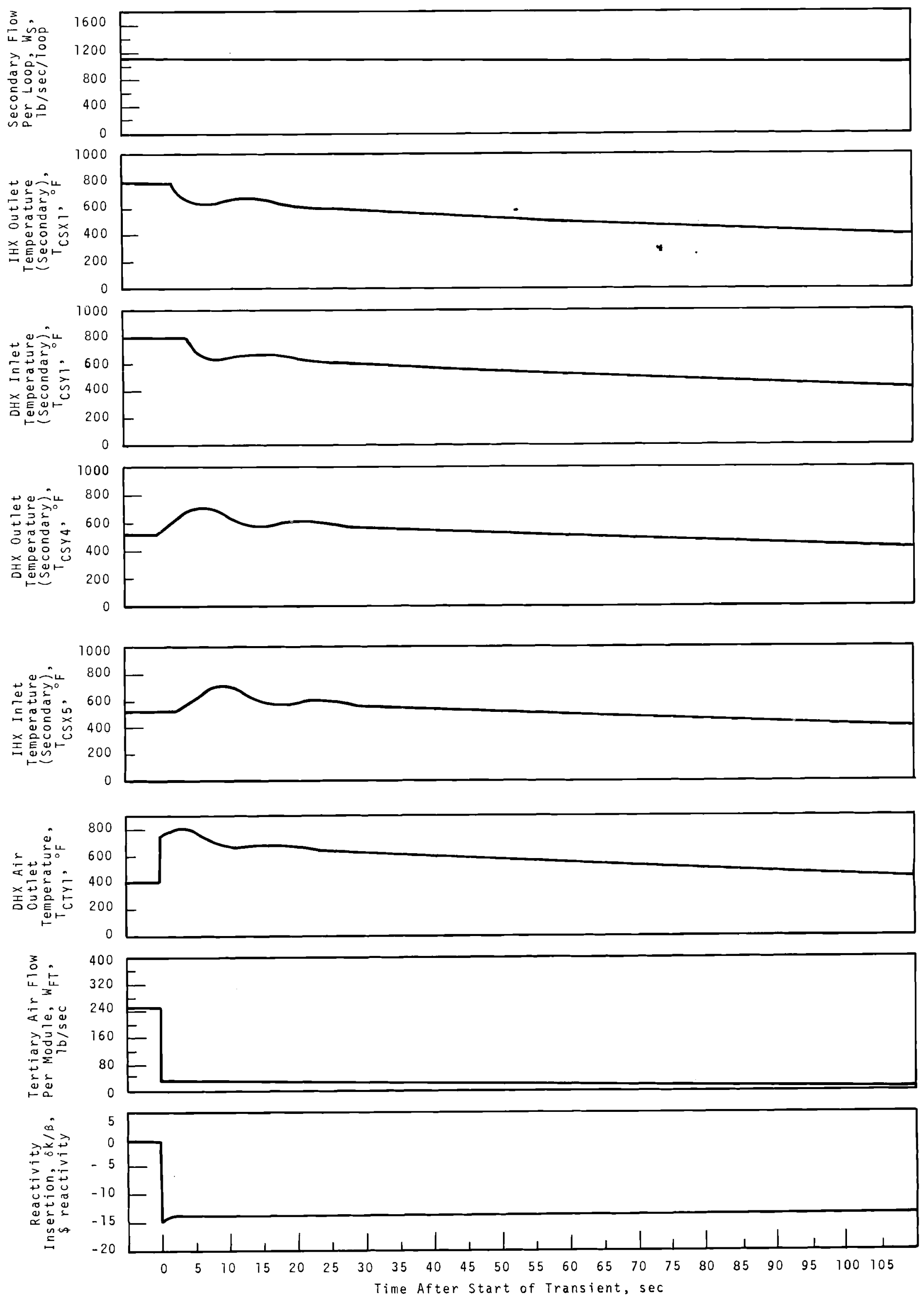

EIGURE 4.2. Hybrid Simulation Model Results for Manual Scram with Fulz Primary, Secondary, and Tertiary Flows (Results from output channels 9-16). (Results for channels 1-8 are in Figure 4.1.)

Time After Start of Transient, sec

FIGURE 4.2. Hybrid Simulation Model Results for Manual Scram with Fulz Primary, Secondary, and Tertiary Flows (Results from output Channels 9-16). (Results for channels $1-8$ are in Figure 4.1.) 

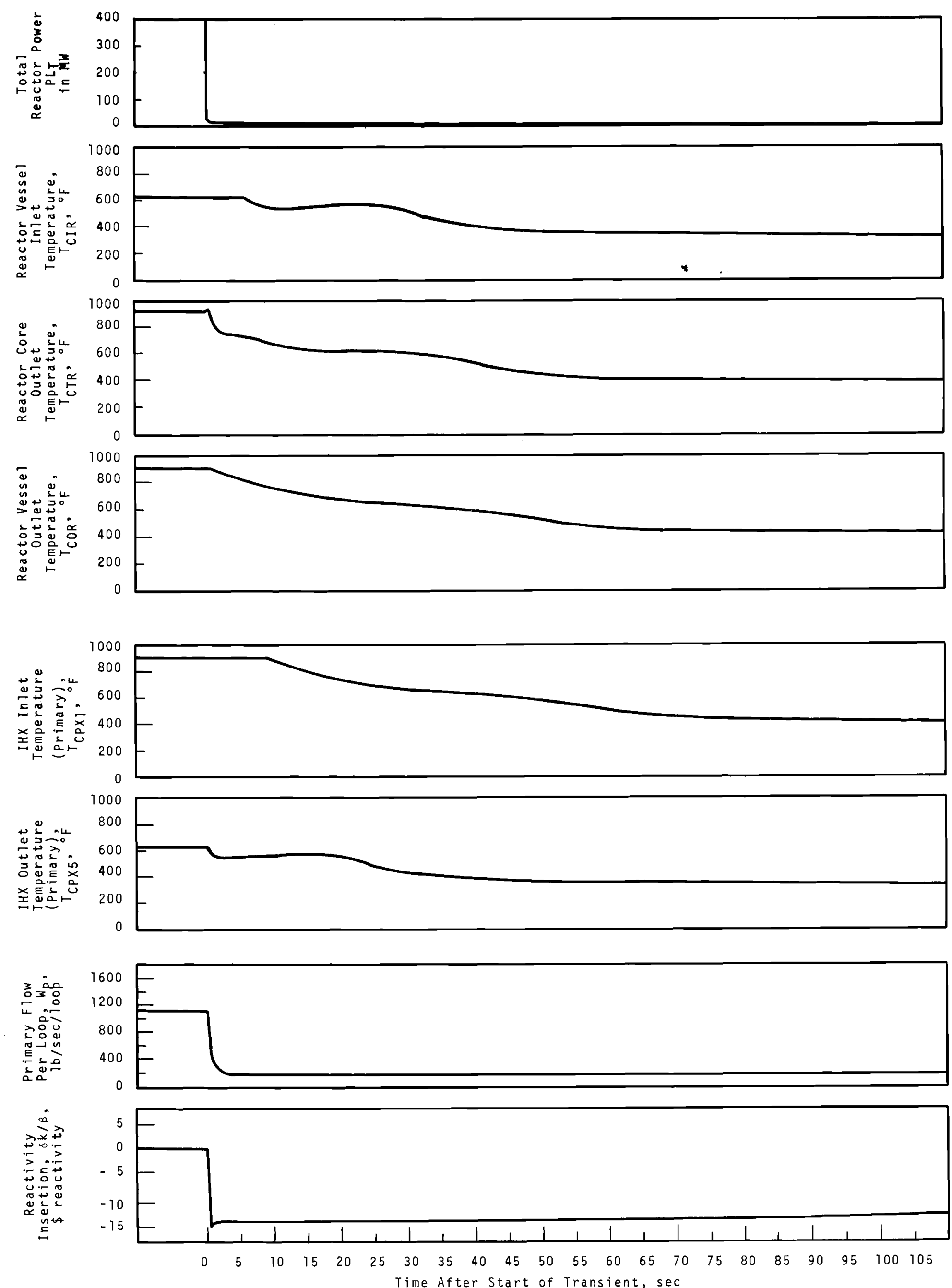

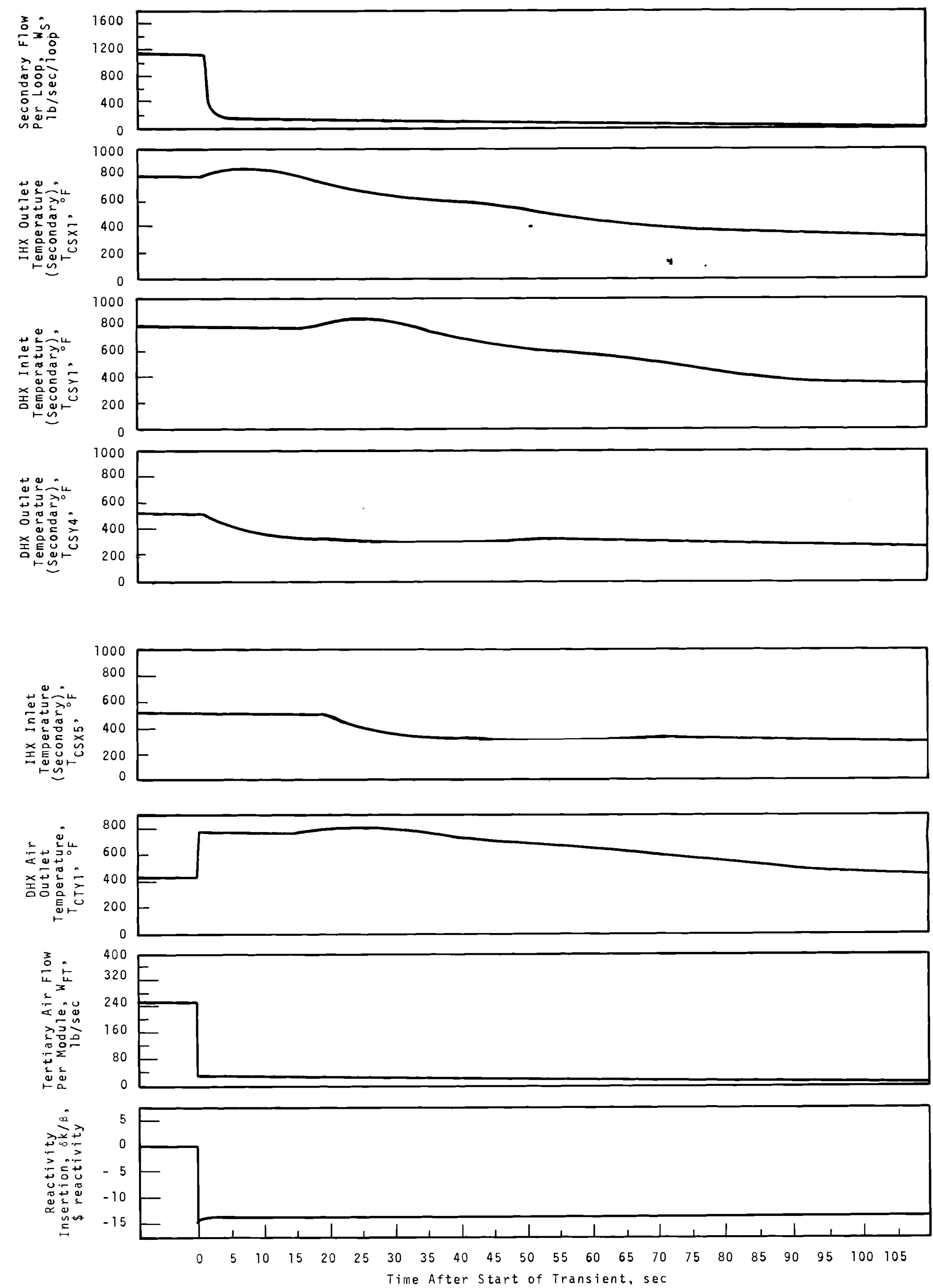

FIGURE 4.4. Hybrid Simulation Model Results for Manual Scram with Immediate Primary, Secondary, and Tertiary Flow Decays (Results from output Channels 9-16).

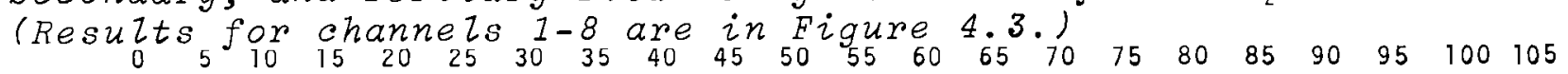
Time After Start of Transient, sec 
TABLE 4.1. Sample Transient Design Data

Numerical values in this table are of a conceptual nature and are subject to future revision.

\section{Reactor Core}

Number of Equivalent Driver Fuel Subassemblies $\left(\mathrm{N}_{\mathrm{ER}}\right) \quad 82$

Prompt Neutron Power $\left(\mathrm{PL}_{\mathrm{N}}\right)$

Fission Product Power $\left(\mathrm{PL}_{\mathrm{F}}\right) \quad 20 \mathrm{MW}$

Fraction of Total Power Generated

in Closed Loops $\left(\gamma_{\mathrm{CR}}\right)$

Fraction of Neutron Power Generated
in Radial Reflector ( $\left.\gamma_{R R}\right)$
0.0526

Driver Fuel Subassembly Data

Fuel Composition $\left(\mathrm{UO}_{2}, \mathrm{PuO}_{2}\right) \quad 20$ to $25 \% \mathrm{PuO}_{2}$

Clad Material

TP 304 SS

Active Fuel Height

34 in.

Fuel Geometry

Hexagonal Rod

Cluster (Triangular Pitch)

Pin Diameter

0.25 in.

Number of Pins Per Subassembly

217

Fuel Pin Pitch to Diameter Ratio

1.12

Subassembly Duct Dimensions

Hexagonal 4.5 in. Across Flats, 0.150 in. Thick

Reactor Vessel Flow Split

Driver Fuel Subassemblies 0.90

Leakage

0.05

Radial Reflector

0.05

Intermediate Heat Exchanger (4 Units - One Per Loop)

Design Duty Per Unit

Total Surface

$133 \mathrm{MW}$

Log-Mean Temperature Difference

$3810 \mathrm{ft}^{2}$

Tube OD

$125^{\circ} \mathrm{F}$

1.0 in. 


\section{TABLE 4.1. (contd)}

Intermediate Heat Exchanger (4 Units - One Per Loop) (contd)

Tube Wall Thickness

$0.065 \mathrm{in.}$

Tube Pitch (Triangular)

1.375 in.

Number of Tubes Per Unit

858

Effective Tube Length

$16 \mathrm{ft}$

Dump Heat Exchanger ( 4 Units with 4 Modules Per Unit)

Design Duty Per Unit

$133 \mathrm{MW}_{\mathrm{t}}$

Outside Finned Surface Per Unit

$301,300 \mathrm{ft}^{2}$

Log-Mean Temperature Difference

$322^{\circ} \mathrm{F}$

Tube OD

1.0 in.

Tube Wall Thickness

0.065 in.

Tube Pitch (Triangular)

2.75 in.

Fin $O D$

2.25 in.

Fin Thickness

$0.022 \mathrm{in}$.

Fin Spacing

8 Fins/in.

Number of Tubes Per Unit

748

Number of Tube Passes

6

Number of Tube Rows Per Pass

2

Effective Tube Length

Primary Loop Piping (Primary Pump in Cold Leg)

Reactor to IHX

Length

Pipe ID

$93 \mathrm{ft}$

23.25 in.

IHX to Primary Pump

Length

Pipe ID

$43 \mathrm{ft}$

23.25 in.

Primary Pump to Reactor

Length

Pipe ID

$123 \mathrm{ft}$

17.25 in.

Secondary Loop Piping (Secondary Pump in Cold Leg)

IHX to DHX Length

Pipe ID

$422 \mathrm{ft}$

15.25 in.

DHX to Secondary Pump

Leng th

Pipe ID

$172 \mathrm{ft}$

$15.25 \mathrm{in}$. 


\section{TABLE 4.1. (contd)}

Secondary Loop Piping (Secondary Pump in Cold Leg) (contd)

Secondary Pump to IHX Length

Pipe ID

Primary Sodium Pumps

Capacity Rating

Total Dynamic Head

Pumping BHP

Pump Assembly Inertia

Drive Motor Assembly Inertia

Maximum Operating Speed

Secondary Sodium Pumps

Capacity Rating

Total Dynamic Head

Pumping BHP

Pump Assembly Inertia

Drive Motor Assembly Inertia

Maximum Operating Speed

Air Blower (One Per DHX Module)

Capacity Rating

Equivalent Pressure

Blower BHP

Efficiency

Speed
$247 \mathrm{ft}$

15.25 in.

$12,000 \mathrm{ga} 1 / \mathrm{min}$

$440 \mathrm{ft}$

1480

$13181 \mathrm{~b}-\mathrm{ft} \mathrm{t}^{2}$

$41731 b-f t^{2}$

$870 \mathrm{rpm}$

$12,000 \mathrm{gal} / \mathrm{min}$

$250 \mathrm{ft}$

870

$7181 b-f t^{2}$

$27541 \mathrm{~b}-\mathrm{ft} \mathrm{t}^{2}$

$1170 \mathrm{rpm}$

$279,000 \mathrm{ft}^{3} / \mathrm{min}$

7.6 in. Water

372

$79 \%$

$1170 \mathrm{rpm}$ 


\section{NOMENCLATURE}

\begin{tabular}{|c|c|c|}
\hline & & Units \\
\hline$A$ & Surface or flow area & $f t^{2}$ \\
\hline$A^{\prime}$ & Area per unit length & $f t^{2} / f t$ \\
\hline a & Constant & \\
\hline $\mathrm{b}$ & Constant & \\
\hline $\mathrm{C}$ & Specific heat & $\mathrm{Btu} / 1 \mathrm{~b}-{ }^{\circ} \mathrm{F}$ \\
\hline $\mathrm{C}_{f}$ & Pressure loss coefficient & $\begin{array}{l}1 \mathrm{~b}(\mathrm{sec})^{1.8} / \\
\mathrm{ft} \mathrm{t}^{2}(1 \mathrm{~b})^{1.8}\end{array}$ \\
\hline $\mathrm{C}_{i}$ & $\begin{array}{l}\text { Power due to concentration } \\
\text { of ith decay group }\end{array}$ & $\mathrm{MW}$ \\
\hline $\mathrm{C}_{\mathrm{v}}$ & Valve flow coefficient & \\
\hline D & Diameter & $f t$ \\
\hline $\mathrm{D}_{\mathrm{e}}$ & Equivalent diameter & $f t$ \\
\hline $\mathrm{F}$ & Analog function generator & \\
\hline$f$ & Darcy friction factor & \\
\hline$g_{c}$ & Acceleration of gravity & $1 b_{m}-f t / 1 b_{f}-\sec ^{2}$ \\
\hline G & Mass velocity & $1 \mathrm{~b} / \mathrm{sec}-\mathrm{ft} \mathrm{t}^{2}$ \\
\hline $\mathrm{H}$ & Height & $f t$ \\
\hline $\mathrm{H}_{\mathrm{p}}$ & Pump head & psi \\
\hline $\mathrm{H}_{\mathrm{FT}}$ & Fan head & in. of water \\
\hline h & Film coefficient for Heat Transfer & $B t u / h r-f t^{2}-{ }^{\circ} F$ \\
\hline I & Mass Moment of Inertia & $1 b-f t-\sec ^{2}$ \\
\hline j & $\begin{array}{l}\text { Sieder and Tate heat transfer } \\
\text { factor }\end{array}$ & \\
\hline $\mathrm{k}$ & Thermal conductivity & $\mathrm{Btu} / \mathrm{sec}-\mathrm{ft}-{ }^{\circ} \mathrm{F}$ \\
\hline
\end{tabular}


Units

$\delta \mathrm{k} \quad$ Reactivity feedback

I Length

$f t$

$N_{P} \quad$ Pump speed

rpm

$\mathrm{N}_{\mathrm{M}} \quad$ Motor speed

rpm

$\mathrm{N}_{\mathrm{FT}} \quad$ Fan speed

rpm

$\mathrm{N}_{i} \quad$ Number of converging flow paths

P Pressure

psi

PL Power level

$\mathrm{MW}$

p Tube pitch

$f t$

$\mathrm{P}_{\mathrm{e}}$ Peclet number

$\mathrm{P}_{\mathrm{r}} \quad$ Prandt 1 number

$\mathrm{P}_{\mathrm{W}} \quad$ Wetted perimeter

ft

$R$ Heat transfer resistance/unit length or ideal gas constant

r Radius

$\sec -f t-{ }^{\circ} \mathrm{F} / \mathrm{Btu}$
$\mathrm{ft}-1 \mathrm{~b}_{\mathrm{f}} / 1 \mathrm{~b}_{\mathrm{m}}-{ }^{\circ} \mathrm{R}$

Re Reynolds number

$\mathrm{S}_{\mathrm{M}} \quad$ Motor sip

$\mathrm{T}$ Temperature or torque

${ }^{\circ} \mathrm{F}$ or $f t-1 b$

$t \quad$ Time

$\sec$

U Overall heat transfer coefficient

$\mathrm{Btu} / \mathrm{sec}-\mathrm{ft} \mathrm{t}^{2}-{ }^{\circ} \mathrm{F}$

u,v Velocity

$\mathrm{ft} / \mathrm{sec}$

$\mathrm{V} \quad$ Volume

$f t^{3}$

$V^{\prime} \quad$ Volume/unit length

$f t^{3} / f t$

W Weight flow rate

$1 \mathrm{~b} / \mathrm{sec}$ 


\section{Units}

$\begin{array}{ll}x & \text { Distance or length } \\ y_{b} & \text { Fin thickness } \\ z & \text { Elevation }\end{array}$

$\mathrm{ft}$

$f t$

$f t$

Greek Letters

\begin{tabular}{|c|c|c|}
\hline$\alpha$ & Reactivity feedback coefficients & $\delta \mathrm{k}$ or $\delta \mathrm{k} /{ }^{\circ} \mathrm{F}$ \\
\hline$\beta_{i}$ & $\begin{array}{l}\text { Delayed neutron fraction for } \\
\text { ith Group }\end{array}$ & \\
\hline$\beta$ & $\begin{array}{l}\text { Effective delayed neutron } \\
\text { fraction }=\sum \beta_{i}\end{array}$ & \\
\hline$\gamma$ & Heat generation fraction & \\
\hline$\theta$ & Valve angle of opening & Angular degrees \\
\hline$\lambda_{i}$ & $\begin{array}{l}\text { Decay constant for ith Group } \\
\text { of delayed neutrons }\end{array}$ & $\sec ^{-1}$ \\
\hline$\mu$ & Viscosity & $1 b / f t-s e c$ \\
\hline$\ell$ & Coolant inertance coefficient & $\sec ^{2} / f t^{2}$ \\
\hline$\ell^{*}$ & Prompt neutron lifetime & sec \\
\hline$\rho$ & Density & $1 \mathrm{~b} / \mathrm{ft}^{3}$ \\
\hline$\tau$ & $\begin{array}{l}\text { Time delay for coolant flowing } \\
\text { through a pipe section }\end{array}$ & sec \\
\hline & $\left(\mu / \mu_{W}\right)^{0.14}$ & \\
\hline $\bar{\psi}$ & $\begin{array}{l}\text { Average value of ratio of } \\
\text { diffusivity for heat transfer } \\
\text { to diffusivity for momentum } \\
\text { transfer }\end{array}$ & \\
\hline
\end{tabular}




\section{ACKNOWLEDGEMENTS}

The authors would like to recognize the following people for their contributions to this work: Wendell Nielson, for initial simulation of DHX and tertiary hydraulics; H. G. Johnson, for technical guidance throughout, and A. L. Gunby, for technical editing and rewriting services. 
BNWL - 707

APPENDIX A

REACTOR FUEL TO COOLANT HEAT TRANSFER COEFFICIENT 


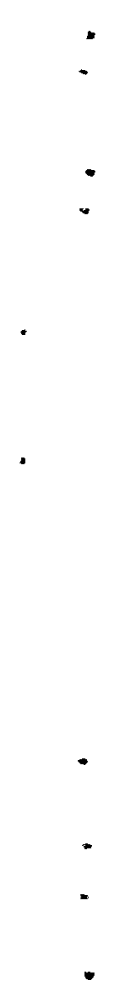




\section{APPENDIX A}

\section{REACTOR FUEL TO COOLANT HEAT TRANSFER COEFFICIENT}

The overall heat transfer conductance $\left(U^{\prime}\right)_{R}$ between the fuel and the coolant consists of the following heat transfer resistances: 1) fuel resistance, 2) fuel-clad gap resistance, 3) clad resistance, and 4) sodium film resistance. The following equation applies:

$$
\left(\mathrm{UA}^{\prime}\right)_{\mathrm{R}}=\frac{\mathrm{n}_{\mathrm{p}}}{\mathrm{R}_{\text {fuel }}+\mathrm{R}_{\text {gap }}+\mathrm{R}_{\text {clad }}+\mathrm{R}_{\text {film }}}
$$

where $n_{p}=$ number of fuel pins per subassembly.

The number of pins per subassembly is included because the resistances are al1 based on the heat transfer area per fuel pin. With the factor $n_{p}$ included, the total (UA') ${ }_{R}$ is then defined for one subassembly, as desired. Figure A-1 shows the fuel pin cross-section used to obtain the resistance terms.

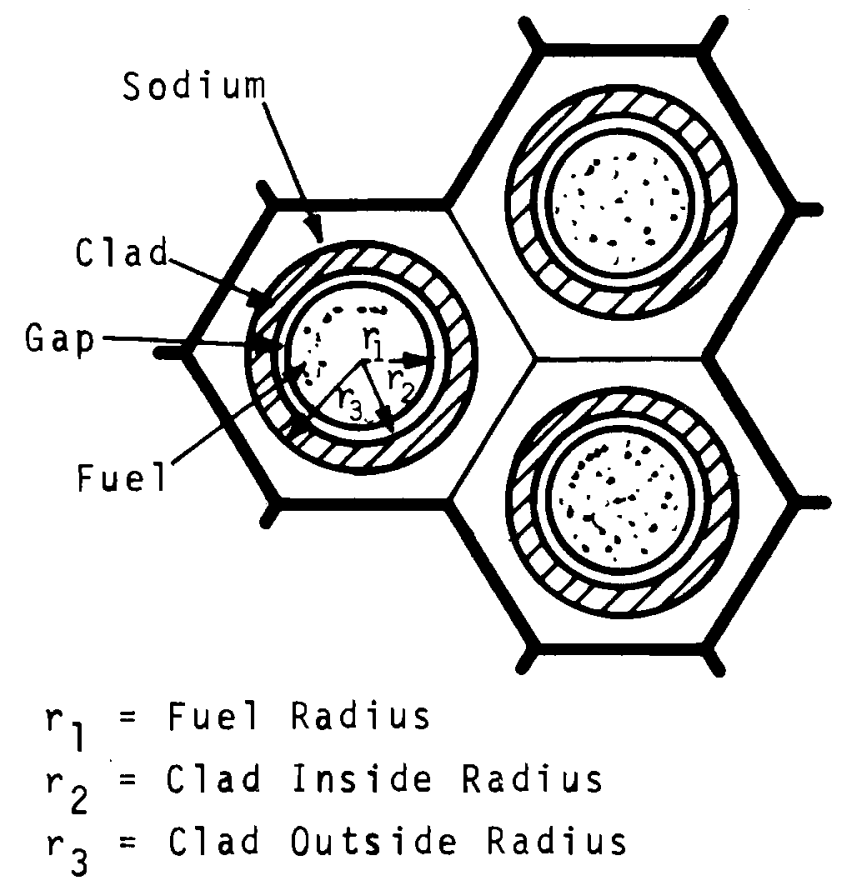

EIGURE A-1. Fuel Pin Cross-Section 
The individual resistances are defined as follows.

Fuel Resistance, $\mathrm{R}_{\text {fuel }}$ :

Since only one radial node is simulated in the fuel region, we have assumed that the average fuel temperature is located at the volume average radius, $0.707 r_{1}$, where $r_{1}=$ fuel radius. The fuel resistance then is

$$
R_{\text {fue } 1}=\frac{1}{8 \pi k_{f}}
$$

where $k_{f}=$ fuel thermal conductivity, Btu/sec-ft- ${ }^{\circ} \mathrm{F}$. A length term does not appear since the overall coefficient is calculated on a per unit length basis.

Gap Resistance, Rgap:

A constant gap coefficient, $h_{g}\left(B t u / \sec -f t^{2}{ }^{\circ} F\right)$, is assumed. The gap resistance is defined as

$$
R_{\text {gap }}=\frac{1}{2 \pi r_{2} h_{g}} \text {. }
$$

$R_{\text {gap }}=42.0 \mathrm{ft}-\mathrm{sec}-{ }^{\circ} \mathrm{F} / \mathrm{Btu}$ for present reference concept. Clad Resistance, $\mathrm{R}_{\mathrm{clad}}$ :

Cylindrical heat transfer resistance is assumed to calculate the clad resistance.

$$
\mathrm{R}_{\text {clad }}=\frac{\ln \left(\mathrm{r}_{3} / \mathrm{r}_{2}\right)}{2 \pi \mathrm{k}_{\mathrm{clad}}}
$$

where $\mathrm{k}_{\mathrm{clad}}=\mathrm{clad}$ thermal conductivity, Btu/sec-ft- ${ }^{\circ} \mathrm{F}$. Outside Film Resistance, $\mathrm{R}_{\mathrm{fi}} \mathrm{m}$ :

The clad surface film resistance is calculated by the following expression

$$
R_{f i l m}=\frac{1}{2 \pi r_{3} h_{0}}
$$

where $h_{0}=$ sodium film coefficient, Btu/sec-ft ${ }^{2}{ }^{\circ} \mathrm{F}$. 
The fuel resistance provides the bulk of the total heat transfer resistance in Equation (A-1) ( $(70 \%)$. The gap resistance provides $\sim 25 \%$, assuming a gap coefficient of $1500 \mathrm{Btu} /$ $\mathrm{hr}-\mathrm{ft} \mathrm{t}^{2}-{ }^{\circ} \mathrm{F}$. Therefore, the fuel $\mathrm{clad}$ and film resistances contribute only about $5 \%$ to the total. The clad, fuel, and film resistances for the reference concept are shown in Figures A-2, A-3, and A-4. The clad conductivity is plotted as a function of coolant temperature since the clad and coolant are nearly the same temperature. Fuel thermal conductivity data for 93\% $\mathrm{TD}$ (Theoretical Dense) $\mathrm{PuO}_{2}-\mathrm{UO}_{2}$ fuel were used to obtain Figure A-3. Reference 15 was used to obtain the film resistances in Figure $\mathrm{A}-4$. The curves in Figure $\mathrm{A}-4$ apply only to turbulent flow. The sodium film coefficients, however, will remain quite high even with laminar flow, and the overall conductance will not be affected appreciably whether the flow is laminar or turbulent.

Since we have assumed a constant gap coefficient, it is obvious from Figures A-2, A-3, and A-4 that the only parameter that will cause significant change in the overall heat transfer conductance, $\left(\mathrm{UA}^{\prime}\right)_{R}$, is the variation of the average fuel temperature. Therefore, constant clad and film resistances have been assumed. This makes the overall heat transfer conductance, (UA') $R$, a function of the average fuel temperature only, and Figure A-5 results. This curve is simulated to represent the fuel to coolant heat transfer. 


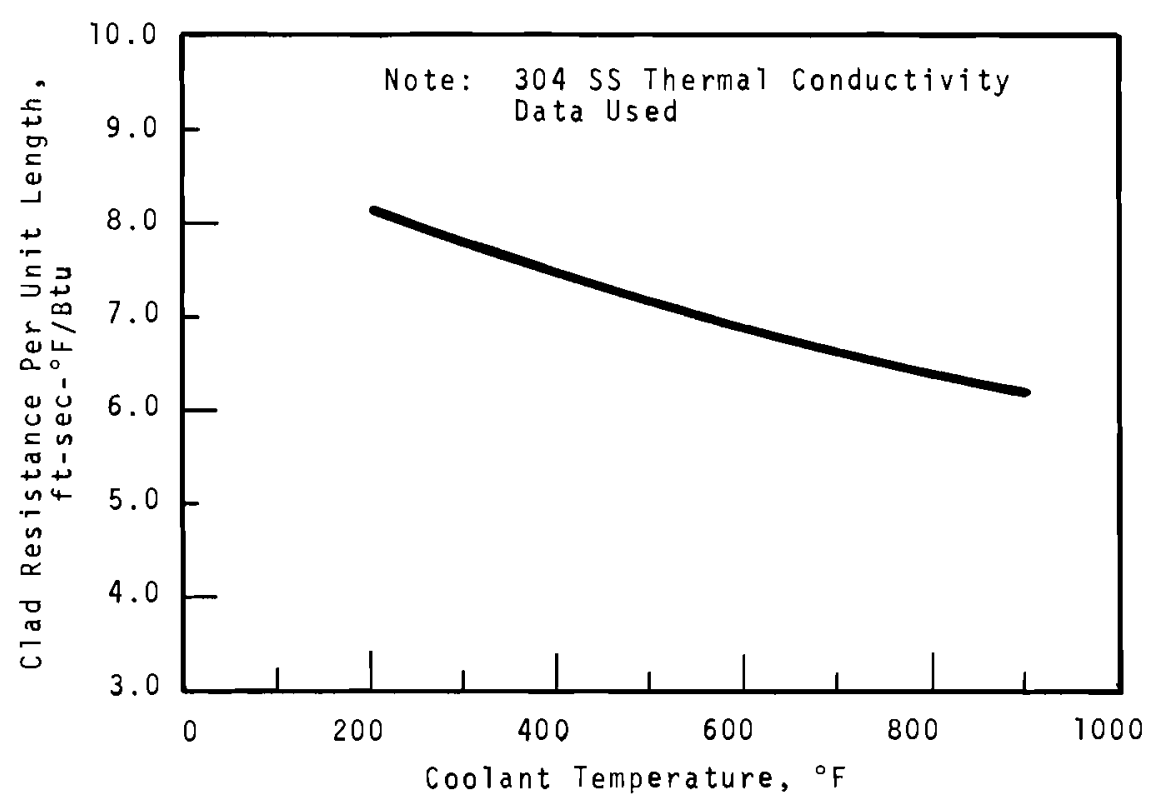
FIGURE A-2. Clad Heat Flow Resistance as a Function
of Coolant Temperature

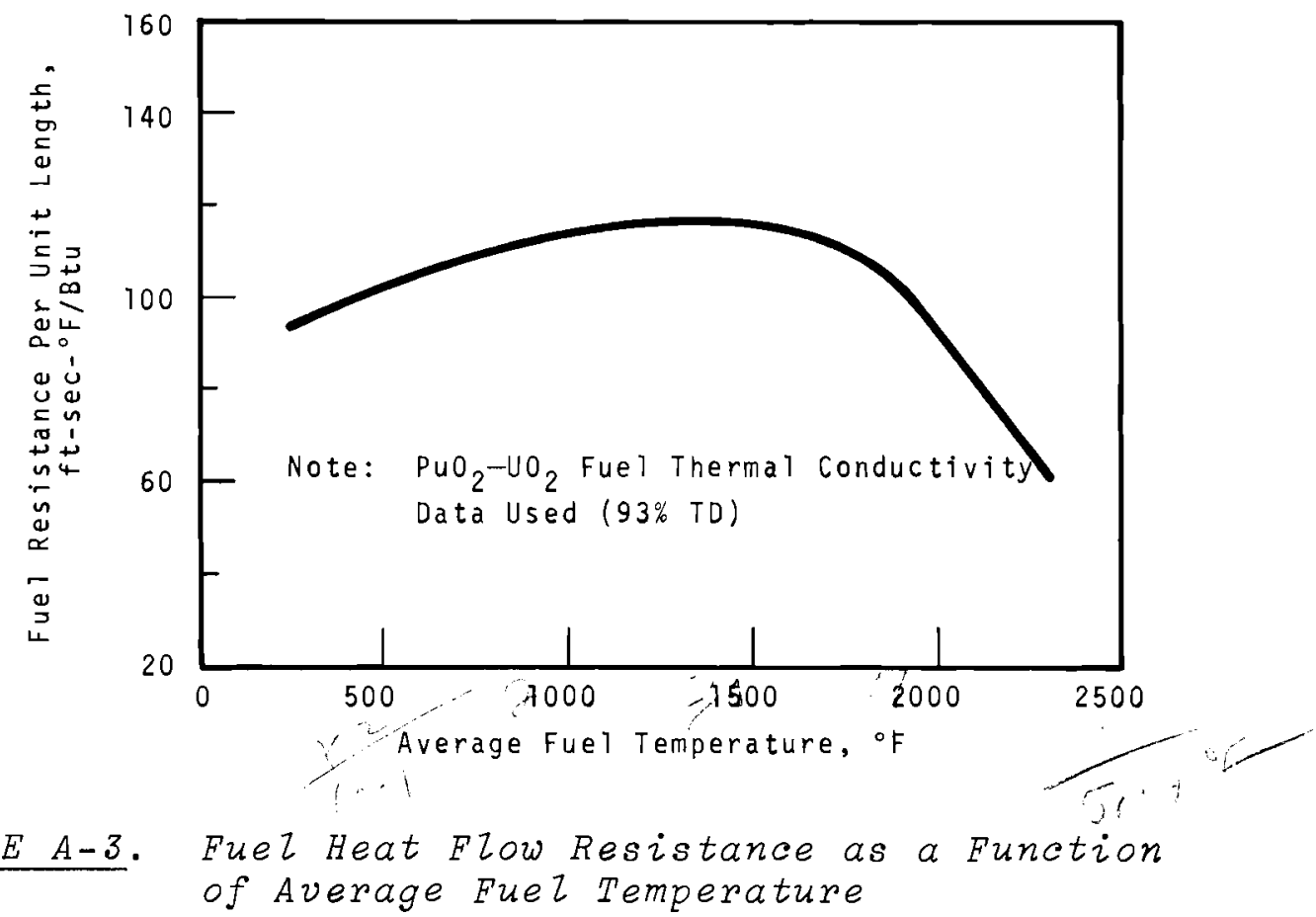




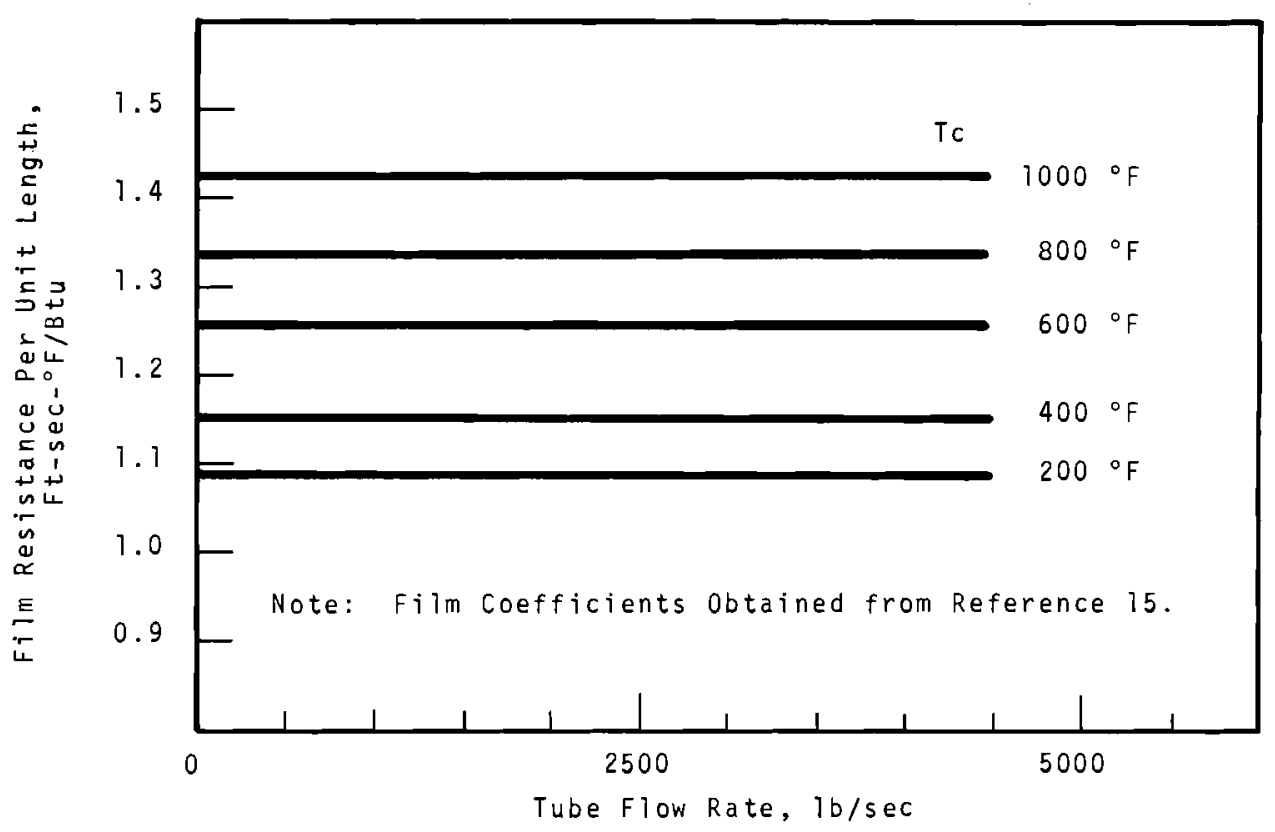
FIGURE A-4. Coolant Film Heat Flow Resistance as a Function
of Tube Flow Rate and Coolant Temperature

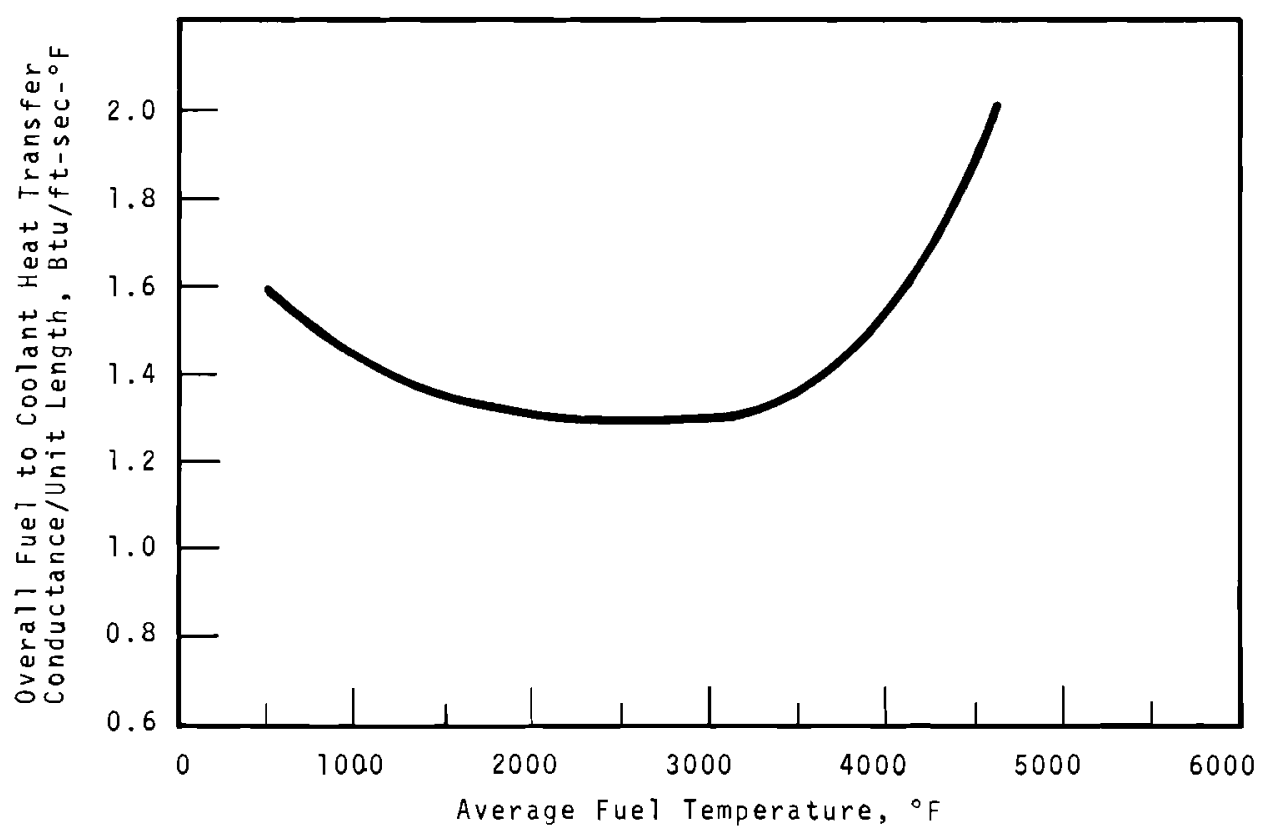

FIGURE A-5. Overall Fuel-Coolant Heat Transfer Conductance
as a Function of Average Fuel Temperature 


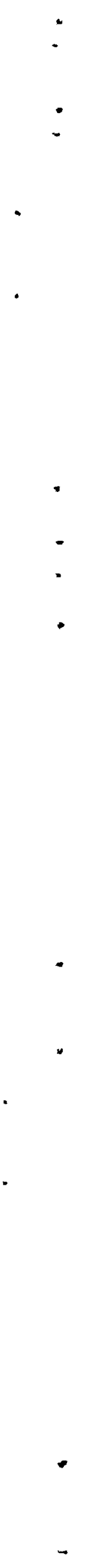


BNWL - 707

\section{APPENDIX B \\ IHX CONSTANTS AND HEAT TRANSFER COEFFICIENTS}




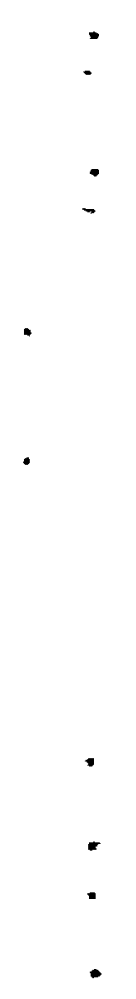




\section{APPENDIX B}

\section{IHX CONSTANTS AND HEAT TRANSFER COEFFICIENTS}

\section{VOLUMES AND AREAS}

The geometry of the IHX is assumed to be the triangular pitch arrangement of Figure B-1.

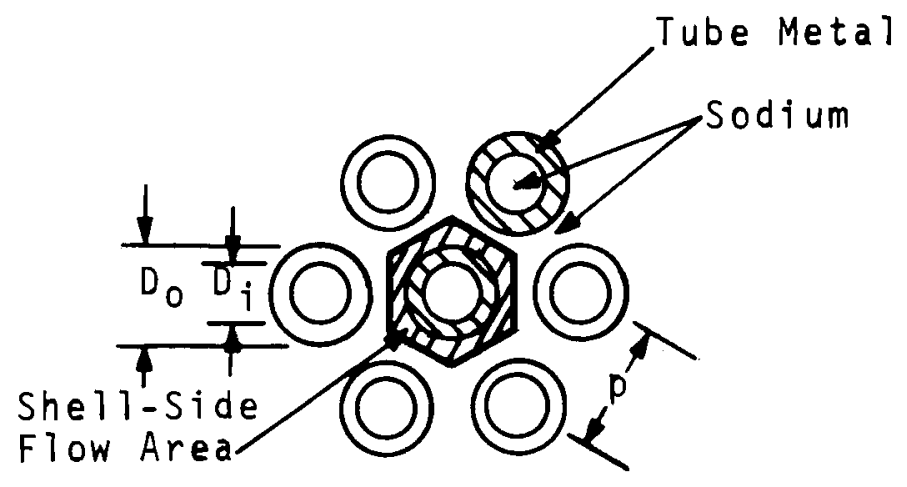

\section{FIGURE B-1. IHX Tube Geometry}

From the above configuration, the following parameters for the analog-hybrid model may be calculated:

She11-Side Flow Volume Per Unit Length (primary flow):

$$
V_{C P X}^{\prime}=\frac{N_{T X}}{4}\left(2 \sqrt{3} p^{2}-\pi D_{0}^{2}\right),
$$

Tube-Side Flow Volume Per Unit Length (secondary flow):

$$
V_{C S X}^{\prime}=\frac{N_{T X}}{4}\left(\pi D_{i}^{2}\right)
$$

Tube Metal Volume Per Unit Length:

$$
V_{M X}^{\prime}=N_{T X}\left(\frac{\pi}{4}\right)\left(D_{0}^{2}-D_{i}^{2}\right),
$$

where $\mathrm{N}_{\mathrm{TX}}=$ number of tubes. The proper coefficients for the 
simulation may be computed from the above three expressions by lumping half the metal volume with each sodium volume.

Stored Heat Per Unit Length, Primary Side:

$$
\left(\rho V^{\prime} C\right)_{P X}^{*}=(\rho C)_{N a} V^{\prime}{ }_{C P X}+\left(\frac{1}{2}\right) \quad(\rho C)_{M} V^{\prime}{ }_{M X}
$$

Stored Heat Per Unit Length, Secondary Side:

$$
\left(\rho V^{\prime} C\right)_{S X}^{*}=(\rho C)_{N a} V^{\prime}{ }_{C S X}+\left(\frac{1}{2}\right)(o C)_{M^{\prime}}{ }^{\prime}{ }_{M X}, \quad(B-5)
$$

where $(\rho C)_{\mathrm{Na}}$ and $(\rho C)_{M}$ are the products of density and specific heat for sodium and tube metal, respectively. Values of $\rho$ and $C$ are selected based on average temperatures at steady-state conditions.

Heat Transfer Area Per Unit Length:

$$
A^{\prime} X={ }^{N} \operatorname{TX}^{\pi D_{0}}
$$

Heat transfer area is arbitrarily based on the tube outside diameter. Appropriate corrections are included in the heat transfer coefficient for the inside film coefficient and the tube metal heat resistance.

\section{HEAT TRANSFER COEFFICIENT}

The IHX heat transfer coefficient is computed from the following basic expression:

$$
U_{X}=\left[\frac{1}{h_{0}}+\frac{1}{h_{i}\left(D_{i} / D_{0}\right)}+\frac{D_{0} \ln \left(D_{0} / D_{i}\right)}{2 k_{M}}\right]^{-1}
$$

where $h_{0}$ and $h_{i}$ are the outside and inside film coefficients, respectively, and $k_{M}$ is the thermal conductivity of the tube metal. The parameters $h_{0}$ and $h_{i}$ are functions of temperature and flow, while $k_{M}$ is a function of tube temperature only. Each of the three terms in the above expression is simulated as a function of the appropriate temperature and flow. The 
last term, corresponding to the heat transfer through the tube is shown in Figure $B-2$ as a function of the wall temperature (assumed to be an average of the average sodium temperature on each side). The other two terms require more extensive derivation.

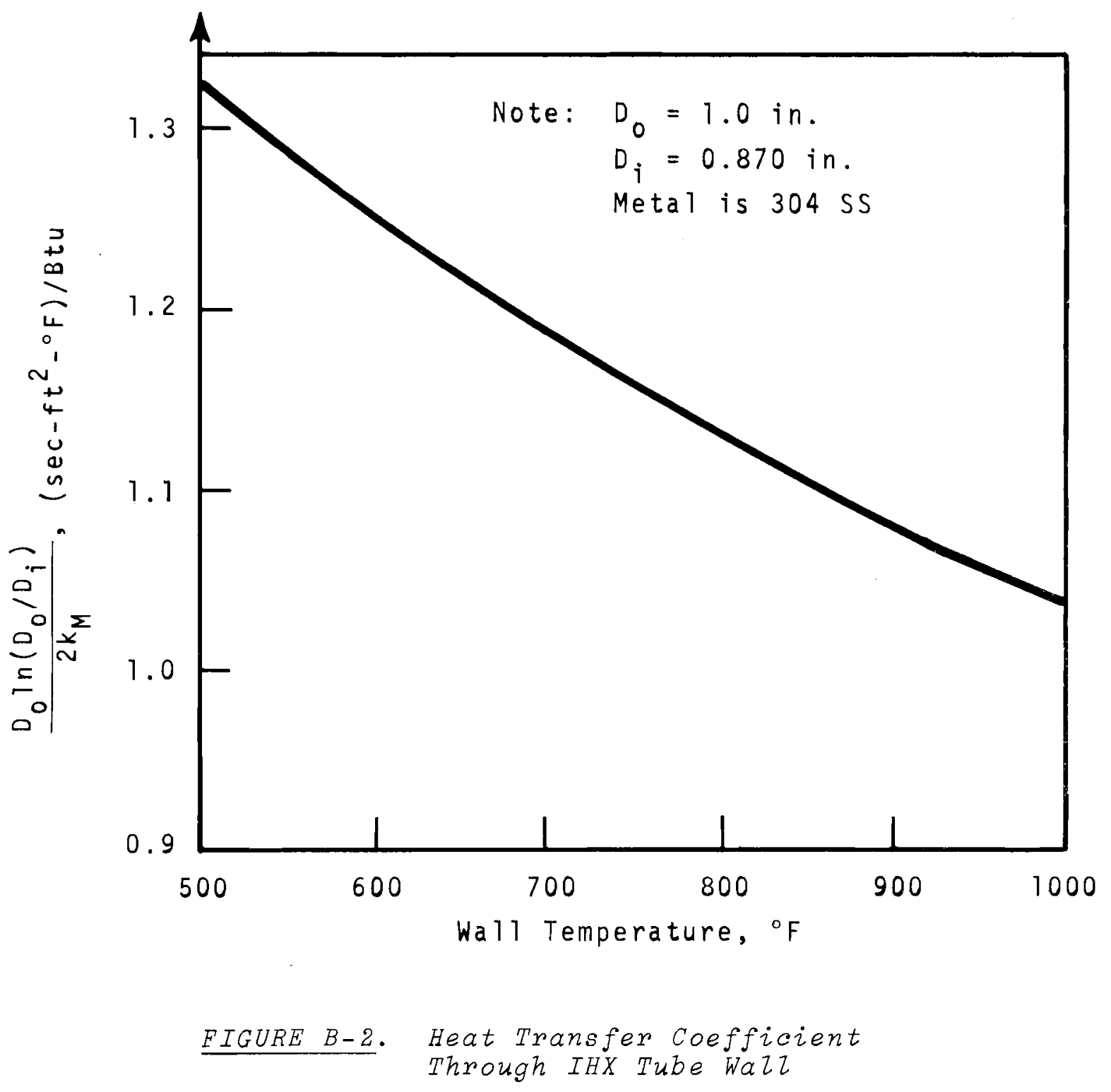




\section{FILM COEFFICIENTS}

Film coefficients for sodium flow inside and outside the IHX tubes are obtained as functions of flow and temperature. The basic work of correlating experimental information to mathematical expressions was performed by O. E. Dwyer and M. W. Maresca. (6) The Nusselt number relations are as follows:

$h_{i}=\frac{k_{i}}{D_{i}}\left(N u_{i}\right)$, and $h_{0}=\frac{k_{0}}{D_{e}}\left(N u_{0}\right)$,

where $k_{i}$ and $k_{0}$ are sodium thermal conductivities at average temperatures inside and outside the tube, respectively; $\mathrm{Nu}_{i}$ and $\mathrm{Nu}_{0}$ are inside and outside Nusselt numbers, respectively. The equivalent outside diameter $\left(D_{e}\right)$ is based on the following :

$D_{e}=4 \frac{(\text { flow area })}{(\text { wetted perimeter })}=D_{0}\left[\frac{2 \sqrt{3}}{\pi}\left(\frac{p}{D_{0}}\right)^{2}-1\right]($ shell side)

For turbulent flow and pitch/diameter ratios between 1.3 and 3.0 , the Nusselt numbers may be expressed as

Tube Side: $N u_{i}=A+0.025\left(\bar{\psi}_{i} \mathrm{Pe}_{i}\right)^{0.8}$, and

She11 Side: $\mathrm{Nu}_{\mathrm{O}}=6.66+3.126\left(\mathrm{p} / \mathrm{D}_{\mathrm{O}}\right)+1.184\left(\mathrm{p} / \mathrm{D}_{\mathrm{o}}\right)^{2}$

$$
+0.0155\left(\bar{\psi}_{0} \mathrm{Pe}_{0}\right)^{0.86} \text {, }
$$

where $\mathrm{Pe}_{i}$ and $\mathrm{Pe}_{0}$ are the inside and outside Peclet numbers, respectively. The constant (A) accounts for data scatter and is given the value $A=5.0$. The $\bar{\psi}$ terms represent the average, effective ratio of the eddy diffusivity of heat transfer to that for momentum transfer and are defined as follows:

$$
\bar{\psi}=1-\frac{1.82}{\operatorname{Pr}\left(\varepsilon_{M} / v\right)_{\max }^{1.4}}
$$


where $\operatorname{Pr}$ is the Prandt 1 number, and $\bar{\psi}$ may only be positive. The factor $\left(\varepsilon_{\mathrm{M}} / v\right)$ is obtained from Dwyer's work, (16) as presented in Figure B-3. The familiar Peclet, Prandt1, and Reynolds numbers are as follows:

$$
\begin{aligned}
& \operatorname{Pe}=\frac{4 C(W)}{k\left(P_{W}\right)}, \\
& \operatorname{Pr}=\frac{\mu \cdot C}{k}, \\
& \operatorname{Re}=\frac{v D_{\rho}}{\mu},
\end{aligned}
$$

where $C$ is specific heat, $\mu$ is viscosity, $\rho$ is density, $W$ is flow rate, $P_{W}$ is wetted perimeter, $v$ is fluid velocity, and $D$ is the diameter ( $D_{i}$ for the tube side fluid and $D_{e}$ for the shell side fluid).

Design data for the IHX and appropriate sodium temperatures and flows are used to determine the foregoing parameters with the end result of inside and outside film coefficients as functions of flow and temperature. These results for the current IHX design are shown in Figures B-4 and $B-5$. On either side of the IHX, sodium temperature is assumed to be the average temperature.

The overall heat transfer coefficient $\left(U_{X}\right)$ is then computed from the information of Figures B-2, B-4, and B-5. At present, these families of curves are simulated on the analog computer with curve-fitting techniques; future modifications to the program will transfer such computations to the digital portion of the hybrid computer. It must be emphasized that this analysis is valid only for fully developed turbulent flow. Heat transfer will change markedly below Re 23000 , corresponding to flow rates of about $2 \%$ of FFTF design flow. For current plans, the simulation is adequate; however, should laminar flow regions be of interest in future work, the model may easily be altered to account for it. 


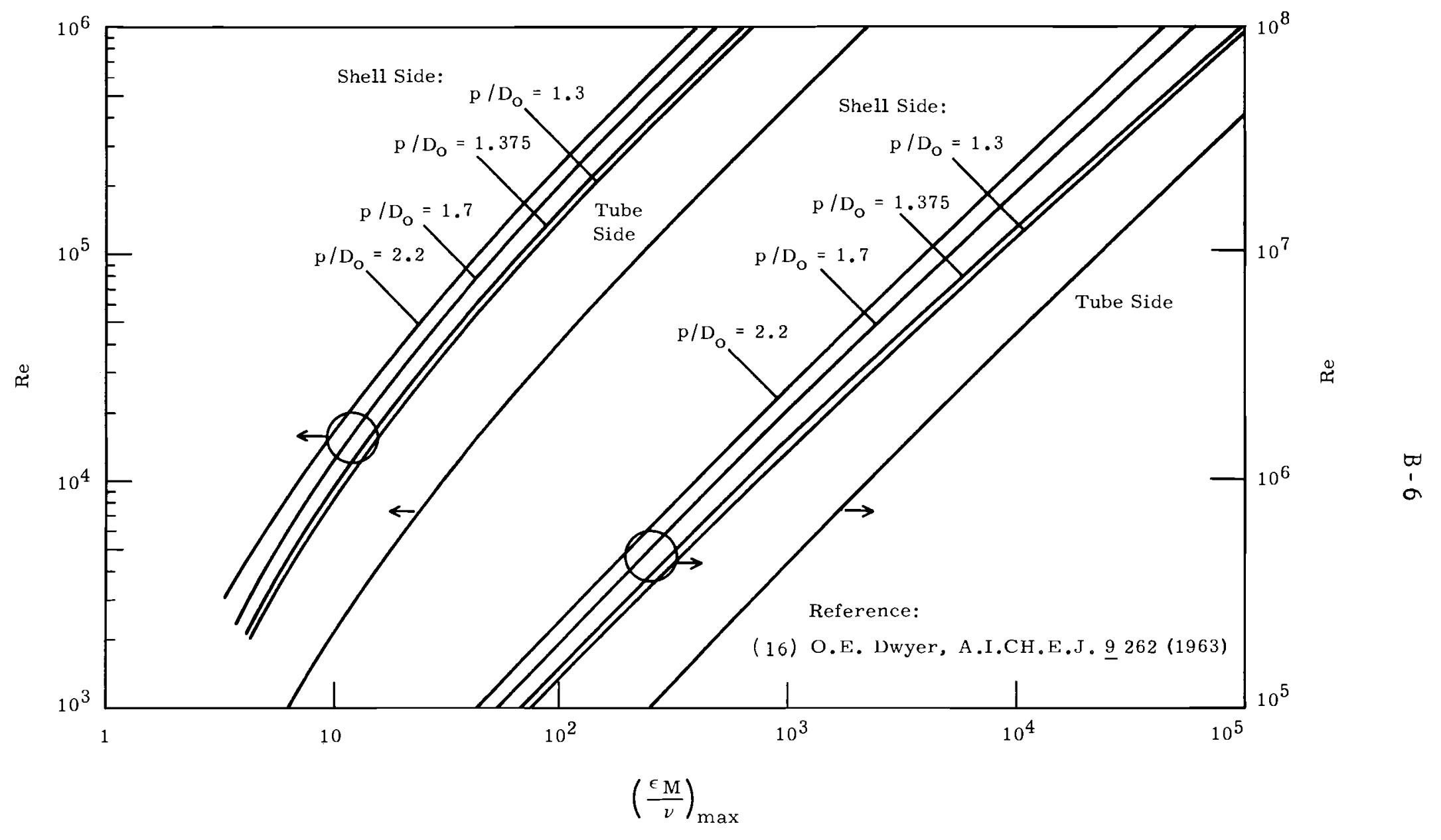

FIGURE B-3. Value of $\left(\frac{\varepsilon}{v}\right)_{\max }$ for Fully Established Turbulent Flow of Liquid Metals Through Circular Tubes, and Rod Bundles with Equilateral spacing 


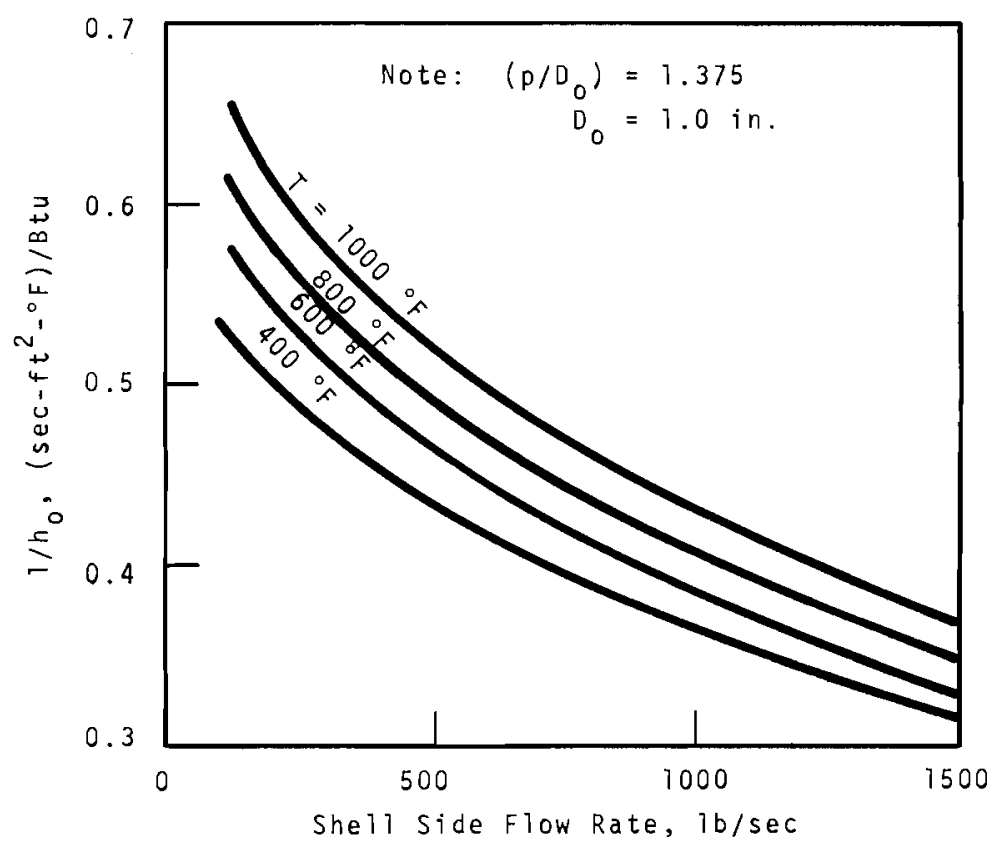

FIGURE B-4. Shell Side IHX Inverse Film Coefficient

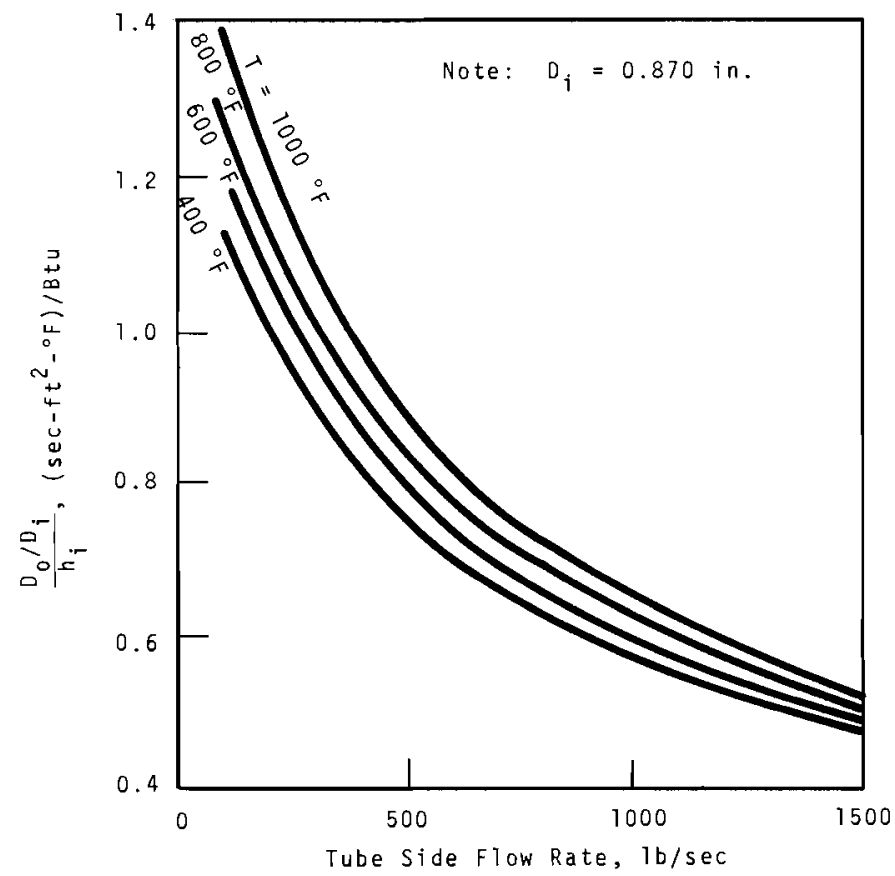

FIGURE B-5. Tube Side IHX Inverse Film Coefficient 


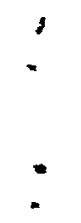


BNWL -707

\author{
APPENDIX C \\ PRIMARY AND SECONDARY COOLANT LOOPS HYDRAULICS THEORY
}

4 


\section{APPENDIX C \\ PRIMARY AND SECONDARY COOLANT LOOPS HYDRAULICS THEORY}

The hydraulics model used in the FFTF Dynamics Hybrid Simulation was derived from Newton's second law of motion applied to a viscous noncompressible fluid and nonsteady flow. The equation is

$$
-\frac{g_{c}}{\rho} \frac{\partial P}{\partial S}-g \frac{\partial Z}{\partial S}-\frac{g_{c}{ }^{\tau}}{\rho} \frac{2}{r}=\frac{\partial}{\partial S} \frac{u^{2}}{2}+\frac{\partial u}{\partial t},
$$

where $S=$ axial distance along flow path

$r=$ radius of flow path

$u=$ fluid velocity

$\tau=v$ iscous force.

The following derivation assumes that all loop pressure losses can be expressed as equivalent straight pipe pressure losses. Therefore, the following relations apply

$$
\begin{aligned}
\tau & =\frac{h_{L} \rho r}{2 L} \\
h_{L} & =f(L / D) u^{2} / 2 g_{C} \\
u & =\frac{W}{\rho A}
\end{aligned}
$$

where $h_{L}=$ head loss

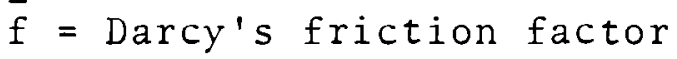

$\mathrm{L} / \mathrm{D}=$ pipe length/diameter ratio.

If we assume that the weight flow rate is the same at any point in a pipe section and that the coolant density is constant in the pipe section, substitution of Equation (C-2), $(\mathrm{C}-3)$, and $(\mathrm{C}-4)$ into Equation (C-1) yields the following equation:

$$
-\frac{\partial P}{\partial S}-\rho \frac{\partial Z}{\partial S}-f \frac{W^{2}}{2 g_{C} D A^{2} \rho}=\frac{W^{2}}{2 g_{C} \rho} \frac{\partial}{\partial S}\left(\frac{1}{A^{2}}\right)+\frac{1}{g_{C} A} \frac{W}{t} .
$$


Integration over a section with constant cross-sectional area then yields

$$
-(\Delta P)_{i}-\rho_{i}(\Delta Z)_{i}-\frac{f_{i} W_{i}^{2}(\Delta L)_{i}}{2 g_{C} D_{i} A_{i}^{2} \rho_{i}}=\frac{(\Delta L)_{i}}{g_{C} A_{i}} \frac{\partial W_{i}}{\partial t}
$$

where $i$ indicates parameters and variables for the ith section. Equation (C-6) assumes friction and inertial losses are for uniform pipe sections. For a closed loop, $\Sigma(\Delta P)_{i}=0$, and $\Sigma($ Kinetic Energy) $=0$. Therefore, summation of Equation (C-6) around a closed loop yields

$$
\rho H_{p}-\int \rho d z-\frac{W^{2}}{2 g_{c}} \sum \frac{f_{i}(\Delta L)_{i}}{D_{i} A_{i}^{2} \rho_{i}}=\frac{1}{g_{c}}\left[\sum \frac{(\Delta L)_{i}}{A_{i}}\right] \frac{d w}{d t}
$$

where $W=$ flow per loop

$$
\begin{aligned}
H_{p} & =\text { pump head encountered by flowing fluid } \\
\int \rho d Z & =\Sigma \rho_{i}(\Delta Z)_{i}=\text { natural circulation pressure head. }
\end{aligned}
$$

Let the inertance coefficient, $\ell$, be defined by the following relation

$$
\ell=\frac{1}{g_{c}} \sum \frac{(\Delta L)_{i}}{A_{i}} \quad(\text { explained in detail 1ater) }
$$

and the friction pressure drop $(\Delta P)_{f}$ be defined as

$$
(\Delta P)_{f}=\frac{W^{2}}{2 g_{c}} \sum \frac{f_{i}(\Delta L)_{i}}{D_{i} A_{i}^{2} \rho_{i}} \text {. }
$$

The following assumption was made: $f_{i}$ is governed by a smooth pipe relationship ( $r_{0} / \varepsilon \approx 10^{4}$ for stainless steel) and turbulent flow. By inspection of the Moody Diagram, the Darcy friction factor ( $f_{i}$ ) for turbulent flow, can be approximated by the following empirical equation 


$$
f_{i}=K_{f} \operatorname{Re}_{i}^{-\alpha} f
$$

where $\operatorname{Re}_{i}=$ Reynolds number of the section

$$
\begin{aligned}
& k_{f}=0.184 \\
& \alpha_{f}=0.2 .
\end{aligned}
$$

The Reynold's number can be written as

$$
\operatorname{Re}_{i}=\frac{4 W}{P_{w i}{ }^{\mu}}
$$

where $P_{\text {wi }}$ is the wetted perimeter of the flow cross section, and $\mu_{i}$ is the coolant viscosity for the section. Substitution of Equations $(\mathrm{C}-10)$ and $(\mathrm{C}-11)$ in Equation $(\mathrm{C}-9)$ yields

$$
(\Delta P)_{f}=\frac{K_{f}(W)^{2-\alpha_{f}}}{g_{C}(2)^{3+2 \alpha_{f}}} \sum \frac{(\Delta L)_{i}\left(P_{w i}\right)^{1+\alpha_{f}}}{A_{i}^{3}} \frac{\left(\mu_{i}\right)^{\alpha_{f}}}{\rho_{i}} .
$$

Assuming constant density and viscosity for all sections in the loop, and substituting the known constants, Equation (C-12) becomes (units are in $1 b$, ft, and sec):

$$
(\Delta \mathrm{P})_{\mathrm{f}}=\left(2.709 \times 10^{-4}\right) \frac{(\mu)^{0.2}}{\rho}\left[\sum \frac{\left(\mathrm{P}_{\mathrm{wi}}\right)^{1.2}(\Delta \mathrm{L})}{\mathrm{i}} \mathrm{A}_{\mathrm{i}}^{3} \mathrm{w}^{1.8}\right. \text {. }
$$

Equation (C-13) can be expressed more simply as

$$
(\Delta P)_{f}=C_{f} W^{1.8}
$$

where $C_{f}=\left(2.709 \times 10^{-4}\right) \frac{(\mu)^{0.2}}{\rho} \sum \frac{\left(P_{w i}\right)^{1.2}(\Delta L)}{i} A_{i}^{3}$.

Rather than summing up equivalent straight pipe pressure losses as calculated in Equation (C-13), a simpler approach may be taken. If the primary and secondary pressure losses and flows at steady state are known from design 
conditions, Equation (C-14) can be used to calculate the pressure loss coefficient $\left(\mathrm{C}_{\mathrm{f}}\right)$ for both primary and secondary loops as follows.

Primary Loop:

$$
C_{f p}=\frac{(\Delta P)_{f p}}{w_{p}^{1.8}} \text {, }
$$

Secondary Loop:

$$
C_{f s}=\frac{(\Delta P)_{f s}}{W_{s}^{1.8}},
$$

where $(\Delta P)_{f p}=$ total primary 1oop pressure 1oss, $1 \mathrm{~b} / \mathrm{ft}^{2}$

$\left(\Delta P_{f s}^{f p}=\right.$ total secondary loop pressure loss, $1 \mathrm{~b} / \mathrm{ft}^{2}$

$W_{p}=$ primary flow per loop, $1 \mathrm{~b} / \mathrm{sec}$

$W_{S}^{p}=$ secondary flow per loop, $1 \mathrm{~b} / \mathrm{sec}$.

The inertance coefficients for the primary and secondary loops are calculated from Equation (C-8). The inertance terms for pipe sections can be calculated directly. In the heat exchangers (IHX and DHX) the inertance is calculated as the inlet-to-outlet length divided by the total flow area. The reactor inertance is more difficult to calculate, however, since nonuniform parallel flow paths are involved. The total primary flow splits three ways in the reactor vessel:

1) driver fuel and open loop tubes, 2) bypass leakage, and 3) radial reflector. An equivalent reactor vessel inertance $\left(\ell_{R V}\right)$ can be calculated as follows:

$$
\frac{1}{\ell_{R V}}=\frac{1}{\ell_{1}}+\frac{1}{\ell_{2}}+\frac{1}{\ell_{3}}
$$

where $\ell_{1}=$ inertance of driver fuel and open loop tubes

$\ell_{2}=$ inertance of leakage region

$\ell_{3}=$ inertance of radial reflector region. 
Each individual inertance is calculated as follows. Tube Inertance:

$$
\ell_{1}=\frac{1}{g_{c}} \frac{\Delta L_{T}}{N_{E R} \bar{A}_{T}}
$$

where $\Delta \mathrm{L}_{\mathrm{T}}=$ total tube length through reactor

$\mathrm{N}_{E R}=$ number of equivalent driver fuel elements

$\overline{\mathrm{A}}_{\mathrm{T}}=$ average flow area per fuel and open loop tube for total tube length (calculated on a length weighted basis to account for different tube cross-sections along the tube length);

$$
\bar{A}_{T}=\frac{\sum A_{j} \Delta L_{j}}{\Delta \mathrm{L}_{T}}
$$

where $A_{j}=$ flow area of tube section $j$

$\Delta L_{j}=1$ length of tube section $j$ with flow area $A_{j}$.

Leakage Inertance:

$$
\ell_{2}=\frac{1}{g_{c}} \frac{\Delta L_{L}}{\bar{A}_{L}}
$$

where $\Delta L_{L}=$ bypass leakage length through reactor

$$
\overline{\mathrm{A}}_{\mathrm{L}}=\text { average leakage flow area through reactor. }
$$

Radial Reflector Inertance:

$$
\ell_{3}=\frac{1}{\mathrm{~g}_{\mathrm{c}}} \frac{\Delta \mathrm{L}_{\mathrm{RR}}}{\overline{\mathrm{A}}_{\mathrm{RR}}}
$$

where $\Delta L_{R R}=$ radial reflector length through reactor

$\overline{\mathrm{A}}_{\mathrm{RR}}=$ average radial reflector flow area through reactor. 
Substituting Equations (C-19), (C-21), and (C-22) into Equation (C-18), we get

$$
\frac{1}{\ell_{R V}}=g_{C}\left(\frac{N_{E R} \bar{A}_{T}}{\Delta L_{T}}+\frac{\bar{A}_{L}}{\Delta L_{L}}+\frac{\bar{A}_{R R}}{\Delta L_{R R}}\right) \text {. }
$$

If we assume that the lengths of the three paths are identical (reasonable for FTR), Equation (C-23) reduces to

$$
\frac{1}{{ }_{R V}}=g_{C}\left(\frac{N_{E R} \bar{A}_{T}+\bar{A}_{L}+\bar{A}_{R R}}{\Delta L_{R}}\right)
$$

where $\Delta \mathrm{L}_{\mathrm{R}}=\Delta \mathrm{L}_{\mathrm{T}}=\Delta \mathrm{L}_{\mathrm{L}}=\Delta \mathrm{L}_{\mathrm{RR}}$.

Inverting Equation (C-24), we get

$$
\ell_{R V}=\frac{1}{g_{c}} \frac{\Delta L_{R}}{N_{E R} \bar{A}_{T}+\bar{A}_{L}+\bar{A}_{R R}} \text {. }
$$

Since the flow per loop is calculated in Equation (C-7), the inertance term for the reactor vessel must be multiplied by the number of primary loops, $\left(\mathrm{N}_{\mathrm{PL}}\right)$. Therefore, the inertance term for the reactor vessel in Equation $(\mathrm{C}-8)$ is

$$
\ell_{R V}=\frac{1}{g_{c}} \frac{N_{P L} \Delta L_{R}}{N_{E R} \bar{A}_{T}+\bar{A}_{L}+\bar{A}_{R R}} .
$$

The natural circulation term is approximated by

$$
\int \rho d z=(\Delta Z) \frac{\partial \rho}{\partial T}\left(T_{A H}-T_{A C}\right)
$$

where $\mathrm{T}_{\mathrm{AH}}$ and $\mathrm{T}_{\mathrm{AC}}$ are the average hot and cold leg temperatures, respectively, and $(\partial \rho / \partial \mathrm{T}) \simeq-0.0082 \mathrm{lb} / \mathrm{ft}^{3}{ }^{\circ} \mathrm{F}$ (slope of sodium density versus temperature curve). The term $\Delta Z$ is the net elevation difference between the core and IHX in the primary loop, and between the IHX and DHX centerlines in the secondary loop. 
Substituting Equations (C-8), (C-14), and (C-27) into Equation ( $\mathrm{C}-7)$, we obtain the expression that represents primary and secondary sodium hydraulics:

$$
\ell \frac{d W}{d t}=\rho H_{p}+0.0082(\Delta Z)\left(T_{A H}-T_{A C}\right)-C_{f} W^{1.8} \quad(\mathrm{C}-28)
$$

where all terms are defined previously. 


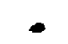

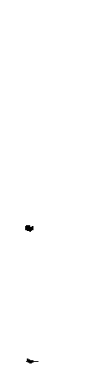

-

-
$i$
$i$

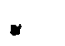

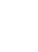

, 
BNWL - 707

\section{APPENDIX D}

DHX CONSTANTS AND HEAT TRANSFER COEFFICIENTS 
$-$

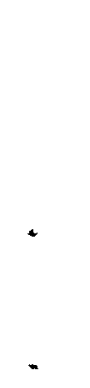

3

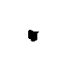




\section{APPENDIX D}

\section{DHX CONSTANTS AND HEAT TRANSFER COEFFICIENTS}

The DHX finned tubes are arranged on an equilateral triangular pitch as shown in Figure D-1.

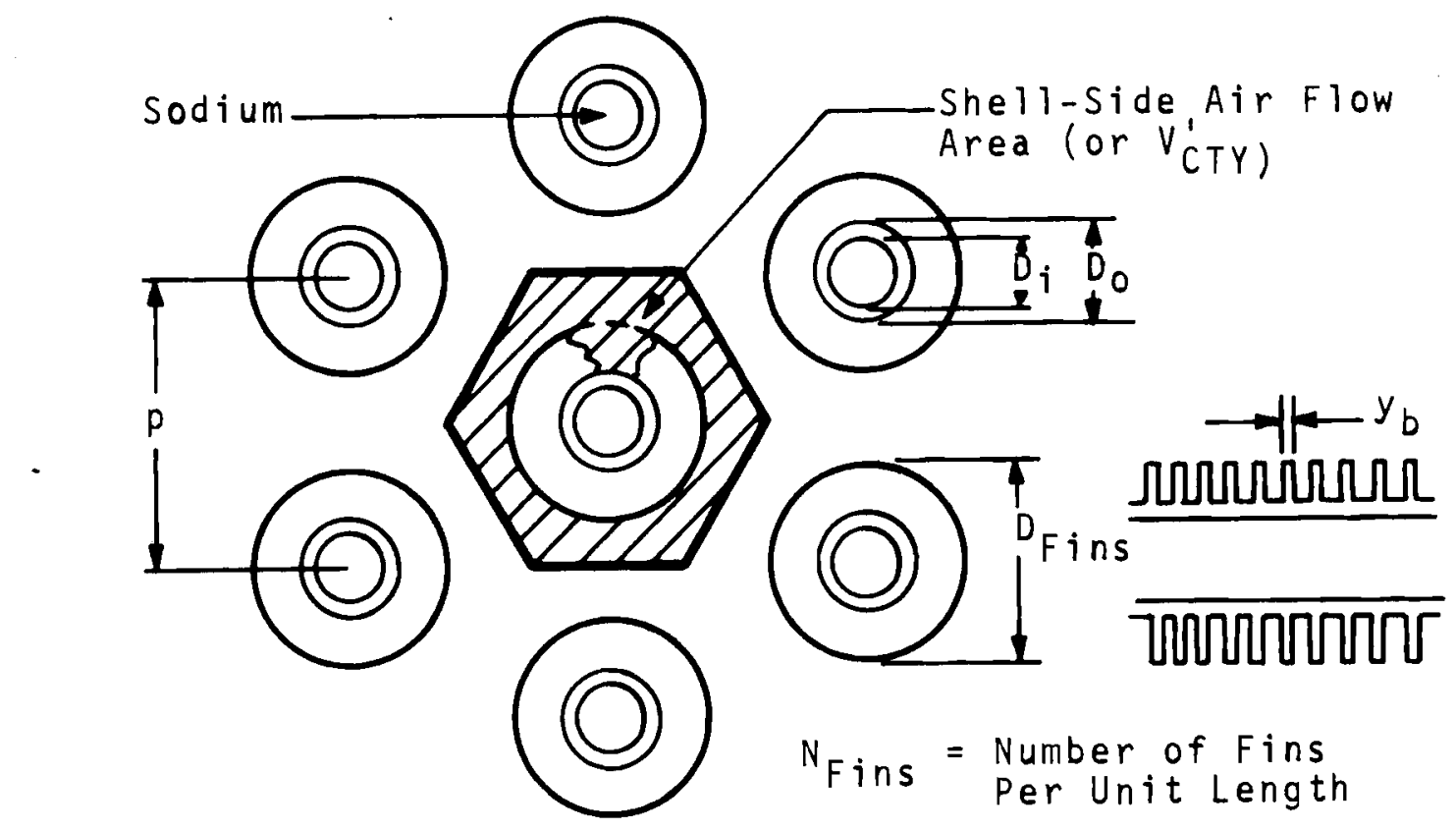

\section{FIGURE D-1. DHX Tube and Fin Geometry}

\section{DHX CONSTANTS}

All volumes and areas are calculated per foot of tube length and are denoted by $V^{\prime}$ and $A^{\prime}$. From Figure D-1 the following DHX parameters may be calculated.

Shel1-Side Flow Volume Per Unit Length (Air Flow):

$V^{\prime}{ }_{\text {CTY }}=N_{\text {TMY }}\left[V^{\prime}{ }_{\text {Hex }}-V^{\prime}\right.$ Tube $-V^{\prime}$ Fins $]$

$V_{\text {CTY }}^{\prime}=N_{\text {TMY }}\left[0.866 p^{2}-\frac{\pi}{4} D_{o}^{2}-N_{\text {Fins }} \cdot y_{b} \cdot \frac{\pi}{4}\left(D_{\text {Fins }}^{2}-D_{0}^{2}\right)\right]$, 
Tube-Side Flow Volume Per Unit Length (Secondary Sodium):

$$
V^{\prime}{ }_{C S Y}=N_{T M Y} \cdot \frac{\pi D_{i}^{2}}{4},
$$

Tube Metal Volume Per Unit Length:

$$
\begin{aligned}
V_{M Y}^{\prime}= & N_{\text {TMY }}\left[V^{\prime}{ }_{\text {Tube }}+V_{\text {Fins }}^{\prime}\right] \\
V_{\text {MY }}^{\prime}= & N_{\text {TMY }}\left[\frac{\pi}{4}\left(D_{0}^{2}-D_{i}^{2}\right)+N_{\text {Fins }} \cdot y_{b}\right. \\
& \left.\cdot \frac{\pi}{4}\left(D_{\text {Fins }}^{2}-D_{0}^{2}\right)\right]
\end{aligned}
$$

where $\mathrm{N}_{\mathrm{TMY}}=$ number of tubes per DHX module

$N_{\text {Fins }}=$ number of fins per unit length

Other nomenclature in Figure D-1.

To obtain the stored heat terms used in the simulation, the tube metal heat storage is lumped with the secondary sodium heat storage.

Secondary Stored Heat Per Unit Length, Tube Side (Sodium):

$$
\left(\rho V^{\prime} C\right)_{S Y}^{*}=(\rho C)_{N a} V^{\prime}{ }_{C S Y}+(\rho C)_{M} V^{\prime}{ }_{M Y},
$$

Tertiary Stored Heat Per Unit Length, Shell Side (Air):

$$
\left.\left(\rho V^{\prime} \mathrm{C}\right)_{\mathrm{TY}}={ }^{(\rho \mathrm{C})}\right)_{\mathrm{Air}} \cdot \mathrm{V}^{\prime}{ }_{\mathrm{CTY}}
$$

where $(\rho C)_{\mathrm{Na}},(\rho C)_{\mathrm{M}}$, and $(\rho C)_{\mathrm{Air}}$ are the products of density and specific heat for sodium, tube metal, and air, respectively. These properties are assumed constant and are based on the average steady-state temperatures, with the tube metal assumed to be at the same temperature as the tube side secondary sodium.

Heat Transfer Area Per Unit Length:

The heat transfer area is based on the tube inside surface area since it is easily calculated. The outside 
film coefficient and tube wall resistance are both corrected to account for this assumption.

$$
A_{Y}^{\prime}=N_{T M Y} \pi D_{i} \text {. }
$$

\section{HEAT TRANSFER COEFFICIENT}

The overall DHX heat transfer coefficient is calculated by the following formula:

$$
U_{Y}=\left[\frac{1}{h_{i}}+\frac{D_{i} \ln \left(D_{0} / D_{i}\right)}{2 k_{M}}+\frac{1}{h_{0}}\right]^{-1}
$$

where $h_{i}$ and $h_{0}$ are the tube inside and outside film coefficients, respectively, $k_{M}$ is the base tube metal thermal conductivity, and $D_{i}$ and $D_{0}$ are inside and outside tube diameters, respectively.

The inside film coefficient $\left(h_{i}\right)$ is calculated in the same manner as the IHX inside film coefficient (see Appendix $B$ ). The tube wall coefficient is for simple cylindrical heat transfer and is based on the tube inside surface. The metal thermal conductivity is a function of tube temperature which is assumed to be identical to the tube side sodium temperature. The shell-side air film coefficient requires further explanation.

Shell-Side DHX Air Film Coefficient

The shell-side film coefficient is calculated for air flowing across finned tube banks and is based on the tube inside surface. Transverse fins of uniform thickness are assumed. Data generated by Jameson ${ }^{(17)}$ has been arranged by Kern $(18)$ in the form of a Sieder-Tate heat transfer factor, as shown in Figure D-2 (curve $b$ in Figure D-2 is used for the air pressure loss calculation in the tertiary hydraulics model, Section 3.8). The " $j$ " factor in Figure $D-2$ is plotted against the air flow Reynolds number and is represented by the following expression: 


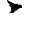

. 
film coefficient and tube wall resistance are both corrected to account for this assumption.

$$
A_{Y}^{\prime}=N_{T M Y} \pi D_{i}
$$

\section{HEAT TRANSFER COEFFICIENT}

The overall DHX heat transfer coefficient is calculated by the following formula:

$$
U_{Y}=\left[\frac{1}{h_{i}}+\frac{D_{i} \ln \left(D_{o} / D_{i}\right)}{2 k_{M}}+\frac{1}{h_{0}}\right]^{-1}
$$

where $h_{i}$ and $h_{0}$ are the tube inside and outside film coefficients, respectively, $k_{M}$ is the base tube metal thermal conductivity, and $D_{i}$ and $D_{0}$ are inside and outside tube diameters, respectively.

The inside film coefficient $\left(h_{i}\right)$ is calculated in the same manner as the IHX inside film coefficient (see Appendix $B)$. The tube wall coefficient is for simple cylindrical heat transfer and is based on the tube inside surface. The metal thermal conductivity is a function of tube temperature which is assumed to be identical to the tube side sodium temperature. The shell-side air film coefficient requires further explanation.

Shel1-Side DHX Air Film Coefficient

The shell-side film coefficient is calculated for air flowing across finned tube banks and is based on the tube inside surface. Transverse fins of uniform thickness are assumed. Data generated by Jameson (17) has been arranged by Kern $(18)$ in the form of a Sieder-Tate heat transfer factor, as shown in Figure D-2 (curve $b$ in Figure $D-2$ is used for the air pressure loss calculation in the tertiary hydraulics model, Section 3.8). The "j" factor in Figure D-2 is plotted against the air flow Reynolds number and is represented by the following expression: 


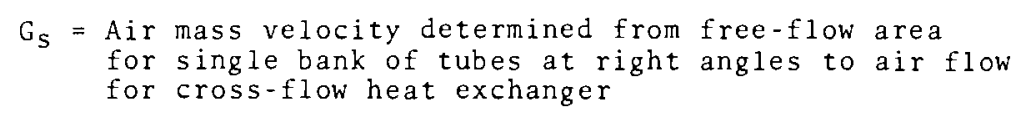

$\dot{D}_{\mathrm{v}}=(4)$ (Net Free Volume/Frictional Surface)

De $=\frac{(2) \text { (Fin Area }+ \text { Bare Tube Area) }}{(\pi) \text { (Projected Perimeter) }}$

$\Delta P=\frac{(f)\left(G_{S}^{2}\right)(L)}{\left(5.22 \times 10^{10}\right)\left(D^{\prime}{ }_{v}\right)(S)\left(\phi_{S}\right)}\left(\frac{D^{\prime} v}{S_{T}}\right)^{0.4}\left(\frac{S_{L}}{S_{T}}\right)^{0.6}$

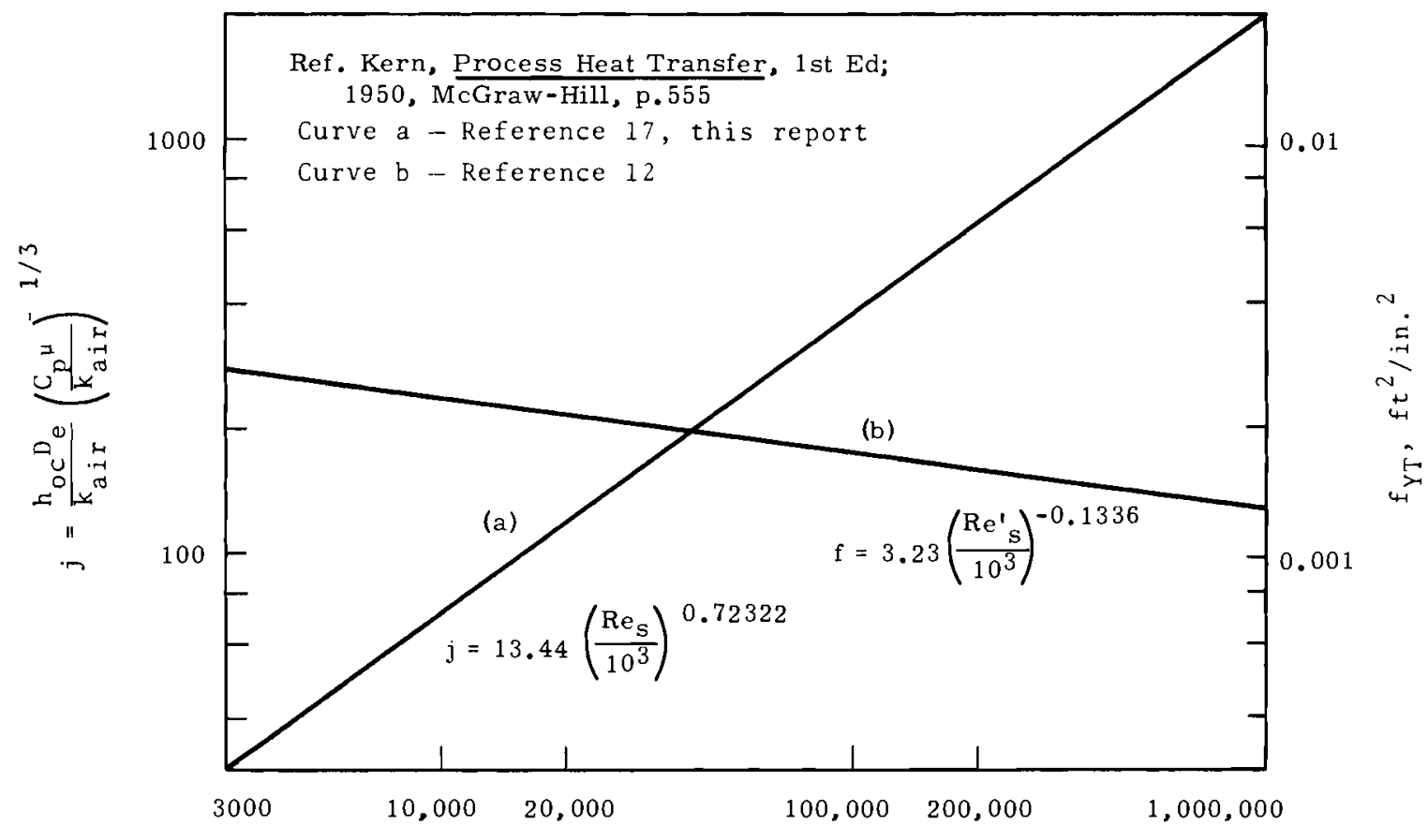

(a) $\operatorname{Re}_{\mathrm{S}}=\mathrm{DeG}_{\mathrm{S}} / \mu$ (Heat Transfer)

(b) $\operatorname{Re}_{\mathrm{S}}^{\prime}=\mathrm{De}_{\mathrm{v}} \mathrm{G}_{\mathrm{S}} / \mu$ (Hydraulics)

FIGURE D-2. Transverse-Fin Heat Transfer and Pressure Drop

$$
j=\frac{h_{o c} \mathrm{D}_{\mathrm{e}}}{\mathrm{k}_{\text {air }}(\operatorname{Pr})^{1 / 3}}
$$

where $h_{o c}$ is the clean air-film-coefficient (fin efficiency not included), $k_{a i r}$ is air conductivity, $\operatorname{Pr}$ is air Prandt 1 number, and $D_{e}$ is outside equivalent diameter. All air physical properties are a function of the DHX (inlet-outlet) 
average air temperature. The air flow Reynolds number (abscissa in Figure D-2) is calculated as:

$$
R_{e}=\frac{D_{e} S_{s}}{\mu} \text {, }
$$

where $G_{S}$ is the mass velocity (units, $I b / s e c-f t^{2}$ ) determined from the free-flow area for a single bank of tubes located at right angles to the air flow (i.e., as in the cross-flow arrangement). The equivalent diameter $\left(D_{e}\right)$ in the " $j$ " factor equation and the Reynolds number equation is calculated as follows:

$$
D_{e}=\frac{2\left(A^{\prime}{ }_{1}+A^{\prime}{ }_{2}\right)}{\pi x_{1}}
$$

where $\mathrm{A}^{\prime}{ }_{1}=$ fin surface per unit length

$$
\begin{aligned}
& =\frac{2 \pi}{4}\left(D_{F i n}^{2}-D_{0}^{2}\right) N_{\text {Fins }} \\
A_{2}^{\prime} & =\text { bare tube surface per unit length } \\
& =\pi D_{0}-\pi D_{0} N_{F i n s} y_{b} \\
x_{1} & =\text { projected perimeter per unit length } \\
& =2 N_{\text {Fins }}\left(D_{\text {Fins }}-D_{0}\right)+2\left(I-N_{\text {Fins }} y_{b}\right)
\end{aligned}
$$

(all terms are given in Figure D-1). The projected perimeter is the sum of all external distances in the plan view of a transverse finned tube. The surface on the outer edge of the fin is neglected since the fins are usually very thin (on the order of $0.03 \mathrm{in}$. or less).

From the Reynolds number, the "j" factor is obtained from Figure D-2. A clean air-film-coefficient (hoc) is then calculated from the " $j$ " factor by rearranging Equation (D-8). This clean air-film-coefficient is then degraded to account for fouling:

$$
h_{\text {of }}=\frac{h_{\text {oc }} / R_{\text {foul }}}{h_{\text {oc }}+1 / R_{\text {foul }}} \text {. }
$$


The actual outside film coefficient $\left(h_{0}\right)$ based on the tube inside surface area is then calculated from the fin efficiency curves given in Figure D-3 for annular fins of constant thickness. The fin efficiency $(\Omega)$ from Figure $D-3$ corrects the fin surface area and, therefore, is multiplied times $\mathrm{A}^{\prime}{ }_{1}$ in the following equation for $\mathrm{h}_{\mathrm{o}}$ :

$$
h_{0}=\left(\Omega A^{\prime}{ }_{1}+A^{\prime}{ }_{2}\right) \frac{h_{o f}}{\pi D_{i}} .
$$

To simulate the overall DHX heat transfer coefficient, the inside and outside film coefficients are plotted as functions of flow and average coolant temperature in the same manner as in the IHX model. The metal conductivity term is

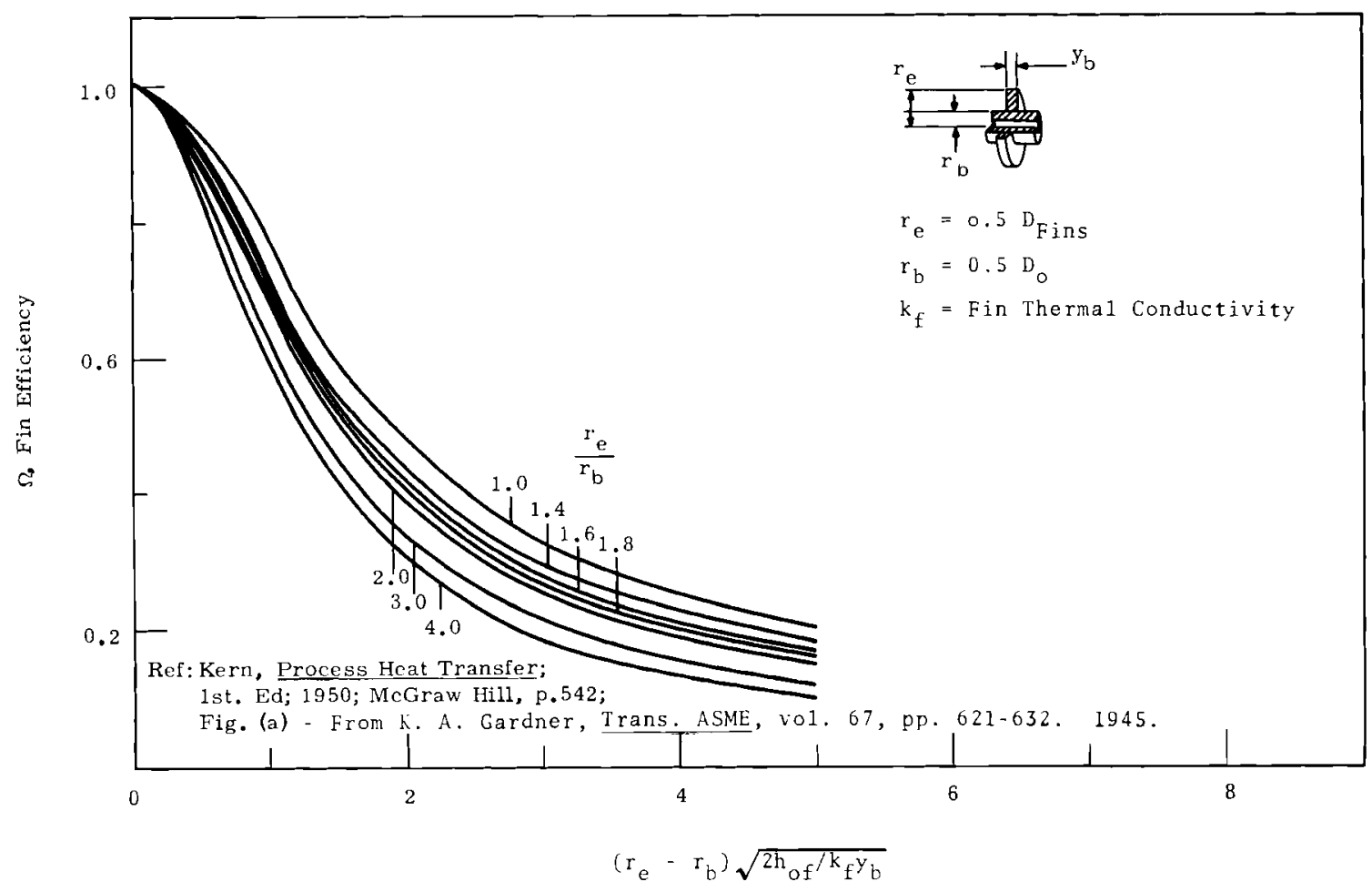

FIGURE D-3. Efficiency of Annular Fins of Constant Thickness 
also treated the same as it was in the IHX model. The curves are then simulated by curve-fitting techniques on the analog computer. The overall coefficient $\left(U_{Y}\right)$ is obtained by summing the terms and inverting as per Equation (D-7). Both air and sodium film coefficients are calculated for turbulent flow only in the present model. Future modifications can easily be made, if necessary, to account for laminar flow. 
:

.

.

-

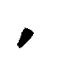

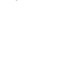

$\dot{5}$

$+$

.

.

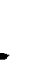




$$
\text { Distr- } 1
$$

BNWL - 707

Number of Copies

$$
\frac{\text { U.S. Atomic Energy Commission }}{\text { Washington, D. C. }}
$$

M. Shaw, Director, RDT Asst Dir for Nuclear Safety Analysis \& Evaluation Br, RDT:NS Environmental \& Sanitary Engrg $\mathrm{Br}, \mathrm{RDT}: \mathrm{NS}$

Research \& Development Br, RDT:NS Asst Dir for Plant Engrg, RDT Applications \& Facilities $\mathrm{Br}, \mathrm{RDT}: \mathrm{PE}$ Components $\mathrm{Br}$, RDT:PE

Instrumentation \& Control $\mathrm{Br}, \mathrm{RDT}: \mathrm{PE}$ Systems Engineering $\mathrm{Br}, \mathrm{RDT}: \mathrm{PE}$ Asst Dir for Program Analysis, RDT Asst Dir for Project Mgmt, RDT Liquid Metals Projects Br, RDT:PM FFTF Project Manager, RDT:PM Asst Dir for Reactor Engrg Control Mechanisms Br, RDT:RE

Core Design $\mathrm{Br}$, RDT:RE (2)

Fue 1 Fabrication $\mathrm{Br}$, RDT:RE

Fue 1 Handling $\mathrm{Br}, \mathrm{RDT}: \mathrm{RE}$

Reactor Vessels Br, RDT:RE

Asst Dir for Reactor Tech

Chemistry \& Chemical Separations $\mathrm{Br}, \mathrm{RDT}: \mathrm{RT}$ (2)

Fuels \& Materials $\mathrm{Br}$, RDT:RT

Reactor Physics Br, RDT:RT

Special Technology $\mathrm{Br}$, RDT : RT

Asst. Dir for Engrg Standards

AEC Chicago Patent Group

G. H. Lee, Chief

R. K. Sharp (Richland)

AEC Division of Technical Extension

AEC Division of Technical Extension

UK/U.S. Fast Reactor Exchange (12)

EURATOM/U.S. Fast Reactor Exchange

AEC Idaho Operations Office

C. W. Bills, Director

AEC RDT Site Representatives - PNL

P. G. Holsted

(2)

L. R. Lucas

A. D. Toth 
Number

of Copies

AEC Richland Operations Office

C. L. Robinson

J. M. Shivley

Technical Information Library

1

AEC San Francisco Operations Office

Director, Reactor Division

4

AEC Site Representatives

Argonne National Laboratory

Atomics International

Atomic Power Development Assoc.

General Electric Co.

2

Argonne National Laboratory

R.A. Jaross

LMFBR Program Office

2

Atomics International

L. E. Glasgow

Liquid Metal Engrg Center

R。W. Dickinson

Atomic Power Development Assoc.

Document Librarian

2

Babcock \& Wilcox Co.

Atomic Energy Division

S. H. Esleeck

Boiler Division

T.P.Farrell

1

Combustion Engineering

1000 MWe Follow-On Study

W。 P. Staker, Project Manager

3

Douglas-United Nuclear

Files

4

General Electric Co. Advanced Products Operation

$K$. Cohen

B. Wolfe

Gulf General Atomic Inc. General Atomic Div.

D. Coburn 
Number

of Copies

1

Idaho Nuclear Corporation

D. R. deBoisblanc

1

PNL Representative

N.A.Hill (ZPR-III)

1 Stanford University

Nuclear Division

Division of Mechanical Engrg

R. Sher

5

Westinghouse Electric Corp. Atomic Power Division Advanced Reactor Systems

J. C. R. Kelly

Battelle-Northwest

S. O. Arneson

E. R. Astley

J。M.Batch

T。 Bauman

R. D. Benham

R. A. Bennett

D. C. Boyd

C. L. Brown

W. L. Bunch

C. M. Cantrell

J. R. Carrel1

W. E。 Cawley

W. L。 Chase

D. L. Condotta

$R$. R. Cone

G. M. Dalen

J.M. Davidson

F. G. Daws on

M. H. Deardorff

V.A. Deliso

D。 R。 Doman

G. E. Driver

R. V. Dulin

E. A. Evans

L. M. Finch

C. D. Flowers (10)

L. H. Gerhardstein

A. L。Gunby
B. R. Hayward

R。 J . Hennig

P. L. Hofmann

B. M. Johnson

H. G. Johns on

$\mathrm{J}$. H. King inger

H. D. Lenkersdorfer

W. W. Little

R. N. Madsen

W. B. McDonald

C. A. Munro

C. R。Nash

A. Padilla

C. L. Peckinpaugh

R. E. Peterson

J. J. Regimbal

W. E. Roake

R. B. Rothrock

F. H. Shadel

D. E. Simpson

C. R. F. Smith

R. J. Squires

D. D. Stepnewski

G. H. Strong

C.D. Swanson

G. G. Thieme

J. C. Tobin

K. G. Toyoda 
Battelle-Northwest (contd)

M. A. Vogel

R. C. Walker

J. H. Westsik

L. A. Whinery

N. G. Wittenbrock

M. R. Wood

F. W. Woodfield

G. A. Worth

FFTF File (5)

Technical Information Files

Technical Publications (2) 


\section{REFERENCES}

1. M. D. Erickson. The Battelze Northwest Hybrid Computer System, BNWL-538. Pacific Northwest Laboratories, Richland, Washington, october 1967.

2. C. D. Swanson. Unpublished Data. Pacific Northwest Laboratory, Richland, Washington, December 1965. (Internal document describing analog simulation study of a preziminary FFTF conceptual design.)

3. H. Etherington. Nuclear Engineering Handbook, McGrawHill Book Co., Inc., New York, 1958. 1st ed., pp. 6-112.

4. R. W. Albrecht and C. Metelmann. The Use of Reduced Delayed Neutron Group Representations in Nuclear Reactor Simulations, HW-81076. Hanford Laboratories, Richland, Washington, March 2, 1964.

5. W. L. Bunch. Unpublished Data. Pacific Northwest Laboratory, Richzand, Washington, August 1966. (Internal document describing heat generation in FTR fuel folzowing shutdown.)

6. M. W. Maresca and O. E. Dwyer. "Heat Transfer to Mercury Flowing In-Line Through a Bundze of Circular Rods," ASME Trans., May 1964.

7. L. H. Gerhardstein. Unpublished Data. Pacific Northwest Laboratory, Richland, Washington, September 1967. (Restricted distribution report describing digital time delay program.)

8. R. A. Walker. Time Variable Time Delay for Analog Computer Simulation, HW-83092 (Revision). Hanford Laboratories, Richland, Washington, December 1964.

9. W. H. Nielson. Unpublished Data. Pacific Northwest Laboratory, Richland, Washington, November 1966. (Systems analysis and simulation memorandum describing FFTF air heat dump model development and simulation.)

10. Pratt, Rubber Seat Butterfly Valves Catalog B-1a, Henry Pratt Co., Chicago, 1953.

11. R. H. Perry, C.H. Chizton, and S. D. Kirkpatrick, Chemical Engineer's Handbook, McGraw-Hizl Book Co., Inc., New York, 1963. 4th ed., pp. 5-30, 31.

12. A. Y. Gunter and W. A. Shaw. "A Correzation of Friction Factors for Various Types of Surfaces in Crossfiow," Tr. ASME, vol. 67, p.643. 1945; and D. Q. Kern. Process Heat Transfer, McGraw-Hizl Book, Co., Inc., New York, 1950 .

13. Fan Engineering, Buffazo Forge Company, Buffalo, New York, 1961. 6th ed., p. 451 . 
14. I. S. Marks. Mechanical Engineer's Handbook, McGraw-Hizl Book Co., Inc., New York, 1941. 4th ed., pp. 1186-1187.

15. 0. E. Dwyer. "Analytical Study of Heat Transfer to Iiquid Metals Flowing In-Line Through Closely Packed Rod Bundles," Nuclear Science and Engineering, vol. 25, pp. $343-358.1966$.

16. 0. E. Dwyer. "Eddy Transport in Liquid-Metal Heat Transfer," A.I.Ch.E. Journal, vol. 9, 1963.

17. S. L. Jameson. "Tube Spacing in Finned-Tube Banks." Tr. ASME, vol. 67, p. 633. 1945 .

18. D.Kern. Process Heat Transfer, McGraw-Hizl Book Co., Inc., New York, 1950. 1st ed., p. 555 . 